Aus der Abteilung Dermatologie, Venerologie und Allergologie

(Prof. Dr. med. M. P. Schön)

im Zentrum Arbeits-, Sozial-,Umwelt-, Rechtsmedizin und Dermatologie

der Medizinischen Fakultät der Universität Göttingen

\title{
In-vitro- und in-vivo-Hemmung des AKT-Signalweges in Melanomzellen durch einen neuen kleinmolekularen Inhibitor
}

\author{
INAUGURAL-DISSERTATION \\ zur Erlangung des Doktorgrades \\ der Medizinischen Fakultät \\ der Georg-August-Universität zu Göttingen
}

vorgelegt von

Philine Schneider

aus

Hamburg

Göttingen 2012 
Dekan:

1. Berichterstatter : Prof. Dr. med. Schön

2. Berichterstatter/in: Prof. Dr. rer. nat. Bastians

3. Berichterstatter/in: Prof. Dr. med. Oppermann

Tag der mündlichen Prüfung: $\quad$ 05.02.2013 


\section{Inhaltsverzeichnis}

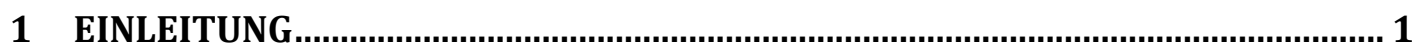

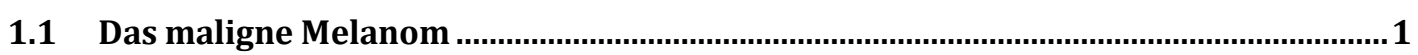

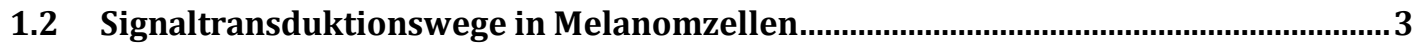

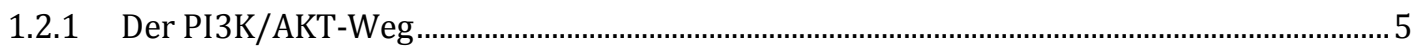

1.2.2 Der MAPK/ERK-Weg ………................................................................................... 11

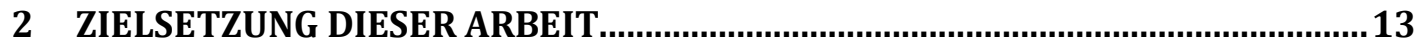

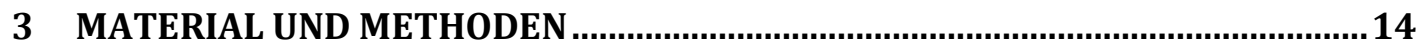

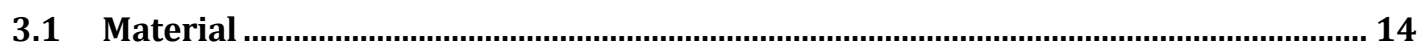

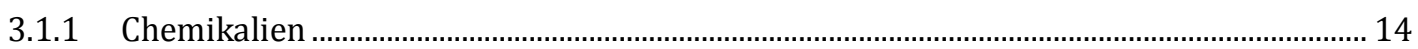

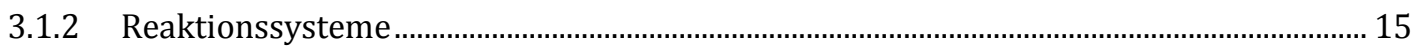

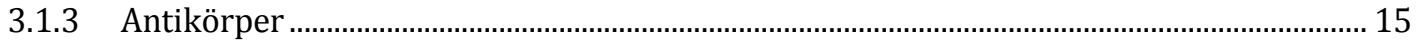

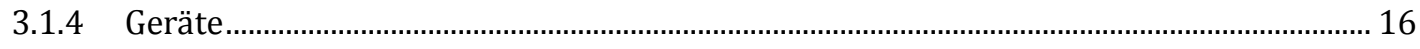

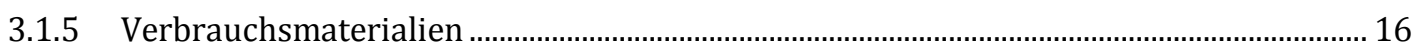

3.1.6 Lösungen und Puffer .............................................................................................................. 18

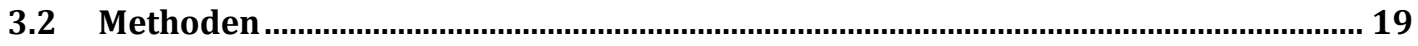

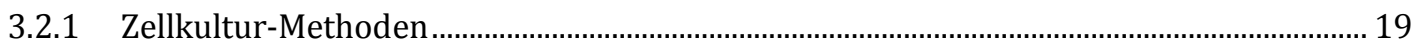

3.2.1.1 Zelltypen und Zellkultur................................................................................................ 19

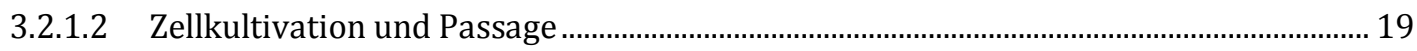

3.2.1.3 Bestimmung der Zellzahlen ........................................................................................ 19

3.2.1.4 Behandlung mit Inhibitoren und Stimulation der Zellen................................................. 20

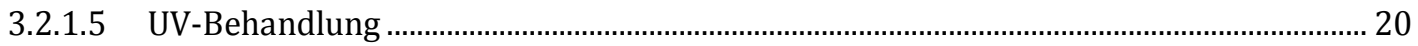

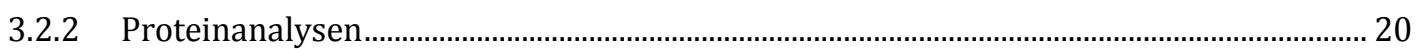

3.2.2.1 Proteingewinnung der Gesamtproteinextrakte ................................................................ 20

3.2.2.2 Proteinkonzentrationsbestimmung nach Bradford........................................................ 21

3.2.2.3 SDS-Polyacrylamid-Gelelektrophorese _........................................................................ 21

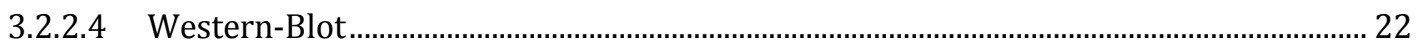

3.2.3 Nukleinsäureanalysen ................................................................................................ 23

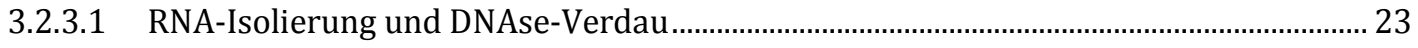


3.2.3.2 Photometrische Bestimmung der RNA-Konzentration .................................................. 23

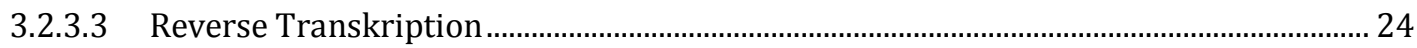

3.2.3.4 Semiquantitative Polymerasekettenreaktion ........................................................... 25

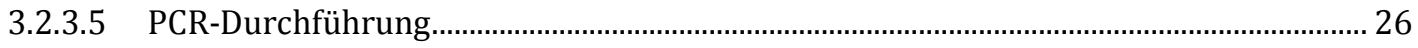

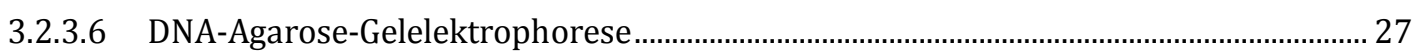

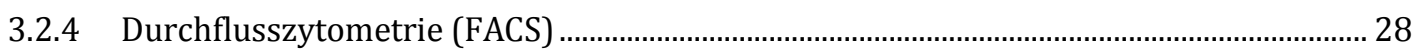

3.2.4.1 Nachweis der Kinasen p-ERK und p-AKT ...................................................................... 28

3.2.4.2 Fixierung und Permeabilisation der Zellen ............................................................... 28

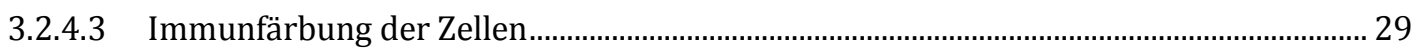

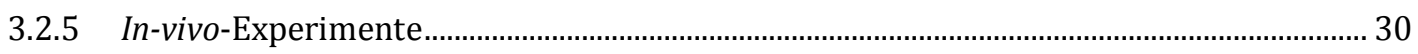

3.2.5.1 Tumorvolumen-Bestimmung durch 3d-Ultraschallmessung ....................................... 31

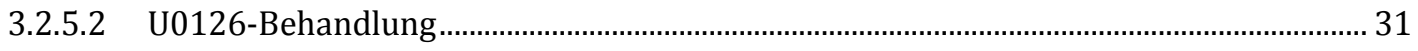

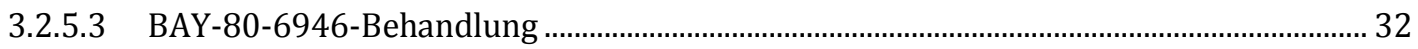

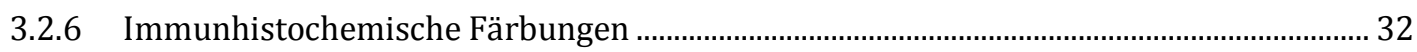

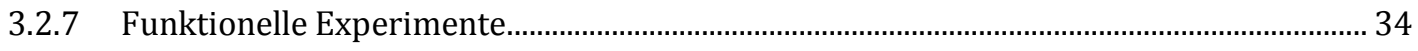

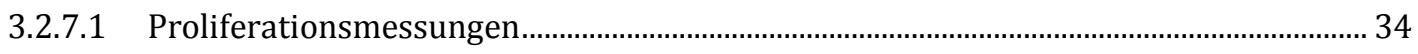

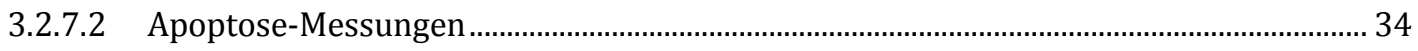

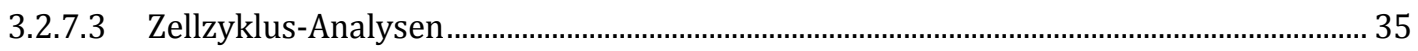

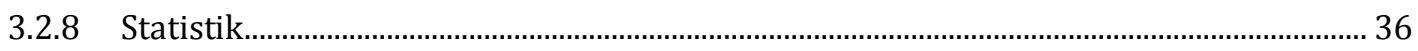

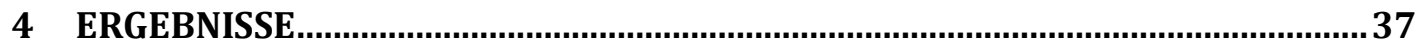

4.1 AKT und ERK sind in humanen Melanom-Zelllinien in vitro unterschiedlich stark exprimiert und aktiviert ................................................................................ 37

4.2 Humane Melanomzellen zeigen unterschiedliche Tumorigenität im in-vivoMausmodell .................................................................................................................. 44

4.3 Humane Melanomzellen exprimieren p-AKT und p-ERK in vivo im Mausmodell sowie in „natürlichen“ Melanommetastasen ...................................................... 47

4.4 BAY-80-6946 inhibiert die Aktivierung von AKT in A375 und LOX ........................ 50

4.5 Inhibition der Signalwege AKT und ERK beeinflusst wichtige MelanomzellFunktionen .......................................................................................................... 52

4.5.1 Inhibition von PI3Kinase und MEK1/2 mindert die Proliferation von Melanomzellen 52

4.5.2 Inhibition von PI3Kinase und MEK1/2 induziert Apoptose in Melanomzellen ...............57 
4.5.3 BAY-80-6946 beeinflusst den Zellzyklus 61

4.5.4 BAY-80-6946 reguliert Proliferations- und Apoptose-relevante Proteine..... 63

4.5.5 Weitere Tumor-relevante Gene im Melanom bleiben von BAY-80-6946 unbeeinflusst66

4.6 Inhibition von PI3K und MEK1/2 in vivo beeinflusst das Wachstum von Melanomen im Mausmodell.

4.6.1 Inhibition der PI3K im Nacktmausmodell verringert das Wachstum von A375Tumoren, nicht aber von LOX.

4.6.2 Inhibition von MEK1/2 im Nacktmausmodell verringert das Wachstum von A375-

Tumoren

5 DISKUSSION .................................................................................................... 71

5.1 Melanomzellen unterscheiden sich in der Aktivierung der Signaltransduktionswege und dem Zellwachstum im Mausmodell

5.2 Kombinierte PI3K-Inhibition und MEK1/2-Inhibition in vitro zeigt größeren therapeutischen Effekt als die Einzelinhibition ..................................................... 73

Inhibitoren im Mausmodell ........................................................................................ 81

6 ZUSAMMENFASSUNG........................................................................................ 83

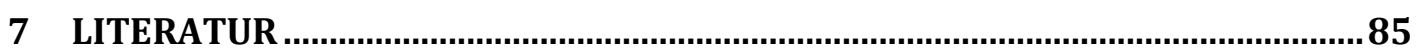




\section{Abkürzungsverzeichnis}

\begin{tabular}{|c|c|}
\hline BSA & Bovines Serumalbumin \\
\hline cdk & Zyklin-abhängige Kinase, engl. cyclin dependent kinase \\
\hline cDNA & komplementärer DNA-Strang, engl: complementary DNA \\
\hline DNA & Desoxyribonukleinsäure, engl. deoxyribonucleic acid \\
\hline EDTA & Ethylendiamintetraacetat \\
\hline ELISA & Enzyme-linked Immunosorbent Assay \\
\hline ERK & Extrazellulärsignal-regulierte Kinase \\
\hline FCS & Fetales Kälberserum, engl. fetal calf serum \\
\hline FDA & Food and drug administration \\
\hline FITC & Fluorescein isothiocyanate \\
\hline GAPDH & Glycerinaldehyd-3-phosphat-Dehydrogenase \\
\hline GSK3 & Glykogensynthase-Kinase 3 \\
\hline GTP & Guanosintriphosphat \\
\hline IGF-1 & insulinähnlicher Wachstumsfaktor 1 , engl: insulin-like growth factor 1 \\
\hline i.p. & Intraperitoneal \\
\hline MFI & mittlere Fluoreszenzintensität \\
\hline n. T. & nach Transplantation \\
\hline PBS & Phosphat-gepufferte Salzlösung, engl. phosphate buffered saline \\
\hline PDGF & Plättchen-Wachstumsfaktor, engl. platelet-derived growth factor \\
\hline PDK1 & $\begin{array}{l}\text { 3-Phosphoinositid-abhängige Kinase 1, engl. 3-phosphoinositide- } \\
\text { dependent kinase } 1\end{array}$ \\
\hline PI3K(s) & Phosphoinositid-3-Kinase(n) \\
\hline PIP2 & Phosphatidylinositol-4,5,Bisphosphat \\
\hline PIP3 & Phosphatidylinositol-3,4,5,Triphosphat \\
\hline PIP3-Phosphatase & Phosphatidylinositol-3,4,5,Triphosphat-Phosphatase \\
\hline PTEN & Phosphatase- und Tensin-Homolog \\
\hline $\mathrm{Rb}$ & Retinoblastom-Tumorsuppressor-Protein \\
\hline RNA & Ribonukleinsäure, engl: ribonucleic acid \\
\hline RT & Raumtemperatur \\
\hline RT-PCR & Reverse-Transkriptase-Polymerasekettenreaktion \\
\hline SD & Standardabweichung \\
\hline SDS & Natriumdodecylsulfat, engl. Sodium Dodecyl Sulfate \\
\hline SDS-PAGE & SDS-Polyacrylamid-Gelelektrophorese \\
\hline UV-Strahlung & Ultraviolette Strahlung \\
\hline
\end{tabular}




\section{Einleitung}

\subsection{Das maligne Melanom}

Das Melanom ist ein maligner Tumor, der von den Melanozyten ausgeht und in fortgeschrittenen Krankheitsstadien sehr aggressiv wächst. Obwohl 95\% aller Melanome an der Haut auftreten, können sie auch auf Schleimhäuten, Meningen und im Auge vorkommen.

Melanozyten entstehen aus Vorläuferzellen der Neuralleiste, den Melanoblasten. Diese wandern während der Embryogenese in verschiedene Gewebe, unter anderem die Haut, ein und differenzieren dort zu Melanozyten. Ihre Funktion in der Haut besteht in der Synthese von Melanin. Dieses geben sie in Melanosomen an die sie umgebenden Keratinozyten der Oberhaut ab. Melanin dient als wichtiger Schutz der Keratinozyten vor ultravioletter Strahlung (UV-Strahlung). Paradoxerweise werden aber auch Melanozyten, deren Aufgabe der Schutz der Haut vor UV-Strahlen ist, durch UV-Strahlung geschädigt und können entarten. Die dabei entstehende Melanomerkrankung ist viel aggressiver, als aus Keratinozyten entstandene epitheliale Tumoren (Markovic et al. 2007b).

Epidemiologische Daten legen nahe, dass für die Melanomentstehung vor allem hohe intermittierende Sonnenexposition und Sonnenbrände eine wichtige Rolle spielen (Bauer et al. 2005, Pfahlberg et al. 2001, Walter et al. 1999). Die anatomische Verteilung von Melanomen zeigt jedoch, dass nur etwa 20\% dieser Tumoren an Sonnenlicht-exponierten Hautstellen wie etwa Kopf, Handrücken oder Fuß auftreten (Kraemer et al. 1994). Dies bedeutet, dass neben UV-Exposition noch weitere Faktoren für die Entstehung eines Melanoms verantwortlich sind. Neben einer genetischen Disposition und hellem Hauttyp gilt die Anzahl melanozytärer Nävi als wichtiger Risikofaktor für die Entstehung eines Melanoms (Holly et al. 1987). Dysplastische Nävi gelten als ein weiterer Risikofaktor (Garbe und Eigentler 2007). 
Die Inzidenz des malignen Melanoms steigt seit Jahren. Als eine Ursache für diesen Inzidenzzuwachs weltweit gilt das veränderte Freizeitverhalten der Menschen mit häufiger Sonnenexposition in den letzten Jahrzehnten. Weitreichende Präventionsund Aufklärungsprogramme, wie die der Deutschen Dermatologischen Gesellschaft, bewirken inzwischen Änderungen im Freizeitverhalten, jedoch werden sich die Auswirkungen wegen der langen Latenz des Melanoms erst in Zukunft zeigen (Markovic et al. 2007b). Fast 18.000 Patienten erkrankten im Jahr 2008 in Deutschland an einem malignen Melanom. Dies bedeutet eine Verdreifachung der altersstandardisierten Erkrankungsraten in Deutschland seit den 1980er-Jahren. Das maligne Melanom macht 4,0\% sämtlicher Tumorerkrankungen bei Frauen und 3,6\% bei Männern aus. Es ist in Deutschland bei beiden Geschlechtern verantwortlich für etwa $1 \%$ der durch Krebs bedingten Todesfälle (Kaatsch et al. 2012).

Die Prognose des Melanoms hängt in erster Linie vom Stadium der Erkrankung ab. Die Standardtherapie des kutanen Melanoms besteht in der chirurgischen Exzision und führt bei kompletter Tumorentfernung meist zur Heilung. Ist der Tumor jedoch inoperabel oder gibt es Fernmetastasen, besteht nahezu keine Aussicht auf eine kurative Therapie (Garbe et al. 2011). Trotz intensiver Forschung ist die Prognose für Patienten mit metastasiertem Melanom mit einer mittleren 5-JahresÜberlebensrate von weniger als $5 \%$ sehr schlecht. Es gibt kaum Therapiemöglichkeiten, da die meisten der Chemotherapeutika in klinischen Studien an der Chemoresistenz des Melanoms gescheitert sind. IL-2 und Dacarbazin, die bisher einzigen Substanzen, die für die Behandlung des metastasierten Melanoms von der Food and Drug Administration (FDA) zugelassen wurden, zeigen nur moderates Ansprechen bei etwa 10-20\% der Patienten und führen nicht zu einer signifikanten Verlängerung der mittleren Überlebenszeit. (Atkins et al. 1999, Eggermont und Kirkwood 2004, Garbe et al. 2011, Markovic et al. 2007a). Neue Hoffnungen für Patienten mit metastasiertem Melanom ruhen auf kürzlich durch die FDA und EMA zugelassenen spezifischen Therapien, wie dem CTLA4-gerichteten Antikörper Ipilimumap, der über eine T-Zell-vermittelte antitumorale Immunantwort einen Überlebensvorteil in Phase-III-Studien zeigen 
konnte und Vemurafenib, einem BRAF-Inhibitor, der ebenfalls in Studien einen prognostischen Vorteil bei dem metastasierten Melanom mit BRAF-V600EMutation zeigte (Chapman et al. 2011, Lens et al. 2012). Dennoch ändert dieses nichts Wesentliches an der weiterhin schlechten Prognose von Patienten mit metastasierten Melanomen.

\subsection{Signaltransduktionswege in Melanomzellen}

Um Gewebeaufbau, -integrität und -funktionalität zu gewährleisten, wird das Zellwachstum in sämtlichen Geweben durch komplexe molekulare Mechanismen genauestens reguliert und steht im Gleichgewicht mit der Apoptose der Zellen. Um in eine proliferative Zellzyklusphase einzutreten, benötigt eine normale Zelle mitogene Wachstumssignale (Wachstumsfaktoren, Zytokine, Matrix-Kontakte) von außerhalb der Zelle. Diese Signale werden durch Rezeptoren vermittelt, die über membranständige sowie zytosolische Adapter-Proteine, Kinasen und Phosphatasen komplexe Signalkaskaden in der Zelle aktivieren und Transkriptionsfaktoren regulieren. Letztere steuern dann die Expression zahlreicher Gene, die in die Kontrolle zellulärer Funktionen involviert sind. So unterliegt der Zellzyklus einem komplexen Regulationsmechanismus, der vor entscheidenden Schritten wie der Desoxyribonukleinsäure (engl. deoxyribonucleic acid, DNA)-Synthese oder der Mitose kontrolliert, ob in der Zelle beispielsweise DNA-Schäden vorliegen oder die Zelle gegebenenfalls in der jeweiligen Zellzyklusphase arretiert werden soll, um die Reparatur der DNA-Schäden zu ermöglichen oder die Apoptose der Zelle einzuleiten. Ein Zusammenspiel aus Zyklinen, Zyklin-abhängigen Kinasen (engl: cyclin-dependent kinase, cdk) und cdkInhibitoren ermöglicht die Zellzykluskontrollpunkte (Afshari und Barrett 1993). Das in dieser Arbeit untersuchte CyclinD1 führt zusammen mit cdk4 und cdk6 zu einer Phosphorylierung des Retinoblastom-Tumorsuppressor-Proteins (Rb). Dies resultiert über eine Aktivierung von CyclinE in einer Progression von der G1- zur SPhase (Schmitt et al. 2007). Eine Hochregulation von CyclinD1 führt folglich zu vermehrter Zellproliferation. Ein potenter cdk-Inhibitor ist das ebenfalls in dieser Arbeit untersuchte p21 (Schmitt et al. 2007). Tumorzellen gelingt es, sich durch 
Dysregulierung dieser Signalwege von äußerer Wachstumskontrolle unabhängig zu machen und unkontrolliert zu proliferieren.

Zusätzlich besitzen Tumorzellen oftmals Mutationen, die es ihnen ermöglichen, der Apoptose zu entgehen (Hanahan und Weinberg 2011). Dieser physiologische Zelltod beseitigt beispielsweise Zellen mit beschädigtem Erbgut oder Zellen, die ihre Funktion nicht (mehr) erfüllen. Die Apoptose ist gekennzeichnet durch charakteristische Veränderungen wie das Schrumpfen der Zelle, das Abschnüren von Vesikeln und die Fragmentierung der nukleären DNA. Zwei wesentliche Wege der Apoptoseeinleitung werden unterschieden: die intrinsche und die extrinsische Aktivierung. Bei der extrinsischen Aktivierung führen Moleküle von außerhalb der Zelle über die Aktivierung von „Todesrezeptoren“ aus der TNF-Familie zu einer intrazellulären Aktivierung von Caspasen, die den apoptotischen Zelltod bewirken. Der intrinsische Weg der Apoptose wird durch Freisetzung von Cytochrom C aus der Mitochondrienmembran ausgelöst. Dies kann durch verschiedene Faktoren beeinflusst werden. Wichtige Regulatoren sind dabei die Mitglieder der Bcl-2Familie. Diese Proteinfamilie lässt sich in pro-apoptotische Proteine, beispielsweise Bax und PUMA, sowie anti-apoptotische, wie Bcl-2, unterteilen (Borner et al. 1999, Heere-Ress et al. 2002, Helmbach et al. 2001, Jansen et al. 2000). Bcl-2-Proteine sind wichtig für die Stabilisierung der äußeren Mitochondrienmembran. In Komplexbildung können sie sich gegenseitig neutralisieren. Eine besondere Rolle scheint das Verhältnis von Bax zu Bcl-2 zu spielen: ein großer Quotient von Bax und $\mathrm{Bcl}-2$ ist mit höherer Apoptose-Bereitschaft von Melanomzellen assoziiert, während ein kleiner Quotient auf Apoptoseresistenz hinweist (Raisova et al. 2001, Schön et al. 2003). Die Freisetzung von Cytochrom C aus der Mitochondrienmembran führt wie der extrinsische Weg zur Aktivierung von Caspasen. Proteine der IAP (inhibitor of apoptosis)-Gruppe, wie XIAP, können diese Caspasen wiederum durch Komplexbildung deaktivieren und stellen damit einen weiteren Weg zur Apoptose-Verhinderung dar (Raisova et al. 2001, Schön et al. 2003). In Melanomen ist das Proteinverhältnis oftmals zu Gunsten der Antiapoptose verschoben. 
Das Konzept der „oncogenic addiction“ (Abhängigkeit von Tumor-spezifischen Signalen) geht von der Hypothese aus, dass Tumorzellen stärker auf manche der in ihnen überaktivierten Signalmechanismen angewiesen sind als normale Zellen. Da Tumorzellen durch die Inhibition dieser Signalwege und/oder Onkogene stärker zu beeinflussen sind als gewöhnliche Zellen, bietet sich dadurch ein therapeutischer Angriffspunkt. Auf Grund ihrer biochemischen Eigenschaften eignen sich besonders Enzyme wie Kinasen, Phosphatasen und Proteasen als mögliche Zielstrukturen medikamentöser Therapien (Gray-Schopfer et al. 2007). Auf der Suche nach neuen Therapieansätzen wurde in den letzten Jahren vermehrt versucht, die molekularen Grundlagen aufzuklären, die der Entstehung und der Pathophysiologie des Melanoms zugrunde liegen. Dabei wird immer deutlicher, dass es sich bei dem Melanom um eine heterogene Gruppe von Tumoren mit verschiedenen Mutationen handelt (Davies H. et al. 2002, Lin et al. 2008). Oftmals sind unterschiedliche Signaltransduktionswege aktiviert (Davies H. et al. 2002, Davies M. A. et al. 2008, Lin et al. 2008, Lopez-Bergami et al. 2008, Niu et al. 2002, Smalley und Herlyn 2005, Ueda und Richmond 2006). Besonders in den Fokus der Forschung sind der MAPK/ERK-Weg und der PI3Kinase-AKT-Weg gerückt.

\subsubsection{Der PI3K/AKT-Weg}

Der PI3K/AKT-Weg ist ein Signaltransduktionsweg, der Überleben, Proliferation und Wachstum der Zellen beeinflusst (Engelman et al. 2006). In vivo wird die Aktivität dieses Weges durch Wachstumsfaktoren im Serum gesteuert (Burgering und Coffer 1995, Cross et al. 1995, Franke et al. 1995, Kohn et al. 1995). Als ein zentraler Regulationsmechanismus spielt er eine wichtige Rolle bei der Krebsentstehung. In den 1980er-Jahren wurde die Bedeutung der Phosphoinositol3-Kinasen (PI3K) für die unkontrollierte Proliferation von Tumorzellen erstmals aufgrund ihrer Assoziation mit Onkogenen erkannt (Serunian et al. 1990, Sugimoto et al. 1984, Whitman et al. 1985). Genetische Analysen in den 1990er-Jahren zeigten, dass in vielen malignen Tumoren ein Lokus auf Chromosom 10q23 deletiert war. Diese Region kodiert eine Phosphatase, das Phosphatase- und 
Tensin-Homolog (phosphatase and tensin homolog, PTEN) (Li et al. 1997, Steck et al. 1997). Maehama und Dixon zeigten, dass es sich bei PTEN um eine Phosphatidylinositol-3,4,5,Triphosphat-Phosphatase (PIP3-Phosphatase) handelt, die den PI3K/AKT-Signalweg negativ reguliert und somit als Tumorsuppressor wirkt (Maehama und Dixon 1998). Die entscheidende Rolle des PI3K/AKT-Weges in der Tumorigenese wurde durch die Beobachtung bekräftigt, dass Proteine, wie p85, p110alpha, PTEN und AKT, die zentrale Elemente im PI3K/AKT-Signalweg darstellen, in vielen malignen Tumoren Änderungen auf genetischer Ebene aufweisen (Engelman et al. 2006). Experimente mit genetisch veränderten (für bestimmte Gene defizienten „knockout“ oder transgenen) Tiermodellen bestätigten zudem das Tumor-begünstigende Potential einer Überaktivierung des PI3K/AKT-Weges (Engelman et al. 2006, Vivanco und Sawyers 2002).

Auch für das Melanom konnte gezeigt werden, dass der PI3K/AKT-Signalweg oft überaktiviert ist. Die p-AKT-Expressionsstärke als Parameter der PI3K/AKTAktivierung wurde in primären Melanomen und Melanommetastasen überprüft, von denen bei Ersteren 49\% und bei Letzteren $77 \%$ der Proben hohe p-AKT Expression zeigten (Dai et al. 2005). Andere Studien konnten in mehr als 66\% der untersuchten Melanome eine starke AKT-Aktivierung nachweisen (Dhawan et al. 2002). Zudem korreliert die p-AKT-Expression negativ mit der 5-JahresÜberlebensrate der Melanom-Patienten (Dai et al. 2005). Auch wenn die genauen Mechanismen der Überaktivierung dieses Weges noch nicht vollständig geklärt sind, so gibt es doch Anhalt dafür, dass PTEN-Funktionsverlust eine wichtige Rolle dabei spielt. Studien zeigten, dass bei bis zu 30\% der Melanom-Zelllinien und bei bis zu $10 \%$ allen menschlichen Tumormaterials ein Verlust der PTEN-Expression stattfindet (Birck et al. 2000, Guldberg et al. 1997, Lin et al. 2008, Teng et al. 1997, Tsao et al. 2000). Es gibt zudem Hinweise darauf, dass PTEN auch als haploinsuffizienter Tumorsuppressor wirkt. Der Verlust eines Allels des PTEN-Gens konnte nämlich in fast $60 \%$ der untersuchten Melanommetastasen nachgewiesen werden (Birck et al. 2000).

Die PI3Ks bilden eine Enzymfamilie, deren Funktion es ist, die 3'-hydroxyl-Gruppe von Phosphoinositol und Phosphoinositiden zu phosphorylieren. Es gibt drei 
Klassen von PI3Ks (I-III), von denen jede ihre eigene Substratspezifität zeigt und Subklassen aufweist (Engelman et al. 2006, Katso et al. 2001). Während über die spezifischen Funktionen von Klasse II und III noch relativ wenig bekannt ist, wurden die Klasse-I-PI3Ks ausgiebig untersucht. Sie sind in vielen Tumoren konstitutiv aktiviert und spielen eine zentrale Rolle für Tumor-beeinflussende Zellfunktionen. Die Klasse-I $\mathrm{A}_{A}-\mathrm{PI} 3 \mathrm{~K}$ ist ein Heterodimer aus der regulatorischen Untereinheit p85 und einer katalytischen Untereinheit p110. RezeptorTyrosinkinasen in der Zellmembran vermitteln über die regulatorische Untereinheit p85 eine Aktivierung der Klasse-I $\mathrm{A}_{\mathrm{A}} \mathrm{PI}$ 3K. Dies kann über Adaptorproteine erfolgen, durch den Insulin-Rezeptor und die Insulin-ähnlicherWachstumsfaktor-1 (insulin-like growth factor 1, IGF-1)-Rezeptoren, oder direkt, wie durch den Plättchen-Wachstumsfaktor (platelet-derived growth factor, PDGF) -Rezeptor (Engelman et al. 2006). Klasse-I $-\mathrm{P}$-PI3K bestehen aus einer regulatorischen p101-Untereinheit und einer katalytischen $\mathrm{p} 110 \mathrm{p}$-Untereinheit. Ihre Aktivierung geschieht vor allem über einen G-Protein-gekoppelten Rezeptor (engl: G-protein coupled receptor, GPCR) auf einem Guanosintriphosphat (GTP) abhängigen Weg (Engelman et al. 2006, Rodriguez-Viciana et al. 1996). Eine gesonderte Rolle bei der Aktivierung von PI3K nehmen RAS-Proteine ein; sie können unabhängig von weiteren äußeren Einflüssen die PI3Ks direkt aktivieren (Rodriguez-Viciana et al. 1996). Dies ist wichtig, da in vielen Melanomen RAS durch verschiedene Mutationen in kontrollierenden Elementen aktiviert sein kann (Brose et al. 2002, Davies H. et al. 2002). Die Aktivierung und Rekrutierung der Klasse-IPI3Ks zur Zellmembran führt zur Phosphorylierung des Substrates Phosphatidylinositol-4,5,Bisphosphat (PIP2) zu Phosphatidylinositol3,4,5, Triphosphat (PIP3). Dieses aktiviert seinerseits über die 3-Phosphoinositidabhängige Kinase 1 (3-phosphoinositide-dependent kinase 1, PDK1) die Serin/Threonin Proteinkinase AKT. Die Phosphorylierung von AKT an Thr ${ }^{308}$ durch die PDK1 und an Ser ${ }^{473}$ über einen mTOR/rictor-abhängigen Prozess resultiert in dessen vollständiger Aktivierung (Engelman et al. 2006). PTEN, eine Phosphatase mit Lipid-Phosphatase-Funktion, hydrolysiert das 3-Phosphat von PIP3, um PIP2 zu generieren. Hierdurch wird die PI3K antagonisiert. PTEN reguliert somit negativ den PI3K/AKT-Signalweg (Maehama und Dixon 1998, Salmena et al. 2008). Diese 
komplexen Regulationsmechanismen sind schematisch in Abbildung 1 zusammengefasst.

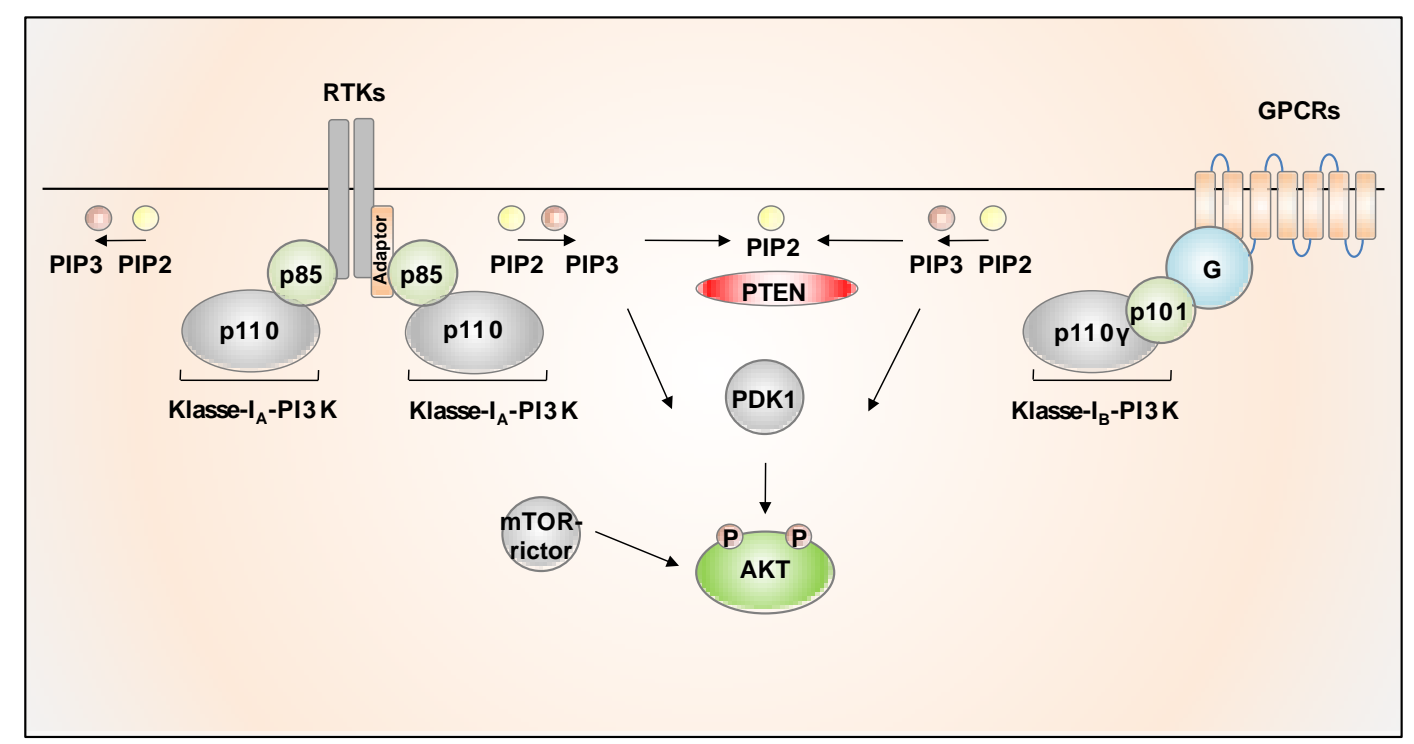

Abb. 1: Die Klasse-I-PI3K Die Klasse-I $-\mathrm{AI} 3 \mathrm{~K}$ (links) bestehen aus einer regulatorischen p85- und einer katalytischen p110-Untereinheit. Rezeptor-Tyrosinkinasen (RTK) vermitteln eine Aktivierung der PI3K durch p85 entweder direkt oder über Adaptorproteine (in Grafik mit Adaptor gekennzeichnet). Die Klasse- $\mathrm{I}_{B}-\mathrm{PI} 3 \mathrm{Ks}$ (rechts) wiederum werden über G-Protein-gekoppelte Rezeptoren (GPCR) aktiviert. Sie bestehen aus einer regulatorischen Untereinheit p101 und einer katalytischen p110y-Untereinheit. Die regulatorische Untereinheit interagiert GTP-abhängig mit dem trimeren G-Protein des Rezeptors. Eine Aktivierung der Klasse-I-PI3Ks rekrutiert diese zur Zellmembran, wo sie PIP2 zu PIP3 phosphorylieren. PIP3 wiederum aktiviert die Kinase PDK1, welche als Zielprotein AKT phosphoryliert. Ist AKT zusätzlich in einem mTOR-rictorabhängigen Prozess phosphoryliert, resultiert dieses in einer vollständigen Aktivierung der Kinase. PTEN als Lipid-Phosphatase hydrolysiert PIP3 zu PIP2 und reguliert somit den PI3K/AKT-Weg negativ. (modifiziert nach: Engelman et al. 2006, Seite 610)

Die Aktivierung und Überexpression von AKT spielt eine wichtige Rolle bei der Karzinogenese (Engelman et al. 2006, Hennessy et al. 2005, Jiang und Liu 2009). Durch die Phosphorylierung vieler wichtiger Zielproteine nimmt AKT eine zentrale Stellung in der Kontrolle elementarer Zellfunktionen ein. Aktiviertes AKT führt zur Inaktivierung vieler pro-apoptotischer Proteine wie FASL, Bim, BAD, Caspase 9, p53 und der Transkriptionsfaktoren der Forkhead-Familie (Brunet et al. 1999, Cardone et al. 1998, Datta et al. 1997, Franke et al. 1997, Gottlieb et al. 2002, Mayo und 
Donner 2001, Oren et al. 2002, Romashkova und Makarov 1999, Vivanco und Sawyers 2002). Auch der Zellzyklus wird von aktiviertem AKT beeinflusst. Durch Blockade der Transkription von Zellzyklus-inhibierenden Proteinen wie p21 oder RBL2 (Retinoblastoma-like2) kommt es zum G1-zu-S-Phase-Übergang und zu einer beschleunigten Proliferation der Zellen. Zusätzlich stabilisiert AKT über die Inhibition der Glykogen-Synthase-Kinase 3 (GSK3) und die Aktivierung des NF-KBWeges Zellzyklusproteine wie CyclinD1 und CyclinD3 (Diehl et al. 1998, Dufourny et al. 2000, Muise-Helmericks et al. 1998, Spofford et al. 2006, Vivanco und Sawyers 2002). AKT kann außerdem weitere Schlüsselsignale der Tumorigenese, beispielsweise den NF-kB-Weg und mTOR, aktivieren, die wiederum über komplexe Mechanismen die Entartung der Zelle und viele mit Malignität assoziierte Eigenschaften eines Tumor bedingen können (Jiang und Liu 2009, Kane et al. 1999, Karbowniczek et al. 2008, Smalley 2010). So beeinflusst der PI3K-Weg aufgrund seiner oben umrissenen regulatorischen Funktionen auf der Ebene der ganzen Zelle oder des Zellverbandes viele Eigenschaften, die in die Progression von Tumoren involviert sind, beispielsweise Angiogenese, Gewebeinvasion, Metastasierung und Umgehung der Immunabwehr (Jiang und Liu 2009). Die PI3Kinase als zentrales Kontrollelement des PI3K/AKT-Weges stellt also prinzipiell einen vielversprechenden Angriffspunkt für die Therapie mancher Melanome dar. Ein Inhibitor, der therapeutisch an dieser Stelle angreift, ist der neue PI3K-Inhibitor BAY-80-6946. In verschiedenen Experimenten konnte seine Spezifität für sein Zielprotein, die Klasse-I-PI3K gezeigt werden (Berndorff et al. 2011, Patnaik et al. 2011). Ergebnisse und Untersuchungen der Wirkung von BAY-80-6946 auf Melanomzellen liegen jedoch bisher nicht vor; dies wird in dieser Arbeit erstmals erforscht. 


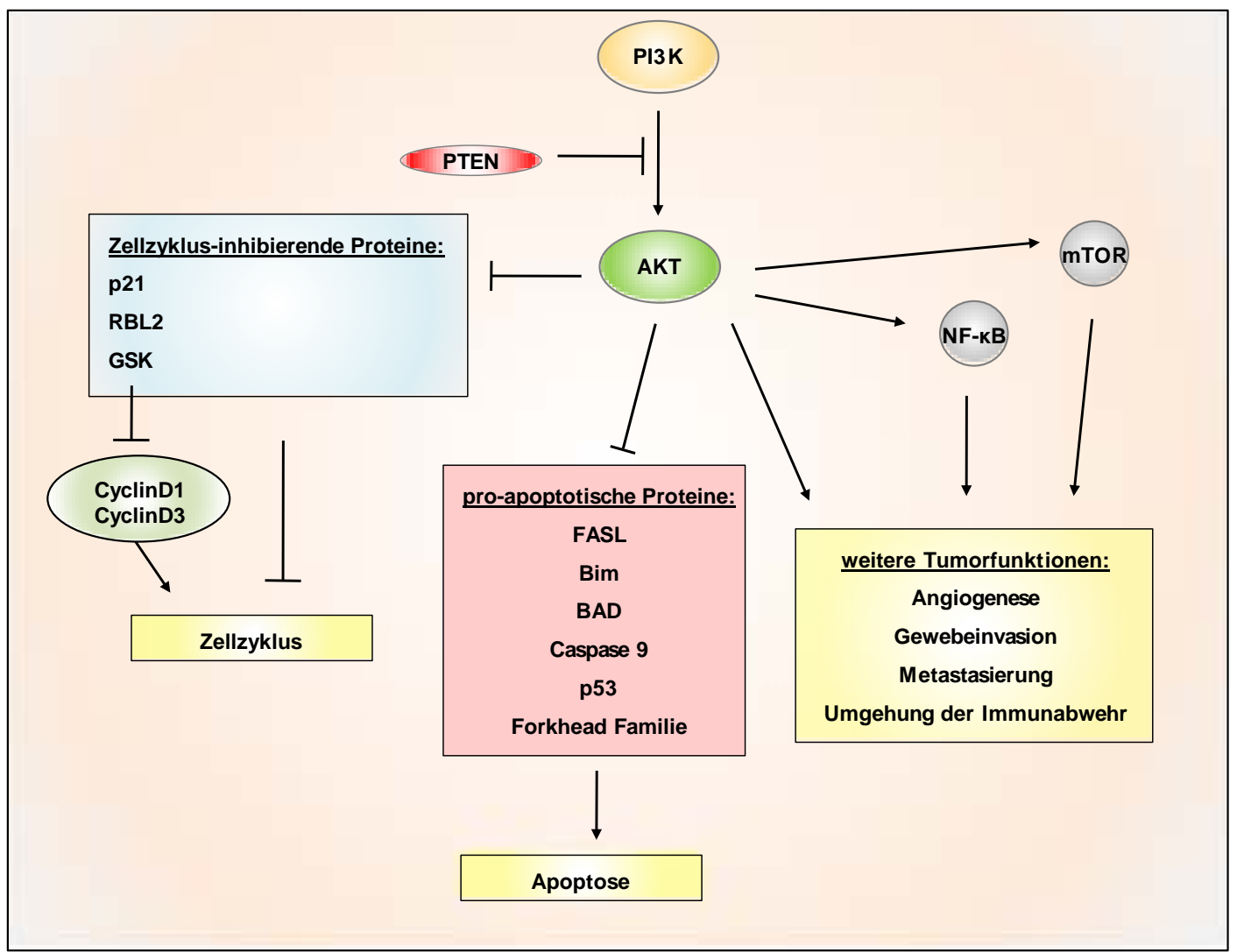

Abb. 2: AKT beeinflusst zentrale Zellfunktionen Aktiviertes AKT inhibiert Zellzyklus-inhibierende Proteine wie p21, RBL2 und GSK und fördert somit indirekt die Proliferation der Zellen. Durch Inaktivierung proapoptotischer Proteine wie FASL, Bim, BAD, Caspase 9, p53 und Transkriptionsfaktoren der Forkhead-Familie kann eine Gegenregulation durch Zelltod-Einleitung nicht stattfinden. Zudem aktiviert AKT weitere Tumorbeeinflussende Signalwege wie den NF-KB-Weg und mTOR. Hierdurch und über weitere Mechanismen werden Tumorfunktionen wie übermäßige Angiogenese, Gewebeinvasion, Metastasierung und Umgehung der Immunabwehr gefördert. 


\subsubsection{Der MAPK/ERK-Weg}

Der Ras/Raf/MEK/ERK-Signalweg, auch MAPK/ERK-Weg genannt (Russo et al. 2009), ist wesentlich an der Regulation von Zellwachstum und Proliferation der Melanomzellen beteiligt. Unter physiologischen Bedingungen folgt die Aktivierung dieses Weges einer Stimulation durch Wachstumsfaktoren von außerhalb der Zelle. Membranständige Oberflächenrezeptoren interagieren dabei mit den Wachstumsfaktoren und übermitteln durch RAS, eine GTPase, ihre Signale an das Innere der Zellen (Robinson und Cobb 1997). Sobald RAS durch die Bindung von GTP aktiviert ist, aktiviert es wiederum mehrere Effektorproteine, von denen einige zur RAF-Familie der Serin/Threonin-Kinasen gehören. Zu dieser Familie gehören drei Isoformen von RAF: A-RAF, B-RAF und C-RAF. Einmal aktiviert, phosphoryliert RAF zwei weitere Kinasen, nämlich MEK1 und MEK2, die wiederum die Extrazellulärsignal-regulierte Kinase (ERK) 1 sowie ERK2 phosphorylieren (Crews et al. 1992, Kyriakis et al. 1992). Die aktivierten ERK-Proteine translozieren dann entweder in den Kern und phosphorylieren dort verschiedene Transkriptionsfaktoren oder sie aktivieren zytoplasmatische Zielproteine. Diese steuern die Expression von Genen, die an Proliferation und Zellzyklusregulation beteiligt sind (Russo et al. 2009).

Unter physiologischen Bedingungen bewirken Wachstumsfaktoren in Melanozyten eine schwache MAPK/ERK-Aktivierung, die nicht ausreicht, um Zellproliferation zu induzieren (Smalley 2010). Konstitutive MAPK-Aktivität hingegen erhöht in Melanomzellen CyclinD1, das den Zellzyklus beschleunigt, und es reguliert p27, ein Protein, das den Zellzyklus verlangsamt (Bhatt et al. 2005, Kortylewski et al. 2001). Inhibition von BRAF oder MEK können zu einer Hemmung des Wachstums bei Melanomzellen führen (Haass et al. 2008, King et al. 2006, Smalley et al. 2007, Solit et al. 2006, Tsai et al. 2008). Zusätzlich inhibiert der konstitutiv aktivierte MAPK/ERK-Signalweg die Apoptose über verschiedene Mechanismen (Eisenmann et al. 2003, Harada et al. 2004).

Der MAPK/ERK-Weg ist bei vielen Melanomen konstitutiv aktiviert. Mehr als $90 \%$ des klinischen Melanom-Materials weist konstitutive ERK-Aktivierung auf (Cohen 
et al. 2002). In Melanomen sind vor allem aktivierende Mutationen für die Überaktivität des MAPK-Weges verantwortlich (Russo et al. 2009). Die erste MAPK/ERK-aktivierende Mutation im Melanom wurde bei NRAS gefunden (Padua et al. 1984, Padua et al. 1985) und bei 15-33\% aller Melanome beobachtet (Brose et al. 2002, Davies H. et al. 2002, Demunter et al. 2001, Omholt et al. 2003, van Elsas et al. 1995). Die am häufigsten beobachtete MAPK/ERK-aktivierende Mutation im Melanom betrifft aber BRAF (Davies H. et al. 2002, Gorden et al. 2003, Kumar et al. 2003). Meist handelt es sich dabei um eine V600E-Mutation, die sich durch einen Valin-zu-Glutaminsäure-Austausch ergibt (Davies H. et al. 2002). Genau an diesem Punkt wirkt Vemurafenib, ein neuer BRAF-Inhibitor, der in klinischen Studien einen prognostischen Vorteil beim metastasierten Melanom mit BRAF-V600E-Mutation zeigte (Chapman et al. 2011). Weitere 50 verschiedene aktivierende Mutationen im BRAF-Gen sind bisher beschrieben worden (Garnett und Marais 2004). Außer über aktivierende Mutationen kann der MAPK/ERK-Weg in Melanomzellen auch durch autokrin sezernierte Wachstumsfaktoren konstitutiv aktiviert werden (Satyamoorthy et al. 2003). 


\section{Zielsetzung dieser Arbeit}

Die Suche nach medikamentösen Therapien zur Behandlung des Melanoms ist trotz großen Forschungsaufwands bisher unbefriedigend geblieben. PI3K/AKT-Weg und MAPK/ERK-Weg sind als mögliche Angriffspunkte für die Tumortherapie identifiziert worden.

Ziel dieser Arbeit war es, zu überprüfen, ob und inwieweit Tumor-relevante Funktionen in Melanomzellen durch Inhibition von PI3K und MEK1/2 beeinflusst werden. Ein besonderer Schwerpunkt dieser Arbeit liegt auf der Untersuchung der Wirkung des neuen Klasse-I-PI3K-Inhibitors BAY-80-6946 auf Melanomzellen. 


\section{Material und Methoden}

\subsection{Material}

\subsubsection{Chemikalien}

\section{Tabelle 1: Chemikalien}

\begin{tabular}{|c|c|}
\hline Chemikalie & Bezugsquelle \\
\hline AB-Serum & Sigma-Aldrich, St. Louis, USA \\
\hline $\begin{array}{l}\text { Acrylamide } 30 \text { \%: Electrophoresis Purity reagent Bis } \\
\text { Solution 37.5:1 (2,6 \% C) }\end{array}$ & Bio-RAD Laboratories, München, Deutschland \\
\hline $\mathrm{AEC}^{+}$-Lösung & DAKO, Hamburg, Deutschland \\
\hline Agarose & Biozym Scientific, Hessisch Oldendorf, Deutschland \\
\hline Ammoniumpersulfat & Sigma-Aldrich, St. Louis, USA \\
\hline BAY-80-6946 & $\begin{array}{l}\text { Bayer-Pharmaforschungszentrum, Wuppertal, } \\
\text { Deutschland (Kooperation mit Dr. K. Ziegelbauer } \\
\text { und Dr. N. Liu) }\end{array}$ \\
\hline Blockmilch (Non-fat-dry-milk) & Bio-RAD Laboratories, München, Deutschland \\
\hline Bromphenolblau & Sigma-Aldrich, St. Louis, USA \\
\hline BSA & Sigma-Aldrich, St. Louis, USA \\
\hline $\begin{array}{l}\text { Complete Mini }-7 \times \text { Complete Stock Lsg. Protease } \\
\text { Inhibitor Cocktail Tablets }\end{array}$ & Roche, Mannheim, Deutschland \\
\hline DMEM (Dulbecco’s Modified Eagle’s Medium) & PAA Laboratories GmbH, Pasching, Österreich \\
\hline DMSO & Merck, Darmstadt, Deutschland \\
\hline EDTA & Sigma-Aldrich, St. Louis, USA \\
\hline Ethanol & Roth, Karlsruhe, Deutschland \\
\hline FCS & PAA Laboratories GmbH, Pasching, Österreich \\
\hline GelRed $10.000 \times$ & Biotium, Hayward, USA \\
\hline GeneRulerTM 100 bp Plus DNA Ladder & Fermentas, St.Leon-Rot, Deutschland \\
\hline Glycerol & Merck, Darmstadt, Deutschland \\
\hline Glycin & Roth, Karlsruhe, Deutschland \\
\hline Hämatoxylin & DAKO, Hamburg, Deutschland \\
\hline $\mathrm{HCl}$ & Merck, Darmstadt, Deutschland \\
\hline IL-6 & ImmunoTools, Friesoythe, Deutschland \\
\hline Isofluorangas & Abbott Laboratories, Libertyville, USA \\
\hline L-glutamin, $200 \mathrm{mM}$ & PAA Laboratories GmbH, Pasching, Österreich \\
\hline Methanol & J.T.Baker ${ }^{\circledR}$, Deventer, Niederlande \\
\hline $\mathrm{NaCl}$ & Merck, Darmstadt, Deutschland \\
\hline NP40 & Roth, Karlsruhe, Deutschland \\
\hline Page Ruler prestained Protein ladder & Fermentas, St.Leon-Rot, Deutschland \\
\hline PBS Without $\mathrm{Ca}^{2+}$ and $\mathrm{Mg}$ & PAA Laboratories GmbH,Pasching, Österreich \\
\hline PD98059 & New England Biolabs, Ipswich, USA \\
\hline Penicillin-Streptomycin & PAA Laboratories GmbH,Pasching, Österreich \\
\hline PFA & Roth, Karlsruhe, Deutschland \\
\hline Propidiumiodid & Sigma-Aldrich, St. Louis, USA \\
\hline RNase A & Roche, Mannheim, Deutschland \\
\hline SDS & Roth, Karlsruhe, Deutschland \\
\hline
\end{tabular}




\begin{tabular}{|l|l|}
\hline ß-Mercaptoethanol & Roth, Karlsruhe, Deutschland \\
\hline Standardkurvenlösung BGG Standard & Fermentas, St.Leon-Rot, Deutschland \\
\hline Taq-DNA-Polymerase & PEQLab, Erlangen, Deutschland \\
\hline TEMED & Sigma-Aldrich, St. Louis, USA \\
\hline Tris & Roth, Karlsruhe, Deutschland \\
\hline Trypsin- EDTA (1×) 0,05\%/0,02 \% in PBS & PAA Laboratories GmbH, Pasching, Österreich \\
\hline Tween20 & Roth, Karlsruhe, Deutschland \\
\hline U0126 & Merck, Darmstadt, Deutschland \\
\hline Vehikel & Bayer, Leverkusen, Deutschland \\
\hline Wortmannin & Merck, Darmstadt, Deutschland \\
\hline Ziegen-Serum & Roth, Karlsruhe, Deutschland \\
\hline
\end{tabular}

\subsubsection{Reaktionssysteme}

Tabelle 2: Reaktionssysteme

\begin{tabular}{|c|c|}
\hline Reaktionssysteme & Bezugsquelle \\
\hline Bradford Reagenz Protein Assay & Bio-RAD, München, Deutschland \\
\hline Cell Death Detection ELISA Plus & Roche, Mannheim, Deutschland \\
\hline $\begin{array}{l}\text { CellTiter96®Non-Radioactive Cell Proliferation } \\
\text { Assay }\end{array}$ & Promega, Mannheim, Deutschland \\
\hline DAKO Target Retrieval Solution 10x & DAKO, Hamburg, Deutschland \\
\hline E.Z.N.A. ${ }^{\text {TM }}$ Total RNA Kit I & Omega Bio-tek, Norcross, USA \\
\hline ECL plus & Amersham Biotech, Little Chalfont, England \\
\hline First Strand cDNA Synthesis Kit & Fermentas, St.Leon-Roth, Deutschland \\
\hline RNase-Free DNase Set & Omega Bio-tek, Norcross, USA \\
\hline Taq all inclusive & PEQLAB Biotechnologie, Erlangen, Deutschland \\
\hline Tyramide Signal Amplifikation $^{\mathrm{TM}}$ & Perkin Elmer, Waltham, USA \\
\hline
\end{tabular}

\subsubsection{Antikörper}

Tabelle 3: Antikörper

\begin{tabular}{|c|c|}
\hline Antikörper gegen & Hersteller \\
\hline Aktin (C4) mouse monoclonal IgG $_{1}$ & Santa Cruz, Santa Cruz, USA \\
\hline Anti-mouse IgG (H+L),HRP-conjugated & Promega, Madison, USA \\
\hline Anti-Rabbit IgG (H+L),HRP-conjugated & Promega, Madison, USA \\
\hline Anti-rabbit-Goat-F(ab)2 polyklonal & Southern Biotech, Birmingham, USA \\
\hline Bax (2D2), mouse monoclonal IgG 1 & Santa Cruz, Santa Cruz, USA \\
\hline Bcl-2 (C2), mouse monoclonal IgG 1 & Santa Cruz, Santa Cruz, USA \\
\hline Mouse IgG1 isotype control Alexa Fluor ${ }^{\circledR 647}$ & Invitrogen $^{\mathrm{TM}}$, Carslbad, USA \\
\hline $\begin{array}{l}\text { Phospho-Akt (Ser473) (193H12) Rabbit mAb (Alexa } \\
\text { Fluor }{ }^{\circledR} 647 \text { Conjugate) }\end{array}$ & Cell Signaling Technology, Danvers, USA \\
\hline Phospho-AKT polyklonal & Cell Signaling Technology, Danvers, USA \\
\hline $\begin{array}{l}\text { Phospho-ERK1/2 p44/42 MAPK } \\
\text { monoklonal (D13.14.4E) }\end{array}$ & Cell Signaling Technology, Danvers, USA \\
\hline $\begin{array}{l}\text { Phospho-p44/42 MAPK (Erk1/2) (Thr202/Tyr204) } \\
\text { (E10) Mouse mAb } \\
\text { (Alexa Fluor }{ }^{\circledR} 647 \text { Conjugate) }\end{array}$ & Cell Signaling Technology, Danvers, USA \\
\hline Phospho-SAPK/JNK polyklonal & Cell Signaling Technology, Danvers, USA \\
\hline Phospho-Stat3 & Cell Signaling Technology, Danvers, USA \\
\hline PUMA, rabbit polyclonal purified IgG & MBL International Corporation, Woburn, USA \\
\hline
\end{tabular}




\begin{tabular}{|l|l|}
\hline $\begin{array}{l}\text { Rabbit IgG Isotype Control (Alexa Fluor®647 } \\
\text { Conjugate) }\end{array}$ & Cell Signaling Technology, Danvers, USA \\
\hline XIAP (2F1), mouse monoclonal IgG I $_{1}$ & MBL International Corporation, Woburn, USA \\
\hline
\end{tabular}

\subsubsection{Geräte}

Tabelle 4: Geräte

\begin{tabular}{|l|l|}
\hline Geräte & Hersteller \\
\hline $\begin{array}{l}\text { 3D-Utraschall } \\
\text { VeVo } 770^{\text {TM }} \text { Imaging System }\end{array}$ & Visual Sonics Inc., Toronto, Kanada \\
\hline Appliskan & Thermo Fisher Scientific Inc., Waltham, USA \\
\hline Brutschrank: HERAcell 150i CO ${ }_{2}$ Incubator & Thermo Fisher Scientific Inc., Waltham, USA \\
\hline Elektrophoresekammer Mini PROTEAN® Tetra Cell & BioRad, München, Deutschland \\
\hline FACS Canto II & Becton-Dickinson, Heidelberg, Deutschland \\
\hline Heizblock Thermo Stat plus & Eppendorf AG, Hamburg,Deutschland \\
\hline Kühlzentrifuge Centrifuge 5417R & Eppendorf AG, Hamburg,Deutschland \\
\hline Las 4000 Image Reader & Fujifilm, Tokyo, Japan \\
\hline Mastercycler & Eppendorf AG, Hamburg,Deutschland \\
\hline Mikroskop Axiovert 40 C & Zeiss, Jena, Deutschland \\
\hline Multi Gauge V3.2 (Software) & Fujifilm, Tokyo, Japan \\
\hline Netzgerät Electrophoresis Power Supply EPS 1001 & Amersham Biotech, Little Chalfont, England \\
\hline Neubauer Zählkammer & Brand, Wertheim, Deutschland \\
\hline Photometer Genesys 10 Bio & Thermo Fisher Scientific Inc., Waltham, USA \\
\hline Pipet Boy acu & IBS Integra Biosciences, Fernwald, Deutschland \\
\hline Schneidegerät Leica RM2235 & Leica, Wetzlar, Deutschland \\
\hline Schüttler & Grant-bio, Cambridgeshire, UK \\
\hline Trans Blot ${ }^{\circledR}$ SD Semi Dry Transfer Cell & BioRad, München, Deutschland \\
\hline Transfer-Pipetten & Brand, Wertheim, Deutschland \\
\hline TrayCell- Einsatz & Hellma, Müllheim, Deutschland \\
\hline UV-Kammer U:Genius & Synoptics Ltd, Cambridge, UK \\
\hline Vevo Compact Dual Anesthesia System & Visual Sonics Inc., Toronto, Kanada \\
\hline Vortexer & Labinco, Breda, Niederlande \\
\hline Wasseraufreinigung Stedim arium $® 611 V T ~$ & Sartorius, Göttingen, Deutschland \\
\hline Zellkulturbank HERAsafe & Heraeus, Hanau, Deutschland \\
\hline Zentrifuge Multifuge 1S-R Heraeus & Thermo Fisher Scientific Inc., Waltham, USA \\
\hline & \\
\hline
\end{tabular}

\subsubsection{Verbrauchsmaterialien}

\section{Tabelle 5: Materialien}

\begin{tabular}{|l|l|}
\hline Materialien & Hersteller \\
\hline Filterpapier & BioRad, München, Deutschland \\
\hline Kanüle Microlance TM $30,9 \mathrm{~mm} \times 40 \mathrm{~mm}, 20 \mathrm{G1} \frac{1 / 2}{2}$ & Becton-Dickinson, Heidelberg, Deutschland \\
\hline Nitrozellulose-Membran & BioRad, München, Deutschland \\
Trans-Blot ${ }^{\text {Transfer Medium Pure Nitrocellulose }}$ & \\
$0,45 \mu \mathrm{m}$ & \\
\hline Pipetten & Sarstedt, Nümbrecht, Deutschland \\
\hline Spritze 20 a & B. Braun Petzhold GmbH, Melsungen, Germany \\
Omnifix 40 Solo $1 \mathrm{ml}$ & \\
\hline
\end{tabular}


Einweg-Artikel sowie technische Geräte, die oben nicht aufgelistet sind, wurden von folgenden Firmen erworben: Eppendorf (Hamburg), Schütt (Göttingen), Greiner (Frickenhausen), Brand (Wertheim), Becton-Dickinson (Heidelberg) und Sarstedt (Nümbrecht) 


\subsubsection{Lösungen und Puffer}

\section{NP40-Lysis-Puffer:}

$10 \mathrm{mM}$ Tris/HCl pH 7,0; $150 \mathrm{mM} \mathrm{NaCl} ; 0,5 \%$ (v/v) NP40, in Aqua bidest., 1 Tablette „Complete mini“ in $10 \mathrm{ml}$

\section{0xTBE-Puffer:}

$108 \mathrm{~g}$ Tris, $55 \mathrm{~g}$ Borsäure, $40 \mathrm{ml}$ 0,5 M EDTA pH 8,0, ad 1000 ml Aqua bidest.

TBS:

$10 \mathrm{mM}$ Tris / $\mathrm{HCl} \mathrm{pH} \mathrm{7,0;} 1$ mM EDTA pH8; $150 \mathrm{mM} \mathrm{NaCl}$ in Aquabidest.

\section{TBS/T:}

0,05\% (v/v)-Tween in TBS

\section{Blockmilch:}

$5 \%$ (w/v)-Non-Fat-Drymilk in TBS/T

\section{Blocklösung Immunhistochemie:}

0,1\% -Tween, 5\%-Ziegenserum in PBS

\section{5x-SDS-Proben-Puffer:}

$200 \mathrm{mM}$ Tris pH 6,8, 4 \% (w/v)-SDS, 40 \% (v/v)-Glycerol, 0,07 \% (w/v)-Bromphenolblau

\section{Transfer-Puffer:}

$5 \mathrm{mM}$ Tris, $40 \mathrm{mM}$ Glycin, 3,75 \% (w/v)-SDS und 20\%-Methanol in Aquabidest. ; Lagerung bei $4{ }^{\circ} \mathrm{C}$

Trenngel für Western-Blot (10\%):

$2 \mathrm{ml}$ Aqua $_{\text {bidest.; }}$ 1,65 ml 30 \%-Acrylamid ; 1,25 ml 1,5 M Tris HCl pH 8,8; $50 \mu \mathrm{l} 10 \%$ (w/v)-SDS; $50 \mu \mathrm{l}$ $10 \%$-Ammoniumpersulfat; 7,5 $\mu$ I TEMED (Angaben für ein Gel)

\section{Sammelgel für Western-Blot :}

$1,05 \mathrm{ml}$ Aqua $_{\text {bidest.; }} 250 \mu \mathrm{l}$ 30\% Acrylamide; $190 \mu \mathrm{l}$ 1,0M Tris HCl pH 6,8; $15 \mu \mathrm{l} 10 \%$ (w/v)-SDS ; $15 \mu \mathrm{l}$ $10 \%$-Ammoniumpersulfat ; 1,5 $\mu$ l TEMED (Angaben für ein Gel)

\section{Laufpuffer für Western-Blot $(10 \times)$ :}

2 M Glycin, 250 mM Tris und 0,5\% (w/v)-SDS in Aqua bidest.

\section{FACS-Inkubationspuffer:}

0,5 g BSA/100 ml PBS

\section{AEC-Lösung:}

0,08g AEC in $10 \mathrm{ml}$ DMF, $100 \mathrm{ml}$ 0,1 M Acetatpuffer, $100 \mathrm{ml}$ Aqua $_{\text {bidest., }} 200 \mu \mathrm{l} 30 \%$ (v/v)- $\mathrm{H}_{2} \mathrm{O}_{2}$

\section{Streptavidin- Peroxidase-Lösung:}

$0,2 \%$ (v/v)-Streptavidin-Peroxidase in PBS 


\subsection{Methoden}

\subsubsection{Zellkultur-Methoden}

\subsubsection{Zelltypen und Zellkultur}

Die humanen Melanom-Zelllinien A375, Mel2a, MV3, Sk-Mel23, LOX und MMNH wurden in DMEM-Medium (Dulbecco's Modified Eagle's Medium) kultiviert, das 4,5 g/l Glukose, $10 \%(\mathrm{v} / \mathrm{v})-\mathrm{FCS}, 1 \%(\mathrm{v} / \mathrm{v})$-Penicillin/Streptomycin und $2 \mathrm{mM} \mathrm{L-}$ Glutamin enthielt. Die Zellen wurden bei $37^{\circ} \mathrm{C}, 5 \% \mathrm{CO}_{2}$ und $95 \%$ Luftfeuchtigkeit in Filter-top-Zellkulturflaschen in Kultur gehalten. Für Experimente wurden die Zellen in einer subkonfluenten Population kultiviert und abhängig von ihrem Wachstum alle drei bis fünf Tage passagiert. Für die in dieser Dissertation beschriebenen Experimente und Versuche wurden Zellen der Passagen 22 bis 55 verwendet. Die Kultivierung der humanen Melanom-Zelllinien wurde unter sterilen Bedingungen durchgeführt. Dazu wurden die Arbeiten mit den Zellen unter einer Sterilbank und mit für den sterilen Gebrauch gefertigten oder speziell autoklavierten oder sterilfiltrierten Materialien durchgeführt.

\subsubsection{Zellkultivation und Passage}

Für Passage und Kultivierung der adhärenten Zellen wurden die Zellen nach dem Spülen mit steriler Phosphat-gepufferter Salzlösung (engl. Phosphate buffered saline, PBS) 3 min mit Trypsin-EDTA bei $37^{\circ} \mathrm{C}, 5 \% \mathrm{CO}_{2}, 95 \%$ Luftfeuchtigkeit inkubiert, um die Zellen vom Boden der Kulturgefäße abzulösen. Die TrypsinReaktion wurde dann durch Zugabe von FCS-haltigem Medium gestoppt, die Zellen in der Mediumlösung aufgenommen und $4 \mathrm{~min}$ bei $400 \times \mathrm{g}$ zentrifugiert, in frischem Medium resuspendiert und ausgesät.

\subsubsection{Bestimmung der Zellzahlen}

Um eine konstante Zellzahl in den Versuchen zu gewährleisten, wurden die Zellen nach dem Ablösen von der Kulturoberfläche mit Trypsin in Medium suspendiert. $10 \mu \mathrm{l}$ dieser Suspension wurden in einer Neubauer-Zählkammer mikroskopisch 
ausgezählt. Dabei wurden $4 \times 16$ Felder der Kammer gezählt und die Summe $\times$ 2500 ergab Zellen/ml $/ \mathrm{muspension}_{\text {. }}$

\subsubsection{Behandlung mit Inhibitoren und Stimulation der Zellen}

Die Zellen wurden $16 \mathrm{~h}$ vor den Versuchen in Medium ausgesät, um ein ungestörtes Anwachsen der Zellen zu gewährleisten. Die Inhibitoren BAY-80-6946, U0126, Wortmannin und PD98059 wurden zu Beginn der Arbeit angesetzt, aliquotiert, bei $-20^{\circ} \mathrm{C}$ eingefroren, zu den Versuchen jeweils neu aufgetaut und mit dem Medium vermengt, bevor es auf die Zellen gegeben wurde. So wurde eine homogene Behandlung der Zellen in einem Versuch erreicht.

\subsubsection{UV-Behandlung}

Am Vorabend des Versuchs wurden $2 \times 10^{6}$ Zellen in Petrischalen ausgesät. Am nächsten Morgen wurde das Kulturmedium über den Zellen abgesaugt und die Zellen einmal mit $10 \mathrm{ml}$ PBS gewaschen. Unmittelbar vor der UV-Bestrahlung wurde das PBS abgezogen und die Petrischalen ohne Deckel in die UV-Kammer mit $7,5 \times 10^{3} \mathrm{\mu J} / \mathrm{cm}^{2}$ UV-C bestrahlt. Direkt anschließend wurde den Zellen wieder Medium hinzugegeben. Nach $30 \mathrm{~min}$ bei $37^{\circ} \mathrm{C}, 5 \% \mathrm{CO}_{2}$ und $95 \%$ Luftfeuchtigkeit wurden die Zellen geerntet und lysiert.

\subsubsection{Proteinanalysen}

\subsubsection{Proteingewinnung der Gesamtproteinextrakte}

Das Kulturmedium über den Zellen wurde abgesaugt und die Zellen einmal mit $10 \mathrm{ml}$ PBS gewaschen. Die Zellen wurden mit einem Zellschaber von der Kulturoberfläche gelöst und in $1 \mathrm{ml} \mathrm{PBS}\left(4^{\circ} \mathrm{C}\right.$ kalt) aufgenommen, in ein EppendorfGefäß übertragen und bei $500 \times \mathrm{g}$ und $4^{\circ} \mathrm{C}$ für $10 \mathrm{~min}$ zentrifugiert. Anschließend wurde der Überstand verworfen und das Zellpellet mit 100-300 $\mu$ l (je nach Größe des Pellets) NP40-haltigem Lysispuffer versetzt und 10 min auf Eis inkubiert. Hierdurch wurden die Zellmembranenen aufgeschlossen und weiterführend die Zellen durch manuelles Homogenisieren mit einer Spritze mit einer 20-G-Kanüle lysiert. Um das Lysat von Zelltrümmern zu trennen, wurde anschließend bei 25.000 
x g für 10 min bei $4^{\circ} \mathrm{C}$ zentrifugiert und das Pellet wurde verworfen. Der Überstand mit dem Gesamt-Proteinextrakt der Zellen wurde in ein neues Eppendorf-Gefäß überführt und es wurde die Proteinkonzentration gemessen. Anschließend wurde das Gesamt-Proteinextrakt bei $-20^{\circ} \mathrm{C}$ eingefroren.

\subsubsection{Proteinkonzentrationsbestimmung nach Bradford}

Die Proteinkonzentration in den gewonnenen Gesamt-Zellextrakten wurde nach der Bradford-Methode bestimmt. Diese Methode basiert auf einer Reaktion von Coomassie-Brilliant-Blau, das unter Bindung an Protein von einem Produkt rötlicher Farbe in einen blauen Farbstoff-Proteinkomplex wechselt. Der Komplex ruft eine Änderung des Absorptions-Maximums von 465 nm zu 595 nm hervor, die photometrisch erfasst werden kann. Die Absorptionsänderung ist proportional zur Konzentration des in der Testlösung befindlichen Proteins und ermöglicht so die Berechnung der Proteinkonzentration in der Lösung. Zur Messung der

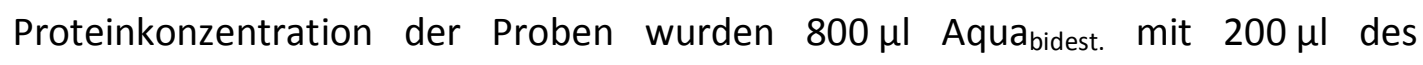
Bradford-Reagenz und $1 \mu \mathrm{l}$ der zu testenden Probe versetzt und für $10 \mathrm{~min}$ bei Raumtemperatur inkubiert. Anschließend wurde die Absorption bei $595 \mathrm{~nm}$ mit dem Photometer gemessen und anhand einer äquivalent angesetzten und gemessenen Standardkurve mit bekannten Proteinkonzentrationen die Proteinkonzentration der Proben bestimmt.

\subsubsection{SDS-Polyacrylamid-Gelelektrophorese}

Bei der SDS-Polyacrylamid-Gelelektrophorese (SDS-PAGE) können Proteine gemäß ihrem Molekulargewicht im elektrischen Feld in einem Polyacrylamid-Gel aufgetrennt werden. Das im Probenpuffer befindliche SDS denaturiert die Proteine und fügt ihnen eine negative Ladung zu. Das Proteinlysat wurde zusammen mit

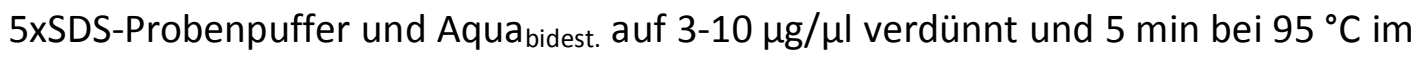
Heizblock aufgekocht. Die SDS-Gele wurden in der Blot-Apparatur gegossen und nach ihrer Aushärtung mit $10 \mu \mathrm{l}$ der vorbereiteten Proben beladen. Parallel wurde ein Größenstandard (farbige Proteine bekannter Molekülgröße) aufgetragen. Die Kammer wurde mit 1x-Laufpuffer für Western-Blot befüllt. Die Trennung der Proteine erfolgte in der Elektrophorese-Kammer bei $50 \mathrm{~V}$ für 30-60 min. 


\subsubsection{Western-Blot}

Nach dem Auftrennen der Proteine im SDS-PAGE-Verfahren wurden die Proteine auf eine Nitrozellulose-Membran übertragen. Hierfür wurde das Semi-dry-BlotVerfahren benutzt. Die Gele wurden aus der Gelelektrophorese-Apparatur gelöst, auf eine mit $4{ }^{\circ} \mathrm{C}$ kaltem Transfer-Puffer durchfeuchtete Membran gelegt und zwischen zwei auch mit dem Puffer getränkten Zellstoffschwämmchen in dem Trans Blot ${ }^{\circledR}$-SD-Semi-Dry-Transfer-Cell-Gerät positioniert. Bei $150 \mathrm{~mA}$ über $40 \mathrm{~min}$ wurden die Proteine auf die Nitrozellulose-Membran transferiert. Anschließend wurden die Membranen für eine Stunde bei Raumtemperatur auf dem Schüttler mit Blockmilch inkubiert, um unspezifische Bindungsstellen abzusättigen. Nach dem Waschen $(3 \times 5 \mathrm{~min}$ in TBS/T) wurde die Membran für $2 \mathrm{~h}$ bei Raumtemperatur oder über Nacht bei $4{ }^{\circ} \mathrm{C}$ mit dem Primärantikörper inkubiert. Anschließend wurde nach dreimaligem Waschen mit TBS/T mit dem HRPkonjugierten Sekundärantikörper für $2 \mathrm{~h}$ inkubiert. Nach 3 Waschschritten in TBS/T erfolgte eine Signaldetektion mit Hilfe einer Chemilumineszenz-Reaktion mit $E C L^{+}$ durch den Las 4000 Image Reader.

Nachfolgend finden sich die verwendeten Antikörper mit ihren Verdünnungen in den spezifischen Inkubationspuffern.

Tabelle 6: Antikörper-Verdünnungen

\begin{tabular}{|l|l|}
\hline Verwendeter Antikörper gegen: & Verdünnung \\
\hline AKT & $1: 1000$ in TBS/T + 5\%BSA \\
\hline Aktin & $1: 10000$ in TBS/T +1\% Blockmilch \\
\hline Bax & $1: 200$ in TBS/T + 1\% Blockmilch \\
\hline Bcl-2 & $1: 200$ in TBS/T + 1\% Blockmilch \\
\hline ERK & $1: 1000$ in TBS/T + 5\%BSA \\
\hline p-AKT & $1: 1000$ in TBS/T + 5\%BSA \\
\hline p-ERK & $1: 2000$ in TBS/T + 5\%BSA \\
\hline p-JNK & $1: 1000$ in TBS/T + 5\%BSA \\
\hline p-STAT3 & $1: 2000$ in TBS/T + 5\%BSA \\
\hline PUMA & $1: 2000$ in TBS/T + 1\% Blockmilch \\
\hline Sekundärantikörper anti-Kaninchen & $1: 2500$ in TBS/T + 1\% Blockmilch \\
\hline Sekundärantikörper anti-Maus & $1: 2500$ in TBS/T + 1\% Blockmilch \\
\hline XIAP & $1: 1000$ in TBS/T + 1\% Blockmilch \\
\hline
\end{tabular}




\subsubsection{Nukleinsäureanalysen}

\subsubsection{RNA-Isolierung und DNAse-Verdau}

Die Isolierung der mRNA aus Zellkulturen und Tumorgewebe wurde mit dem TotalRNA-Kit-I von E.Z.N.A. ${ }^{\text {TM }}$ durchgeführt. Die Methode basiert auf der reversiblen Bindung von Ribonukleinsäure (engl: ribonucleic acid, RNA) an eine Silika-GelMembran. Durch mehrere Wasch- und Zentrifugationsschritte wird die RNA aufgereinigt und die restlichen Zellbestandteile entfernt. Ein zusätzlicher DNaseVerdau mit dem RNase-Free-Dnase-Set reinigt das Produkt zusätzlich von vorhandener genomischer Desoxyribonukleinsäure (engl. deoxyribonucleic acid, DNA).

Vor der Isolierung der RNA wurden die adhärenten Melanomzellen durch Trypsin vom Kulturgefäß gelöst, einmal mit $10 \mathrm{ml}$ PBS gewaschen und in $700 \mu \mathrm{l}$ mit 2-ß-Mercaptoethanol-versetztem-TRK-Lysispuffer aus dem RNA-Isolierungskit aufgenommen. Anschließend wurden die Lysispuffer-Zellsuspensionen durch zehnmaliges Auf- und Abziehen durch eine Spritze mit einer 20-G-Kanüle homogenisiert. Zu dem Homogenisat wurde die gleiche Menge an $70 \%(v / v)-$ Ethanol zugefügt und kurz mithilfe eines Schüttlers vermengt.

Die weitere Aufreinigung der RNA erfolgte nach dem Protokoll "Isolation of Total RNA from Animal Cells" aus dem E.Z.N.A. ${ }^{\text {TM }}$ Total RNA Kit Manual 03/2007. Wie im Protokoll empfohlen, wurde der DNase-I-Verdau durchgeführt. Zuletzt wurde die RNA durch Zugabe von $30 \mu \mathrm{l}$ RNase-freiem-DEPC-behandeltem Wasser aus der Membran gelöst. Die so gewonnene RNA wurde entweder sofort weiter verwendet oder bei $-80^{\circ} \mathrm{C}$ gelagert.

\subsubsection{Photometrische Bestimmung der RNA-Konzentration}

Die Nukleinsäurekonzentration in den Proben wurde photometrisch mit einem Photometer bei einer Extinktion von $260 \mathrm{~nm}$ bestimmt. Dazu wurde $1 \mu \mathrm{lder}$ unverdünnten Probe in den TrayCell-Einsatz gegeben und die optische Dichte (OD) bei $260 \mathrm{~nm}$ gemessen. Eine $\mathrm{OD}_{260}$ von 1 entspricht einer RNA-Konzentration von $40 \mu \mathrm{g} / \mathrm{ml}$. Um den Grad der Verunreinigung der Nukleinsäuren durch Proteine in 
der Probe zu ermitteln, ist es möglich, die $\mathrm{OD}_{260}$ gegen die $\mathrm{OD}_{280}$ (das AbsorptionsMaximum von Proteinen) zu messen. Der Quotient $\mathrm{OD}_{260} / \mathrm{OD}_{280}$ sollte zwischen 1,6-1,8 liegen.

\subsubsection{Reverse Transkription}

Bei der Reversen Transkription wird durch eine RNA-abhängige DNAPolymerase (Reverse Transkriptase) ein zu der vorhandenen RNA komplementärer DNA-Strang (engl: complementary DNA, cDNA) synthetisiert. Für das Umschreiben von isolierter RNA in CDNA wurde das First-Strand-CDNA-Synthesis-Kit genutzt. Dazu wurden $2 \mu \mathrm{g}$ der zuvor isolierten RNA eingesetzt und mit RNase-freiem Wasser bis auf $10 \mu \mathrm{l}$ aufgefüllt. Diesem Ansatz wurde $1 \mu \mathrm{l}$ Oligo(dT) ${ }_{18}$-Primer aus dem Kit hinzugefügt, kurz gemischt, zentrifugiert und 5 min auf dem vorgeheizten Heizblock bei $70^{\circ} \mathrm{C}$ inkubiert. In diesem Schritt hybridisieren die (dT) 18 -Primer mit den Polyadenin-Enden der RNA. Danach wurde die Probe auf Eis abgekühlt und erneut kurz herabzentrifugiert. $\mathrm{Zu}$ der Probe wurden nun in angegebener Reihenfolge folgende Substanzen aus dem First-strand-cDNA-Synthesis-Kit hinzugefügt:

\begin{tabular}{lc} 
5X Reaction Buffer & $4 \mu \mathrm{l}$ \\
RiboLock $^{\mathrm{TM}}$ RNase Inhibitor $(20 \mathrm{u} / \mu \mathrm{l})$ & $1 \mu \mathrm{l}$ \\
$10 \mathrm{mM}$ dNTP Mix & $2 \mu \mathrm{l}$ \\
M-MuLV Reverse Transcriptase $(20 \mathrm{u} / \mu \mathrm{l}$ & $\underline{2 \mu \mathrm{l}}$ \\
\hline Endvolumen mit Probe und Primer & $20 \mu \mathrm{l}$
\end{tabular}

Nun wurden die Proben nach sorgfältiger Vermengung und kurzer Zentrifugation $60 \mathrm{~min}$ bei $37^{\circ} \mathrm{C}$ inkubiert. Dieser Schritt dient der Synthese des cDNA-Strangs durch die Reverse Transkriptase. Die Reaktion wurde durch zehnminütige Inkubation bei $70^{\circ} \mathrm{C}$ gestoppt und die Proben anschließend auf $4{ }^{\circ} \mathrm{C}$ herabgekühlt. 


\subsubsection{Semiquantitative Polymerasekettenreaktion}

Bei der Polymerasekettenreaktion (engl. polymerase chain reaction, PCR) werden kurze, genau definierte Elemente einer DNA-Sequenz amplifiziert. Dadurch ist es möglich, Zellproben, deren mRNA zuvor in cDNA umgeschrieben wurde, hinsichtlich der Transkriptionsmenge bestimmter Gene untereinander zu vergleichen. Dieses Verfahren wird semiquantitative Reverse-TranskriptasePolymerasekettenreaktion (semiquantitative RT-PCR) genannt. Mit Hilfe der TaqPolymerase, einer hitzestabilen DNA-Polymerase, werden die Abschnitte zwischen zwei Primersequenzen vervielfältigt. Die Reaktion besteht aus drei Schritten, deren zyklische Wiederholung zu einer Amplifizierung des DNA-Produkts führt. Zunächst werden bei einer Temperatur von $92{ }^{\circ} \mathrm{C}$ bis $94{ }^{\circ} \mathrm{C}$ die Wasserstoffbrückenbindungen zwischen den DNA-Doppelsträngen gespalten, sodass die DNA als Einzelstränge vorliegt. In der anschließenden Phase des Annealings (Anlagerungsphase) lagern sich die Primer an die ihnen homologen DNASequenzen an. Dazu wird die Temperatur auf ein Primer-spezifisches Temperaturoptimum für die Anlagerung gesenkt. Anschließend findet bei einer Temperatur von $72{ }^{\circ} \mathrm{C}$ die Elongation statt. Dabei lagert die DNA-Polymerase in 5'3'-Richtung Nukleotide an die Primer-Stücke an und fügt sie zu einem neuen DNAStrang zusammen. Die dazu nötigen freien Nukleotide liegen im Überschuss im Reaktionsansatz vor, sodass die Länge der resultierenden DNA-Einzelstränge durch die Dauer der Elongationsphase bestimmt wird. Die DNA-Polymerase amplifiziert bis zu 1000 bp/min. Die genaue Dauer der Elongationsphase hängt von der Länge des zu amplifizierenden DNA-Produkts ab. Mit der Denaturierung bei $94{ }^{\circ} \mathrm{C}$ erfolgt der Abbruch der Strang-Synthese. In den nun anschließenden Wiederholungen der drei Reaktionsschritte erfolgt eine exponentielle Amplifizierung des DNATeilstückes zwischen den beiden Primer-Sequenzen. 


\subsubsection{PCR-Durchführung}

Zur Durchführung der PCR wurde ein „Mastermix" aus folgenden Substanzen hergestellt: Bis auf die Primer sind alle Reagenzien aus dem Taq-all-inclusiveReaktionskit.

Angaben für einen Ansatz:

$\begin{array}{ll}\text { Vorwärtsprimer } & 1 \mu \mathrm{l} \\ \text { Rückwärtsprimer } & 1 \mu \mathrm{l} \\ \text { dNTP } 10 \mathrm{mM} & 1 \mu \mathrm{l} \\ \text { Puffer S } & 2,5 \mu \mathrm{l} \\ \text { Taq-Polymerase } & 0,2 \mu \mathrm{l} \\ \text { Aqua dest. } & 18,3 \mu \mathrm{l} \\ \text { Endvolumen } & 24 \mu \mathrm{l}\end{array}$

Zu dem Mastermix wurde $1 \mu \mathrm{l}$ der zu replizierenden cDNA gegeben. Für jeden PCRLauf wurde eine Negativkontrolle erstellt, um Verunreinigungen oder unspezifische Signale detektieren zu können. Dazu wurde zu dem Mastermix statt der cDNA $1 \mu$ l Aqua dest. hinzugegeben. Die PCRs wurden im Mastercycler ${ }^{\circledR}$ nach folgenden Reaktionsbedingungen durchgeführt:

$\begin{array}{lll}\text { Initiale Denaturierung: } & 94^{\circ} \mathrm{C} & 3 \mathrm{~min} \\ \text { Denaturierung: } & 94^{\circ} \mathrm{C} & 30 \mathrm{~s} \\ \text { Annealing: } & 55^{\circ} \mathrm{C}-62^{\circ} \mathrm{C} & 30 \mathrm{~s} \\ \text { Elongation: } & 72^{\circ} \mathrm{C} & 30-60 \mathrm{~s} \\ 72^{\circ} \mathrm{C} & & 5 \mathrm{~min}\end{array}$


Nachfolgend finden sich die Primer-Sequenzen und genauen Versuchsbedingungen der durchgeführten PCRs:

Tabelle 7: Primersequenzen

\begin{tabular}{|c|c|c|}
\hline Gen & Primer-Sequenz & $\begin{array}{l}\text { Annealing-Temperatur/ } \\
\text { Zyklen/Produktgröße }\end{array}$ \\
\hline COX-2 & $\begin{array}{l}\text { for 5’ - GAGAAAACTGCTCAACACCG - 3’ } \\
\text { rev 5’ - GCATACTCTGTTGTGTTCCC - 3’ }\end{array}$ & $\begin{array}{l}55^{\circ} \mathrm{C} / \\
26 \text { Zyklen/764 bp }\end{array}$ \\
\hline CyclinD1 & $\begin{array}{l}\text { for 5'-GCAGGGAAAAAGGCAGAAAG-3' } \\
\text { rev 5'-GGAGTTACCACACATGACAG-3' }\end{array}$ & $\begin{array}{l}52^{\circ} \mathrm{C} / \\
26 \text { Zyklen/393 bp }\end{array}$ \\
\hline GAPDH & $\begin{array}{l}\text { for 5’ - CTTTGGTATCGTGGAAGGACTC - 3’' } \\
\text { rev 5’ - TTCGTTGTCATACCAGGAAATG - 3' }\end{array}$ & $\begin{array}{l}58^{\circ} \mathrm{C} / \\
26 \text { Zyklen/451 bp }\end{array}$ \\
\hline CXCL-1 & $\begin{array}{l}\text { for 5’ - ATG GCC CGC GCT GCT CTC TCC - 3’ } \\
\text { rev 5' - CTT AAC TAT GGG GGA TGC AGG - } 3\end{array}$ & $\begin{array}{l}58^{\circ} \mathrm{C} / \\
26 \text { Zyklen/282 bp }\end{array}$ \\
\hline IL-8 & $\begin{array}{l}\text { for 5’ -ACAAGCTTCTAGGACAAGAGCCAGGAAG - 3’ } \\
\text { rev 5’ - GTGAATTCAGTGTGGTCCACTCTCAATC - 3' }\end{array}$ & $\begin{array}{l}62^{\circ} \mathrm{C} / \\
26 \text { Zyklen/253 bp }\end{array}$ \\
\hline p21 & $\begin{array}{l}\text { for 5'- AGG ATC CAT GTC AGA ACC GGC TGG -3' } \\
\text { rev 5'- CAG GAT CCT GTG GGC GGA TTA GGG CT -3' }\end{array}$ & $\begin{array}{l}62^{\circ} \mathrm{C} / \\
30 \mathrm{Zyklen} / 510 \mathrm{bp}\end{array}$ \\
\hline
\end{tabular}

\subsubsection{DNA-Agarose-Gelelektrophorese}

Mit der Agarose-Gelelektrophorese werden DNA-Fragmente der Größe nach aufgetrennt. Die dazu benötigten Gele wurden mit $1 \%(w / v)$-Agarose in TBE-Puffer $(1 x)$ erstellt. Die Lösung wurde in der Mikrowelle aufgekocht, bis sie homogen war und nach kurzem Abkühlen wurden $3 \mu \mathrm{l}$ GelRed-10.000x-in-water/100-ml-AgaroseLösung dazugegeben. Dieser Fluoreszenzfarbstoff färbt Nukleinsäuren und kann durch Anregung mit UV-Licht auf einem Gel-Dokumentationsgerät sichtbar gemacht werden. In einem Gel-Träger mit einer Taschenschablone polymerisierte das Gel aus und wurde dann in eine Gel-Kammer überführt. Diese Gel-Kammer wurde mit TBE-Puffer $(1 \mathrm{x})$ befüllt. Die aufzutrennende DNA wurde mit 1/5 ihres Volumens an Ladepuffer versetzt. Der Puffer inaktiviert Enzyme, verleiht der Probe eine hohe Dichte, die das Auftragen der Probe unterstützt und markiert die Proben farblich. Parallel zu der DNA-Probe wurde eine 100-bp-DNA-Leiter mit auf das Agarose-Gel aufgetragen. Als das Gel vollständig beladen war, wurde mit einem Netzteil eine Spannung zwischen 80 - 100 V angelegt. Die Gel-Taschen mit der DNA befanden sich auf der Kathodenseite. Die negativ geladene DNA wanderte im 
elektrischen Feld zur Anode. Nachdem die Elektrophorese beendet war, wurde das Agarose-Gel auf dem Gel-Dokumentationsgerät ausgewertet. Um einen Vergleich der verschiedenen Zellreihen untereinander zu ermöglichen und um zu zeigen, dass gleiche Mengen an RNA eingesetzt wurden, wurde zunächst eine PCR von GAPDH (Glycerinaldehyd-3-phosphat-Dehydrogenase) durchgeführt. Dieses Gen ist in allen Zellreihen unabhängig von Zellzyklus, Zellstadium und äußeren Einflüssen gleichermaßen konstitutiv exprimiert und eignet sich daher als Referenz-Gen.

\subsubsection{Durchflusszytometrie (FACS)}

Die Durchflusszytometrie beschreibt ein Verfahren, bei dem Zellen anhand ihrer Lichtbrechungseigenschaften und ihrer Fluoreszenz unterschieden werden können. Da die meisten Zellen nur geringe Eigen-Fluoreszenzen aufweisen, lässt sich mit Farbstoff-gekoppelten Antikörpern gegen bestimmte Zellproteine das Expressionsmuster extra- und, nach Permeabilisierung der Zellmembran, auch intrazellulärer Proteine quantifizieren und vergleichen. Hierzu wurde das FACS Canto I/ genutzt.

\subsubsection{Nachweis der Kinasen p-ERK und p-AKT}

Das Durchflusszytometer wurde genutzt, um die intrazellulären Proteine $p$-ERK und p-AKT zu detektieren und die 6 Melanomzellreihen hinsichtlich des gemessenen Gehalts zu vergleichen.

\subsubsection{Fixierung und Permeabilisation der Zellen}

Es wurden etwa $2 \times 10^{6}$ der adhärenten Zellen mithilfe von Trypsin/EDTA geerntet und in PBS suspendiert, in ein Zentrifugen-Röhrchen überführt und nach einem Waschschritt mit PBS in 0,5 ml PBS mit $2 \mathrm{ml} 4 \%$-PFA für $10 \mathrm{~min}$ bei $37^{\circ} \mathrm{C}$ fixiert. Anschließend wurden die Zellen für 1 min auf Eis gekühlt. Da es sich bei den zu untersuchenden Kinasen um intrazelluläre Proteine handelt, musste die Zellmembran permeabilisiert werden, um sie für die verwendeten Antikörper durchgängig zu machen. Dafür wurde $-20{ }^{\circ} \mathrm{C}$-kaltes $90 \%$ iges Methanol verwendet, welches nach Zentrifugation der Zellen bei 500 x g über 3 min und Abkippen des 
Überstandes zu den Zellen gegeben wurde. Nun wurde 30 min auf Eis inkubiert. Anschließend konnten die Zellen im Methanol bei $-20^{\circ} \mathrm{C}$ gelagert werden.

\subsubsection{Immunfärbung der Zellen}

Die in 90\%-Methanol gelagerten Zellen wurden zur Immunfärbung zunächst auf 4 FACS-Röhrchen verteilt, sodass sich etwa $0,5 \times 10^{6}$ Zellen in einem Röhrchen befanden. Nach zwei Waschschritten mit jeweils 2-3 $\mathrm{ml}$ des Inkubationspuffers und anschließender Zentrifugation bei 500 x g für 3 min wurde die Flüssigkeit über den sedimentierten Zellen per Hand abgekippt, sodass die Zellen in etwa $100 \mu \mathrm{l}$ Inkubationspuffer verblieben. Nun wurden zu jedem Ansatz $15 \mu \mathrm{l}$ AB-Serum gegeben und für $10 \mathrm{~min}$ bei Raumtemperatur inkubiert. Dieser Schritt dient der Absättigung unspezifischer Bindungsstellen. Nach Zentrifugation der Zellen und Resuspendierung des Zellpellets in $100 \mu \mathrm{l}$ Inkubationspuffer erfolgte eine einstündige Inkubation bei Raumtemperatur mit den durch den Fluoreszenzfarbstoff Alexa Fluor ${ }^{\circledR} 647$ markierten Antikörpern gegen phospho-ERK, phospho-AKT oder den entsprechenden Isotypkontrollen. Nach zwei Waschschritten in PBS wurden die Zellen für die Messung durch das Durchflusszytometer in $500 \mu \mathrm{l}$ PBS aufgenommen. Die Ergebnisse der Messung wurden anschließend mit der BD FACSDiva ${ }^{T M}$ (Becton-Dickinson, Heidelberg) analysiert.

Tabelle 8: Antikörper-Verdünnungen

\begin{tabular}{|l|l|}
\hline Antikörper & Verdünnung \\
\hline $\begin{array}{l}\text { Phospho-p44/42 MAPK (Erk1/2) (Thr202/Tyr204) } \\
\text { (E10) Mouse mAb } \\
\text { (Alexa Fluor }{ }^{\circledR} 647 \text { Conjugate) }\end{array}$ & $1: 10$ in FACS-Inkubationspuffer \\
\hline $\begin{array}{l}\text { Phospho-Akt (Ser473) (193H12) Rabbit mAb (Alexa } \\
\text { Fluor® 647 Conjugate) }\end{array}$ & $1: 10$ in FACS-Inkubationspuffer \\
\hline $\begin{array}{l}\text { Rabbit IgG Isotype Control (Alexa } \\
\text { Fluor }{ }^{\circledR 647 C o n j u g a t e) ~}\end{array}$ & $1: 10$ in FACS-Inkubationspuffer \\
\hline Mouse IgG1 isotype control Alexa Fluor ${ }^{\circledR 647}$ & $1: 25$ in FACS-Inkubationspuffer \\
\hline
\end{tabular}




\subsubsection{In-vivo-Experimente}

Alle für diese Doktorarbeit verwendeten Tierversuche laufen unter dem genehmigten Tierversuchsantrag mit dem Aktenzeichen 33.14.42502-04-099/09 und wurden unter durchgehender Aufsicht von Prof. Dr. Margarete Schön durchgeführt. Die in den Versuchen verwendeten athymischen Nacktmäuse (nu/nu) entstammen der Zucht von Prof. Dr. Frauke Alves und wurden gemäß den im Tierstall der Tierversuchseinrichtung der Universitätsmedizin Göttingen üblichen Bedingungen gehalten. Dies beinhaltet Futter und Wasser ad libitum, optimierte hygienische Bedingungen und einen 12 H/12 H-Tag/Nacht-Zyklus.

Für alle Versuche wurde erwachsenen athymischen männlichen oder weiblichen Nacktmäusen intradermal jeweils $1 \times 10^{6}$ Melanomzellen in $100 \mu$ PBS beidseitig über die Hinterläufe injiziert. Das Tumorwachstum wurde dreimal wöchentlich mithilfe einer Schieblehre gemessen. Dazu wurden die Mäuse mit Isofluran in dem Vevo-Compact-Dual-Anesthesia-System betäubt. Höhe, Länge und Breite der Tumoren wurden gemessen und die Tumoren wurden fotografiert. Nach der Formel „Höhe $\times$ Länge $\times$ Breite $=$ Volumen“ wurde näherungsweise das Volumen der Tumoren bestimmt. Die Versuche wurden gemäß den europäischen Tierversuchsrichtlinien abgebrochen, sobald Hautulzerationen auftraten. Die Tiere wurden dazu mit $\mathrm{CO}_{2}$ narkotisiert und durch Genickbruch getötet.

Direkt anschließend wurden die Gewebeproben entnommen. Mit spitzer Schere, Skalpell und Pinzette wurden die Tumoren mit der sie bedeckenden Haut vorsichtig herauspräpariert. Dann wurden sie gewogen, für die weitere Verwendung aufbereitet und in 4\%iger Paraformaldehyd-Lösung für $24 \mathrm{~h}$ inkubiert. Anschließend wurden die Tumoren in Paraffin eingebettet. 


\subsubsection{Tumorvolumen-Bestimmung durch $3 \mathrm{~d}$-Ultraschallmessung}

Neben der Vermessung der Tumoren mit der Schieblehre erfolgte bei dem Mausversuch zur Tumorigenität der 6 Melanomzellreihen ergänzend an den Versuchstagen 2 und 6 eine sonographische Vermessung in 3 Dimensionen mit dem VeVo $770^{T M}$-Imaging-System. Dieses System macht es möglich, digitale Schnittbilder der Tumoren zu erstellen und zu speichern. Während der Vermessungszeit wurden die Tiere mit Isofluran durchgehend in Narkose gehalten und auf dem beheizten Versuchstisch des VeVo $770^{T M}$-Imaging-Systems gelagert. In dem verwendeten Ultraschall-System ist der Schallkopf fest installiert und kann mit einem Motor um definierte Strecken bewegt werden. In einem definierten Abstand werden die erstellten Ultraschall-Schnittbilder gespeichert. Aus diesen lassen sich dann mit der Vevo $770^{\circledR}$-Software die Tumoren rekonstruieren und die Volumina berechnen.
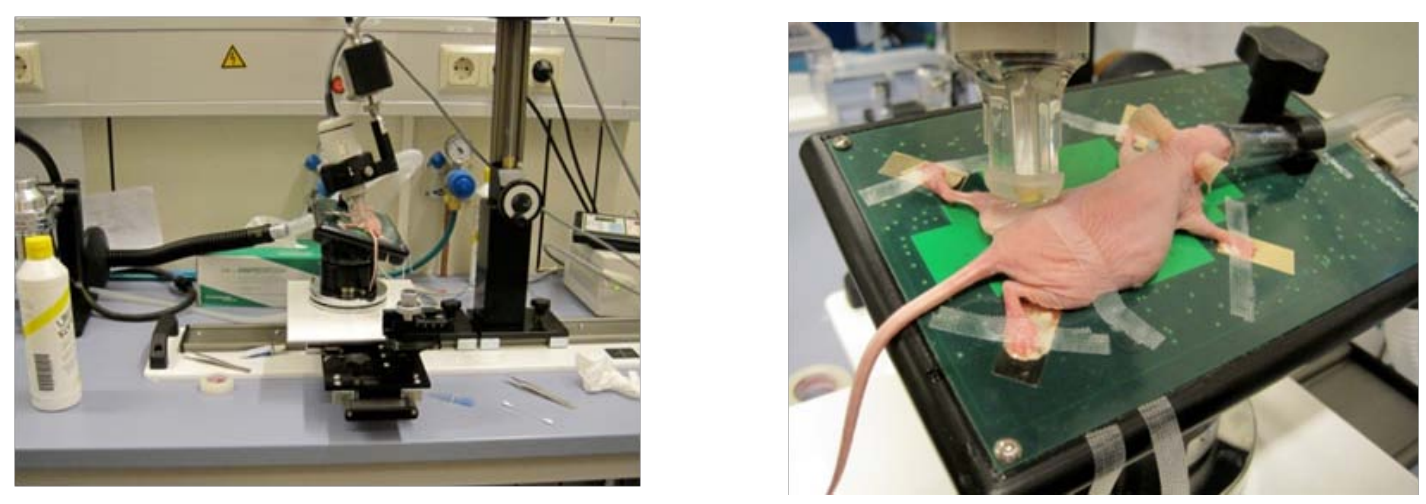

Abb. 3: Athymische Nacktmäuse wurden mit Isofluran narkotisiert und auf dem beheizten Versuchstisch des VeVo $770^{\mathrm{TM}}$-Imaging-System fixiert.

\subsubsection{U0126-Behandlung}

Für das Experiment zur Untersuchung des Einflusses von U0126 auf das Wachstum der Tumoren aus den humanen Melanom-Zelllinien LOX und A375 in der athymischen Nacktmaus wurden die Tiere jeden zweiten Tag mit dem Inhibitor oder einer Lösungsmittelkontrolle behandelt. Dazu wurden die Zellen wie zuvor beschrieben intradermal transplantiert. Nach dem Anwachsen der Tumoren wurde 
an Tag 1 mit der Behandlung begonnen. Dazu wurde gewichtsadaptiert $500 \mathrm{nM}$ bis 900 nM U0126 in PBS pro Maus intraperitoneal (i.p.) injiziert. Als Lösemittelkontrolle diente die gleiche Menge DMSO in PBS. Die Injektionen erfolgten abwechselnd in die linke oder rechte Hälfte des Abdomens.

\subsubsection{BAY-80-6946-Behandlung}

Für die Untersuchung des Einflusses von BAY-80-6946 auf das Tumorwachstum wurden die Tiere dreimal pro Woche mit BAY-80-6946 oder einer Lösungsmittelkontrolle behandelt. BAY-80-6946 wurde in einer Menge von 125 nM-BAY-80-6946/ Maus i.p. verabreicht. Als Lösungsmittelkontrolle diente hier das BAY-80-6946-spezifische Lösungsmittel Vehikel in PBS. Die Injektionen erfolgten abwechselnd in die linke oder rechte Hälfte des Abdomens. Nach 16 Tagen wurden die Versuche beendet und die Tiere getötet. Die ausgewertete Tumorzahl pro Gruppe betrug $n=8$.

\subsubsection{Immunhistochemische Färbungen}

Um die Proteine p-ERK und p-AKT in situ zu detektieren, wurden von den zuvor in Paraffin eingebetteten Tumoren 3- $\mu \mathrm{m}$-dicke Gewebeschnitte erstellt und auf Objektträger überführt. Zur Verwendung der humanen Melanommetastasen liegt ein positives Votum der Ethik-Kommission vom 04.07.2012 unter der Antragsnummer 14/3/12 vor. Die Schnitte wurden zur Entparaffinierung dreimal für $10 \mathrm{~min}$ in Xylol und anschließend $10 \mathrm{~min}$ in Isopropanol inkubiert. Danach erfolgte die schrittweise Rehydrierung in 100\%-, 90\%-, 70\%- und 50\%-Ethanol. Nach einem Waschschritt in PBS wurden die Schnitte in Aqua $_{\text {bidest. }}$-verdünnter (1:10) DAKO-Target-Retrival-Solution(10x) 20 min gekocht, um die Antigene zu demaskieren. Anschließend wurden die Schnitte langsam auf Raumtemperatur gebracht und dreimal für 5 min in PBS gewaschen. Danach wurden die Schnitte mit $3 \%-\mathrm{H}_{2} \mathrm{O}_{2}$ in PBS für $10 \mathrm{~min}$ bei Raumtemperatur inkubiert, um endogene Peroxidasen zu inaktivieren, und wieder mit PBS gewaschen. Um unspezifische Bindungsstellen zu besetzen, wurden die Schnitte in einer Blocklösung mit 5\%Ziegen-Serum für 45 min bei RT geblockt. Anschließend wurden die Antikörper 
gegen $p$-AKT und p-ERK in den unten angegebenen Verdünnungen auf die Schnitte gegeben und die Objektträger über Nacht bei $4^{\circ} \mathrm{C}$ inkubiert. Nun erfolgte nach dreimaligem Waschen in PBS die 40-min-Inkubation bei RT mit dem HRPmarkierten Sekundärantikörper. Anschließend wurde erneut in PBS gewaschen. Um stärkere Signale zu erhalten, wurde das Tyramide-Signal-Amplifikation ${ }^{T M}$-Kit genutzt und die Schnitte mit dem enthaltenen Puffer für 10 min bei RT inkubiert. Nach drei Waschschritten mit PBS, Inkubation mit 0,2\%-Streptavidin-Peroxidase in PBS für 40 min bei RT und erneuten Waschschritten mit PBS, wurden die Schnitte für $5 \mathrm{~min}$ in einer $\mathrm{AEC}^{+}$-Lösung inkubiert, um eine Färbereaktion zu bewirken. Nachdem die Schnitte kurz in Aqua bidest. getaucht wurden, erfolgte eine einminütige Gegenfärbung mit Hämatoxylin.

Tabelle 9

\begin{tabular}{|l|l|}
\hline Antikörper & Verdünnung \\
\hline Phospho-AKT polyklonal & $1: 50$ \\
\hline $\begin{array}{l}\text { Phospho-ERK1/2 p44/42 MAPK } \\
\text { monoklonal (D13.14.4E) }\end{array}$ & $1: 50$ \\
\hline Sekundärantikörper Anti-rabbit-HRP & $1: 500$ \\
\hline
\end{tabular}




\subsubsection{Funktionelle Experimente}

\subsubsection{Proliferationsmessungen}

Um den Einfluss verschiedener Substanzen auf die Proliferation der untersuchten Melanom-Zellinien zu messen, wurde der CellTiter96`Non-Radioactive-CellProliferation-Assay durchgeführt. Vitale Zellen reduzieren MTT-Tetrazolium-Salz (3-(4,5-Dimethylthiazol-2-yl)-2,5-diphenyl-tetrazoliumbromid) zu einem FormazanProdukt. Dieses lässt sich mit einem Platten-Photometer bei einer Wellenlänge von $570 \mathrm{~nm}$ detektieren.

Für die Experimente wurden 3000 Zellen/100 $\mu$ Kulturmedium/Well in eine 96Well-Kulturplatte ausgesät. Nach der Adhäsion der Zellen über Nacht wurde das alte Medium abgesaugt und die Zellen über 24 und 48 Stunden mit den zu testenden Substanzen und deren Lösungsmitteln in Medium kultiviert. Dann wurde in die Reaktionsräume $15 \mu \mathrm{l}$ der Formazan-haltigen Färbelösung zugegeben und über 4 Stunden mit den Zellen bei $37^{\circ} \mathrm{C}, 5 \% \mathrm{CO}_{2}$ und $95 \%$ Luftfeuchtigkeit inkubiert. Nach Zugabe von $100 \mu \mathrm{l}$ „Stopplösung“ wurde die Platte wieder bei den eben genannten Bedingungen über Nacht inkubiert. Am nächsten Tag konnte mit dem Platten-Photometer die Absorption bei Wellenlängen von $595 \mathrm{~nm}$ und $655 \mathrm{~nm}$ gemessen werden. Bei allen vorgenommenen Messungen wurde ein Leerwert (Medium mit zu testender Substanz) parallel mitgeführt und in der späteren Auswertung von den gemessenen Werten abgezogen.

\subsubsection{Apoptose-Messungen}

Um den Einfluss der Inhibitoren auf die Apoptose in den Zellreihen zu untersuchen, wurde ein Cell Death Detection ELISA ${ }^{T M}$ durchgeführt. Diese Methode beruht auf der Detektion von Histon-assoziierten DNA-Fragmenten, die bei der Apoptose entstehen.

In einer 96-Well-Platte wurden $1 \times 10^{4} /$ Well Zellen in Medium ausgesät. Nach der Adhäsion der Zellen über Nacht wurde das alte Medium abgesaugt und die Zellen mit den mit den Inhibitoren und den als Kontrollen mit Lösungsmitteln versetzten Medien über $16 \mathrm{~h}$ behandelt. Nun wurden die Platten mit den Zellen für $10 \mathrm{~min}$ bei 
$200 \times \mathrm{g}$ zentrifugiert und der Überstand verworfen. Das entstandene Zellpellet wurde mit $200 \mu$ l Lysispuffer für 30 min bei Raumtemperatur inkubiert, um die Zellen zu lysieren. Nach einer weiteren zehnminütigen Zentrifugation bei $200 \times \mathrm{g}$ wurden $20 \mu \mathrm{l}$ des Überstandes auf die im Kit enthaltenen und bereits mit Streptavidin beschichteten 96-Well-Platten gegeben. In jedes Well wurden $80 \mu \mathrm{l}$ des frisch angesetzten Immunreagenz pipettiert und diese, mit einer Klebefolie luftdicht verschlossen, für $2 \mathrm{~h}$ bei Raumtemperatur auf dem Platten-Schüttler inkubiert. Nach drei Waschschritten mit im Kit enthaltenem Waschpuffer wurde das Reaktionssubstrat hinzupipettiert und für $15 \mathrm{~min}$ bei Raumtemperatur inkubiert. Anschließend wurde mit dem Platten-Lesegerät die Absorption bei einer Wellenlänge von $405 \mathrm{~nm}$ gemessen.

\subsubsection{Zellzyklus-Analysen}

Die Durchflusszytometrie wurde genutzt, um die Verteilung einer Zellpopulation auf die verschiedenen Zellzyklus-Phasen zu untersuchen. Anhand des DNA-Gehalts einer Zelle kann auf die Phase im Zellzyklus, in der sich die Zelle gerade befindet, rückgeschlossen werden. Misst man eine asynchron proliferierende Zellpopulation, ergibt sich ein typisches Verteilungsmuster für die Anteile der entsprechenden Zellpopulationen an den einzelnen Phasen des Zellzyklus. Dazu wurde mit Propidiumiodid die DNA der Zellen markiert. Propidiumiodid interkaliert in die DNA und kann im Durchflusszytometer gemessen werden.

Für die Durchflusszytometrie wurden jeweils $1 \times 10^{6}$ Zellen geerntet, wobei auch das die Zellen umgebende Medium mit gesammelt wurde, um tote Zellen ebenfalls zu erfassen. Nach 2 Waschschritten mit PBS wurden die Zellen in $500 \mu \mathrm{l}$ PBS resuspendiert und mit $3 \mathrm{ml}$ kaltem Ethanol vermengt. Danach wurden die Zellen durch Zentrifugieren $\left(400 \times \mathrm{g}, 4^{\circ} \mathrm{C}, 5 \mathrm{~min}\right)$ sedimentiert. Unverzüglich nach dem Zentrifugieren wurde der Überstand abgegossen, das Zellpellet in $425 \mu \mathrm{l}$ PBS resuspendiert und mit $50 \mu \mathrm{l}$ Rnase $\mathrm{A}(1 \mathrm{mg} / \mathrm{ml})$ und $25 \mu \mathrm{l}$ Propidiumiodid versetzt. Nach einer Inkubationszeit von 30 min bei Raumtemperatur im Dunkeln wurden die Zellen durch ein Sieb vereinzelt. Anschließend wurde die Probe im Durchflusszytometer analysiert. Die Auswertung der Messergebnisse wurde mit der BD FACSDiva ${ }^{T M}$ durchgeführt. 


\subsubsection{Statistik}

Die Ergebnisse werden als Mittelwerte und Standardabweichungen dargestellt, soweit nicht anders gekennzeichnet. Der statistische Vergleich zwischen den Gruppen wurde mit dem Student's-paired-t-test ermittelt. Ein p-Wert kleiner als 0,05 wurde als statistisch signifikant angesehen. 


\section{Ergebnisse}

\subsection{AKT und ERK sind in humanen Melanom-Zelllinien in vitro unterschiedlich stark exprimiert und aktiviert}

In Melanomzellen sind mehrere Signaltransduktionswege identifiziert worden, denen bedeutende Rollen in der Tumorigenese und der Tumorprogression zugesprochen werden. So sind der MAPK/ERK-Weg und der PI3K/AKT-Signalweg in vielen Melanom-Zelllinien konstitutiv durch verschiedene Mechanismen aktiviert; sie stellen Schlüsselwege bei Melanomentstehung und -progression dar.

Da in dieser Arbeit der Einfluss von zwei PI3K-Inhibitoren verglichen und die Kombinationen dieser mit zwei MEK1/2-Inhibitoren auf Proliferation, Apoptose und Tumorwachstum untersucht werden sollten, wurden zunächst geeignete Zelllinien für weitere funktionelle Analysen in vitro und spätere in-vivoExperimente mit athymischen Nacktmäusen ausgewählt. Dafür galt es zunächst, ein Profil für den PI3K/AKT-Weg und MAPK/ERK-Signaltransduktionsweg für 6 unterschiedliche Melanom-Zelllinien zu erstellen. Um zu untersuchen, ob das konstitutive Aktivierungsniveau in Zusammenhang mit der Suszeptibilität hinsichtlich der verschiedenen Inhibitoren steht, war es wichtig, zu bestimmen, in welcher der Zelllinien der PI3K/AKT-Weg und/oder der MAPK/ERK-Weg aktiviert sind. Dies kann durch Nachweis der jeweils phosphorylierten Proteine im WesternBlot erfolgen. Da es auch interessierte, welche weiteren Signalwege in den Zelllinien konstitutiv aktiviert waren, wurden auch JNK und JAK/STAT3, die ebenfalls durch Phosphorylierung aktiviert werden, untersucht. Um konstitutiv aktivierte Signaltransduktionswege zu identifizieren, wurden Ganzzell-Lysate der in subkonfluentem Zustand lysierten Zellen im Western-Blot untersucht. Antikörper, die spezifisch an die aktivierten Formen der Kinasen ERK ( $p$-ERK), AKT ( $p-A K T)$, JNK ( $p$-JNK) und des Transkriptionsfaktors STAT3 (p-STAT3) binden, wurden dabei zur Detektion eingesetzt. Als Ladekontrolle diente Aktin. Es zeigte sich, dass sich die 6 untersuchten humanen Melanom-Zelllinien sowohl in der Gesamtmenge der Kinasen als auch besonders deutlich hinsichtlich der konstitutiv aktivierten Signaltransduktionswege unterscheiden. Die Kinase AKT liegt vor allem in den 
Zelllinien Mel2a, MV3, Sk-Mel-23 und LOX in der phosphorylierten, aktiven Form vor; $\mathrm{A} 375$ und $\mathrm{MMNH}$ hingegen enthalten nur wenig aktiviertes Akt. Bei der Untersuchung auf p-ERK konnte in MV3, Sk-Mel-23 und LOX ein erhöhter Gehalt nachgewiesen werden, die Zelllinien A375, Mel2a und MMNH zeigten ein geringes Vorhandensein von phosphoryliertem ERK. JNK konnte lediglich in der Zelllinie $\mathrm{MMNH}$ in einem stärkeren Maße als in den anderen 5 Zelllinien in seiner phosphorylierten Form detektiert werden. Phosphoryliertes STAT3 konnte in keiner der untersuchten Zelllinien nachgewiesen werden (Abb.4). 


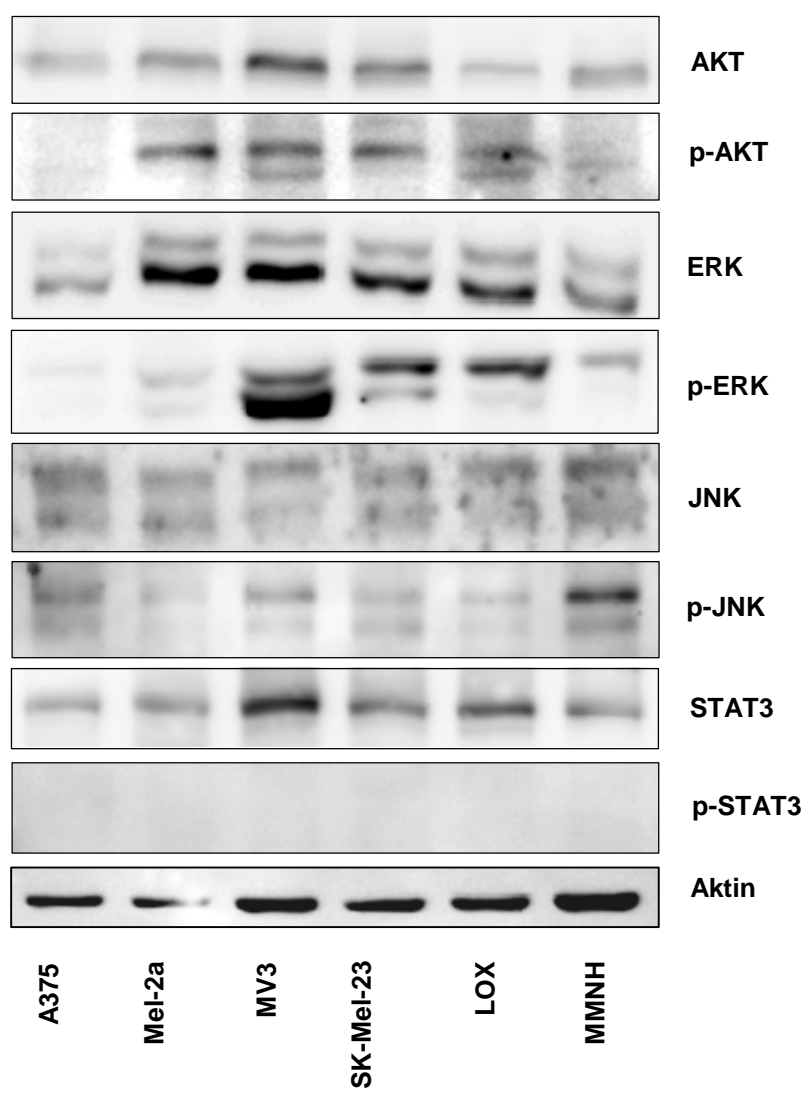

Abb. 4: Konstitutiv aktivierte Signalwege unterscheiden sich in Melanomzellen Aus 6 humanen MelanomZelllinien A375, Mel2a, MV3, Sk-Mel-23, LOX und MMNH wurden Ganzzell-Lysate gewonnen und im WesternBlot die phosphorylierten und unphosphorylierten Formen der Kinasen AKT, ERK und JNK und des Transkriptionsfaktors STAT3 nachgewiesen. Als Ladekontrolle diente Aktin. Es zeigte sich, dass sich die Zelllinien hinsichtlich der aktivierten Signalwege unterscheiden. Die oben dargestellten Western-BlotAbbildungen stehen repräsentativ für in mindestens 2 weiteren Wiederholungen erzielte Ergebnisse. 
Da zunächst unklar war, ob der letztere Befund der tatsächlich fehlenden Expression von p-STAT3 entspricht, oder ob aufgrund eines technischen Problems der Nachweis nicht gelang, wurden die Zellen nun spezifisch stimuliert, um eine induzierte Aktivierung des JAK/STAT3-Signalweges zu erreichen. Durch Behandlung der Zellen mit IL-6 (100 ng/ml; 30 min) konnte in den Zelllinien A375, Mel2a, MV3 und Sk-Mel-23 eine Aktivierung von STAT3 nachgewiesen werden, MMNH und LOX zeigten bei dieser Behandlung keine vermehrte Phosphorylierung von STAT3 (Abb.5). Diese Positiv-Kontrolle bestätigte somit, dass in keiner der untersuchten Melanom-Zelllinien STAT3 konstitutiv aktiviert vorliegt.
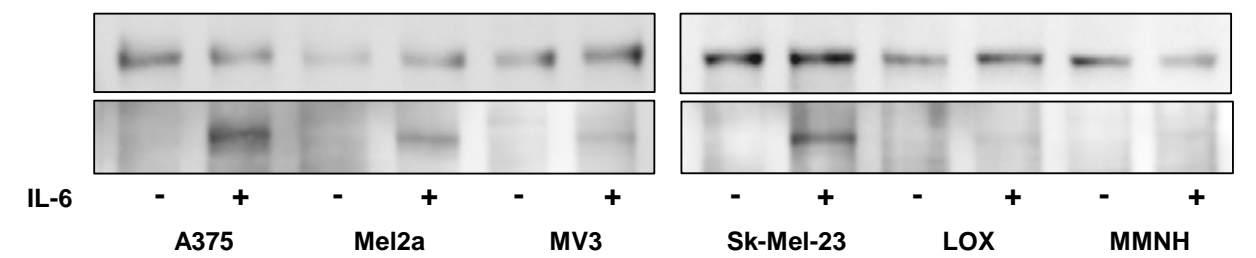

Aktin p-STAT3

Abb. 5: STAT3 ist nicht konstitutiv aktiviert Die 6 humanen Melanom-Zelllinien A375, Mel2a, MV3, Sk-Mel-23, LOX und MMNH wurden einmal mit normalem Medium oder IL-6 $(100 \mathrm{ng} / \mathrm{ml})$ für 30 min inkubiert. Anschließend wurden die Zellen lysiert und nach elektrophoretischer Auftrennung p-STAT3 im Western-Blot nachgewiesen. Aufgetragen wurde jeweils Medium-behandelte Zellen neben IL-6-stimulierter Probe, um einen direkten Vergleich zu ermöglichen. In diesem Versuch zeigte sich, dass sich alle Zelllinien durch IL-6 stimulieren ließen und STAT3 aktiviert wurde. 
Um eine Aktivierung des JNK-Weges zu bewirken, wurden die Melanomzellen darüber hinaus mit UV-C-Licht $\left(7,5 \times 10^{3} \mathrm{~J} / \mathrm{cm}^{2}\right)$ bestrahlt und nach anschließender 30-min-Inkubation in Medium lysiert. Es konnte eine vermehrte Aktivierung von JNK in den Zelllinien A375, MV3, Sk-Mel-23, LOX und MMNH erreicht und im Western-Blot nachgewiesen werden (Abb.6).

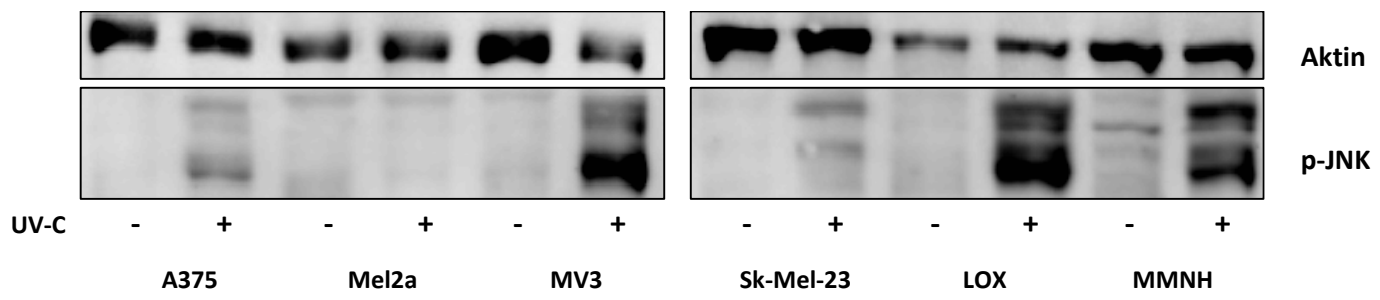

Abb. 6: JNK lässt sich durch UV-C-Bestrahlung aktivieren Die 6 humanen Melanom-Zelllinien A375, Mel2a, MV3, Sk-Mel-23, LOX und MMNH wurden einmal mit 7,5 $\times 10^{3} \mathrm{~J} / \mathrm{cm}^{2}$ UV-C bestrahlt. Nach anschließender 30 min-Inkubation in Nährmedium wurden die Zellen lysiert und nach elektrophoretischer Auftrennung p-JNK im Western-Blot nachgewiesen. Aufgetragen wurden jeweils unbehandelte Zellen neben bestrahlten derselben Zelllinie. Deutlich erkennt man eine Aktivierung von JNK nach UV-C-Bestrahlung in den Zelllinien A375, MV3, Sk-Mel-23, LOX und MMNH.

Um den Nachweis der Aktivierung des AKT- und des ERK-Signalweges in den Zellen aus den Western-Blots zu bestätigen, wurden die Ergebnisse mit einer weiteren unabhängigen Methode überprüft. Dazu wurden die aktivierten Kinasen p-ERK und $\mathrm{p}$-AKT in den fixierten Zellen mit Fluoreszenz-markierten Antikörpern gefärbt und bei einer FACS-Messung die mittlere Fluoreszenzintensität (MFI) ermittelt.(Abb. 7) Dabei bestätigte sich, wie auch zuvor in den Western-Blots gesehen, dass die Zelllinien Mel2a, MV3, Sk-Mel-23 und LOX im Vergleich zu A375 und MMNH eine vermehrte konstitutive Aktivierung von AKT aufwiesen. Die gemessene mittlere Fluoreszenzintensität betrug bei $\mathrm{A} 375$ und MMNH 494 und 519; bei den anderen vier Zelllinien war die gemessene MFI etwa dreimal so hoch (MFI: Mel2a 1763; MV3 1580; SkMel-23 1716; LOX 1699). Auch bei der Messung der p-ERK-Niveaus in den Zellen bestätigten sich die Ergebnisse aus den Western-Blots.(Abb. 8) In den Zellen der Linie MV3, Sk-Mel-23 und LOX ließ sich viel aktiviertes ERK nachweisen (MFI von MV3 13591; Sk-Mel-23 16913; LOX 21883), während sich in den Zelllinien 
A375, Mel2a und MMNH eine geringere Aktivierung des ERK-Weges zeigte (MFI von A375 6680; Mel2a 7444; MMNH 2855).

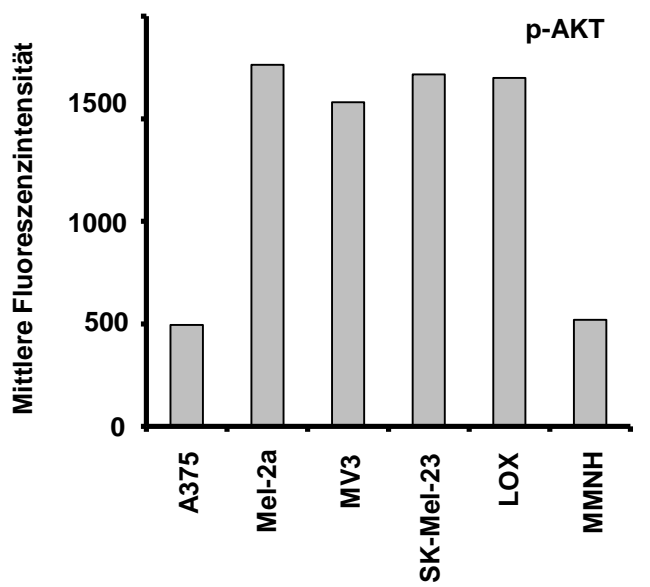

Abb. 7: FACS-Messungen bestätigen die Ergebnisse des Western-Blots für p-AKT Eine FACS-Messung wurde mit 6 verschiedenen Melanom-Zelllinien durchgeführt. Die Zellen wurden permeabilisiert, fixiert, mit Fluoreszenz-markierten Antikörpern gegen p-AKT gefärbt und im Durchflusszytometer die mittlere Fluoreszenzintensität gemessen. Die Analysen zeigten, dass die Zelllinien Mel2a, MV3, Sk-Mel-23 und LOX im Vergleich zu A375 und MMNH eine vermehrte konstitutive Aktivierung von AKT aufwiesen. Somit wurden die in den Western-Blots ermittelten Verhältnisse bestätigt. 


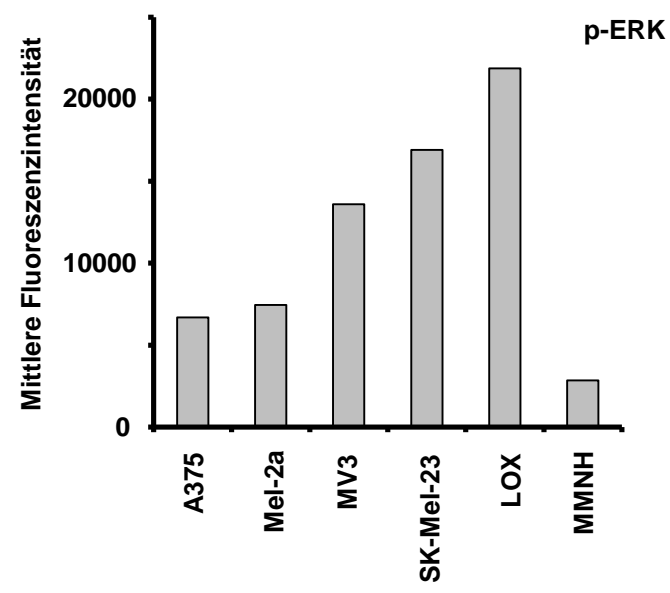

Abb. 8: FACS-Messungen bestätigen die Ergebnisse des Western-Blots für p-ERK Eine FACS-Messung wurde mit 6 verschiedenen Melanom-Zelllinien durchgeführt. Die Zellen wurden permeabilisiert, fixiert, mit Fluoreszenz-markierten Antikörpern gegen p-ERK gefärbt und im Durchflusszytometer die mittlere Fluoreszenzintensität gemessen. In den Zellen der Linie MV3, Sk-Mel-23 und LOX ließ sich viel aktiviertes ERK nachweisen, während sich in den Zelllinien A375, Mel2a und MMNH eine geringere Aktivierung des ERKWeges zeigte. Somit bestätigte dies die Ergebnisse aus den Western-Blots.

Die hier gewonnenen Erkenntnisse hinsichtlich der Signaltransduktions-Profile bildeten die Grundlage für die Wahl der Zelllinien A375 und LOX für weitere funktionelle Analysen im Rahmen dieser Arbeit. Sie stehen exemplarisch für Melanomzellen mit geringer, beziehungsweise starker konstitutiver AKT- und ERK Aktivierung. 


\subsection{Humane Melanomzellen zeigen unterschiedliche Tumorigenität im in-vivo-Mausmodell}

Nach der Charakterisierung auf proteinbiochemischer Ebene in vitro wurde nun die Tumorigenität der unterschiedlichen Melanom-Zelllinien in vivo untersucht. Ziel war es, herauszufinden, inwieweit sich die Zelllinien in der Größe der gebildeten Tumoren in vivo unterscheiden. Dazu wurden Tumoren in athymischen Nacktmäusen durch intradermale Injektion der unterschiedlichen humanen Melanomzellen induziert und das Größenwachstum der entstehenden Tumoren mit der Schieblehre gemessen und verfolgt. Abbildung 9a zeigt das näherungsweise berechnete Volumen der Tumoren im Versuchsverlauf. Es zeigte sich, dass sich die Tumoren der unterschiedlichen Zelllinien untereinander in ihrer Wachstumsgeschwindigkeit deutlich unterscheiden. Die beiden Zelllinien, die die größten Tumoren bildeten, waren LOX mit einem mittleren Tumorvolumen bei Versuchsende an Tag 20 von $2077 \mathrm{~mm}^{3}\left(\mathrm{SD} \pm 632 \mathrm{~mm}^{3}\right)$ und A375 mit $992 \mathrm{~mm}^{3}\left(\mathrm{SD} \pm 326 \mathrm{~mm}^{3}\right)$. Die Zellinie MMNH bildete mittelgroße Tumoren mit mittleren Volumina von $655 \mathrm{~mm}^{3}$ (SD $\pm 482 \mathrm{~mm}^{3}$ ). Mel2a, MV3 und Sk-Mel-23 waren mit mittleren Tumorvolumina von $65 \mathrm{~mm}^{3}\left(\mathrm{SD} \pm 30 \mathrm{~mm}^{3}\right)$ bis $217 \mathrm{~mm}^{3}\left(\mathrm{SD} \pm 138 \mathrm{~mm}^{3}\right.$ ) bei Versuchsende die Zelllinien, die vergleichsweise kleine Tumore bildeten. Der Vergleich der Massen nach Freipräparation und Wiegen der Tumoren bei Versuchsende stützt die mit der Schieblehre ermittelten Größenunterschiede der Tumoren der einzelnen Zelllinien (Abb. 9c). Die mittleren Tumormassen betrugen bei A375 0,89 g (SD $\pm 0,07 \mathrm{~g}$ ), bei Mel2a 0,06g (SD $\pm 0,01 \mathrm{~g}$ ), bei MV3 0,16 g (SD $\pm 0,1 \mathrm{~g}$ ), bei Sk-Mel-23 0,11 g (SD $\pm 0,07 \mathrm{~g})$, bei LOX 1,4 g (SD \pm $0,5 \mathrm{~g})$ und bei $\mathrm{MMNH} 0,5 \mathrm{~g}(\mathrm{SD} \pm 0,15 \mathrm{~g})$.

Mit Hilfe des 3D-Ultraschalls ließ sich bereits in frühen Phasen des Versuchs beobachten, dass die Zelllinien A375 und LOX größere Tumoren als die anderen Zelllinien bildeten. Nach 6 Versuchstagen betrugen die ermittelten mittleren Tumorvolumina bei LOX $29 \mathrm{~mm}^{3}\left(\mathrm{SD} \pm 18 \mathrm{~mm}^{3}\right)$ und bei A375 $19 \mathrm{~mm}^{3}\left(\mathrm{SD} \pm 6 \mathrm{~mm}^{3}\right.$ ) im Vergleich zu $13 \mathrm{~mm}^{3}$ (SD $\pm 6 \mathrm{~mm}^{3}$ ) bei Mel2a, $13 \mathrm{~mm}^{3}\left(\mathrm{SD} \pm 5 \mathrm{~mm}^{3}\right.$ ) bei MV3, $12 \mathrm{~mm}^{3}\left(\mathrm{SD} \pm 11 \mathrm{~mm}^{3}\right)$ bei Sk-Mel-23 und $11 \mathrm{~mm}^{3}\left(\mathrm{SD} \pm 5 \mathrm{~mm}^{3}\right)$ bei MMNH 
(Abb. 9b). Aufgrund der geringen Eindringtiefe des verwendeten hochfrequenten Ultraschallkopfs von maximal $5 \mathrm{~mm}$ konnten nach Tag 6 die Tumoren nicht mehr komplett erfasst werden. Daher wurde für die weiteren Tierexperimente im Verlauf dieser Arbeit das Tumorwachstum basierend auf den SchieblehreMessungen berechnet. 
a

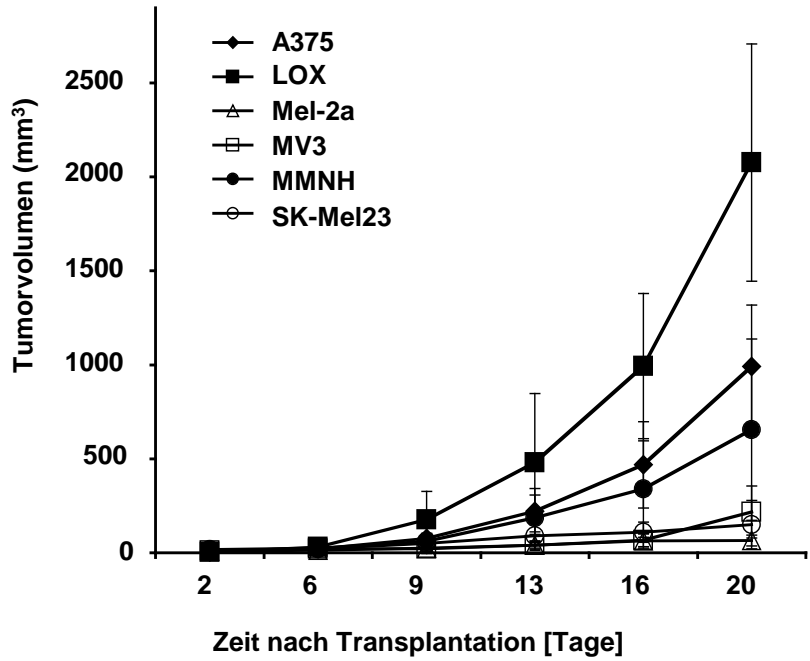

b

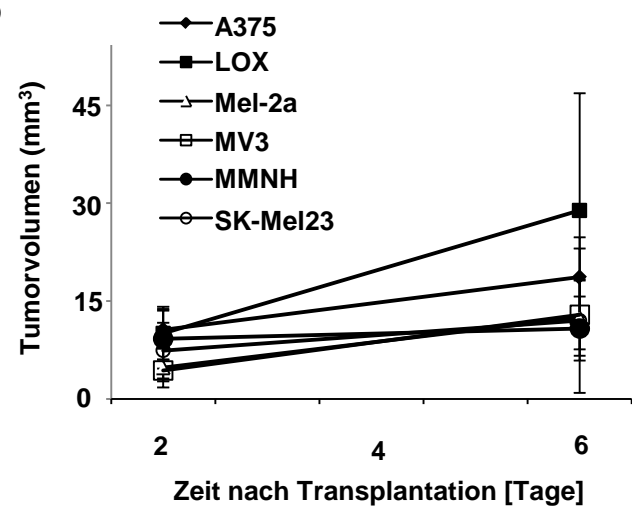

C

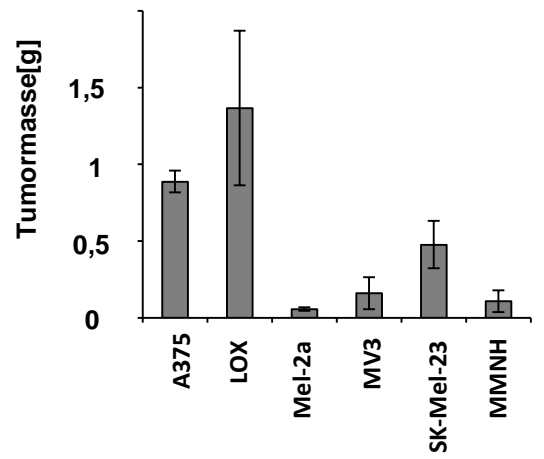

Abb. 9: Humane Melanomzellen zeigen unterschiedliche Tumorigenität im Mausmodell in vivo Athymischen Nacktmäusen wurden $2 \times 10^{6}$ Zellen der Zelllinien A375, Mel2a, MV3, Sk-Mel-23, LOX und MMNH intradermal injiziert und das Tumorwachstum verfolgt. Am 20. Tag nach Transplantation (n. T.) wurde der Versuch beendet. Die ausgewertete Tumorzahl beträgt $n=4$ für die Zelllinien LOX und A375 und $n=6$ für die anderen Zelllinien. Grafik a stellt die über die Formel „Höhe x Breite x Länge“ näherungsweise berechneten Volumina der Tumoren jeder Zelllinie im Versuchsverlauf in $\mathrm{mm}^{3}$ dar. Die Werte stammen aus der Vermessung der Tumoren mit der Schieblehre. Die eingetragenen Fehlerbalken zeigen die Standardabweichung. b An Tag 2 n.T. und 6 n.T. wurden die Tumoren mit hochauflösendem 3D-Ultraschall vermessen. In der Grafik ist das rekonstruierte Tumorvolumen in $\mathrm{mm}^{3}$ im Verlauf von Tag 2 n.T. zu Tag 6 n.T. für die 6 Zelllinien eingezeichnet. Die eingetragenen Fehlerbalken zeigen die Standardabweichung. c Bei Versuchsende an Tag 20 n.T. wurden die Tiere getötet und die Tumoren herauspräpariert. Die Grafik zeigt die mittleren Tumormassen in $g$ mit Standardabweichung für alle 6 Zelllinien. 


\subsection{Humane Melanomzellen exprimieren p-AKT und p-ERK in vivo im Mausmodell sowie in "natürlichen“ Melanommetastasen}

Um zu überprüfen, ob die Signalwege MAPK/ERK und PI3K/AKT auch in vivo aktiviert sind, wurden an Paraffinschnitten von LOX-Tumoren und A375-Tumoren aus Nacktmäusen sowie einer Haut-Metastase eines Melanompatienten (zur Verfügung gestellt von Dr. H.-P. Bertsch, Universitäts-Hautklinik Göttingen, Ethikantrag 14/3/12) immunhistochemische Färbungen mit Antikörpern gegen p-AKT und p-ERK durchgeführt. Die Ergebnisse sind in Abbildung 10 und 11 dargestellt.

Die Tumoren beider Zelllinien wiesen eine starke zytoplasmatische Reaktivität für p-AKT-Antikörper auf. Deutlich ließ sich auch erkennen, dass das umgebende, nicht-tumoröse Mausgewebe diese Färbung nicht aufweist (Abb. 10). Das gleiche Färbemuster ließ sich auch in den Färbungen der humanen Melanommetastase beobachten. ERK hingegen war zwar in beiden Maustumoren aktiviert, in der humanen Melanommetastase jedoch nicht (Abb. 11). Zusammenfassend belegen diese Experimente, dass sowohl der MAPK/ERK- als auch der PI3K/AKT-Signalweg in den Melanom-Tumoren eine wichtige Rolle spielen. Damit wurde die Grundlage geschaffen, in den nun folgenden Experimenten die Wirkungen kleinmolekularer Inhibitoren des AKT- oder ERK-Signalweges auf humane Melanomzellen sowohl in vitro als auch in vivo zu untersuchen. 


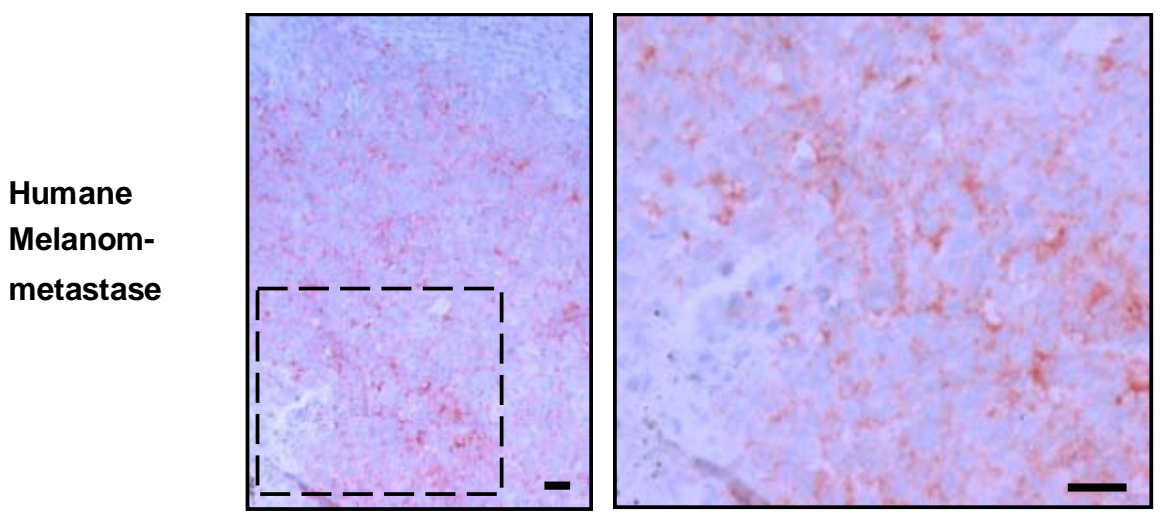

A375-Tumor
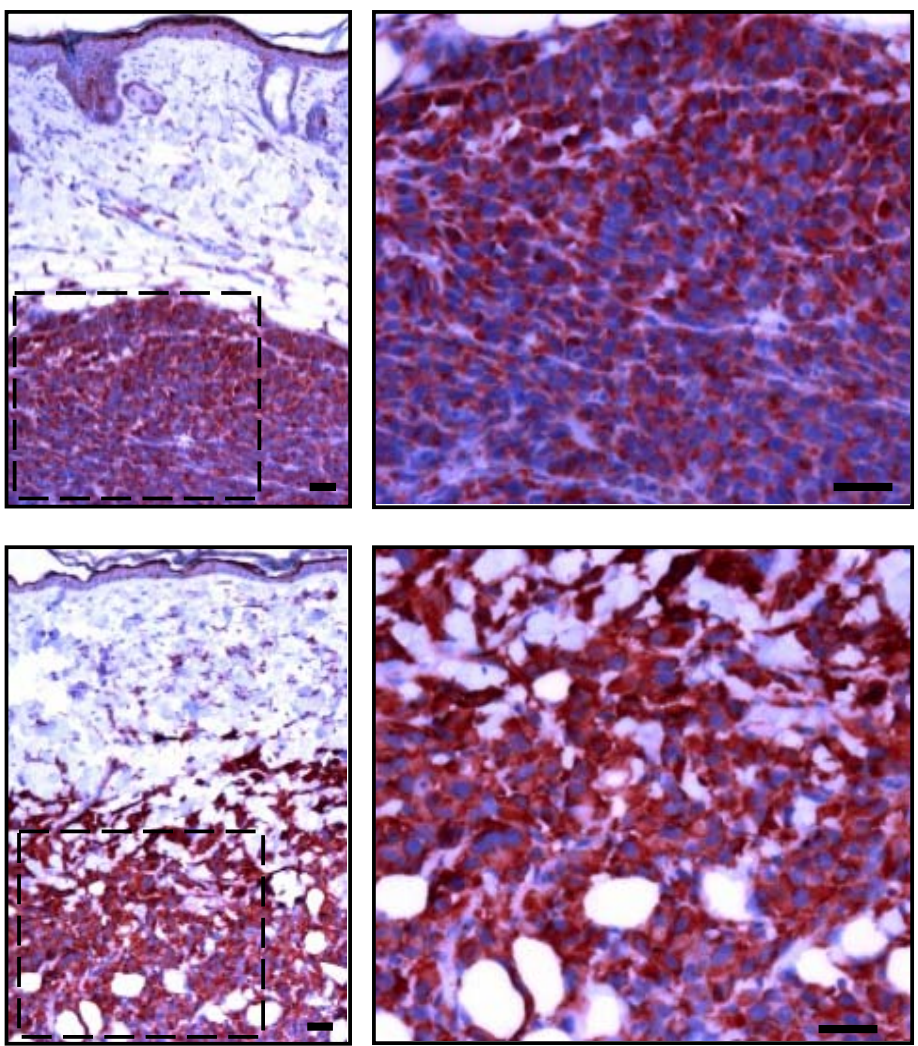

Abb. 10: AKT ist konstitutiv in vivo aktiviert. Paraffinschnitte einer humanen Melanommetastase und aus unbehandelten Nacktmäusen entnommenen Tumoren wurden mit einem Antikörper gegen p-AKT gefärbt. Es zeigte sich, dass der PI3K/AKT-Weg in den Tumoren in vivo stärker aktiviert war, als in dem umgebenden Mausgewebe. Die Abbildungen zeigen repräsentative Ergebnisse für Färbungen an jeweils 2 verschiedenen Tumoren und Metastasen. Die eingezeichneten Größenstandards entsprechen $10 \mu \mathrm{m}$. 


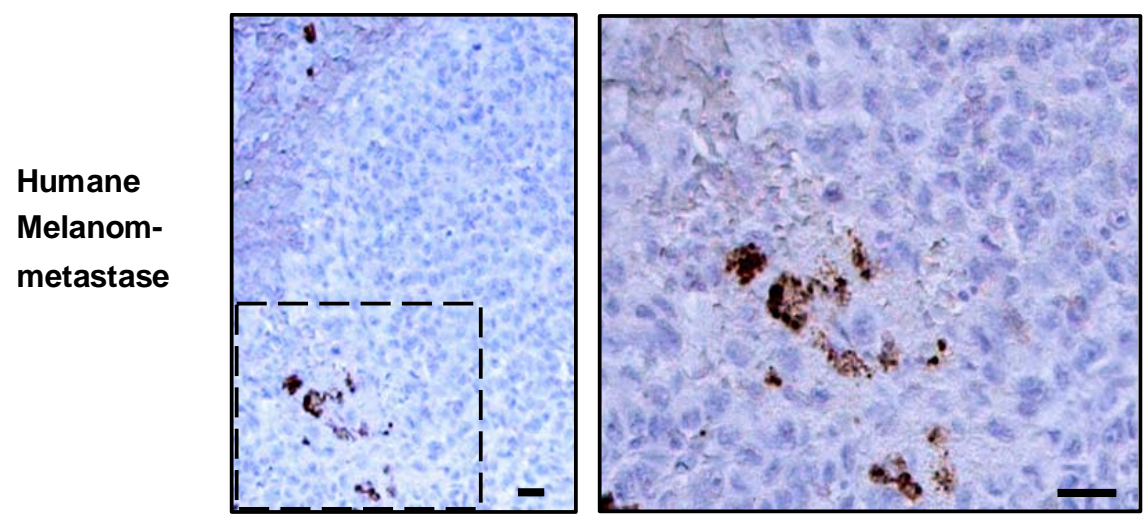

A375-Tumor
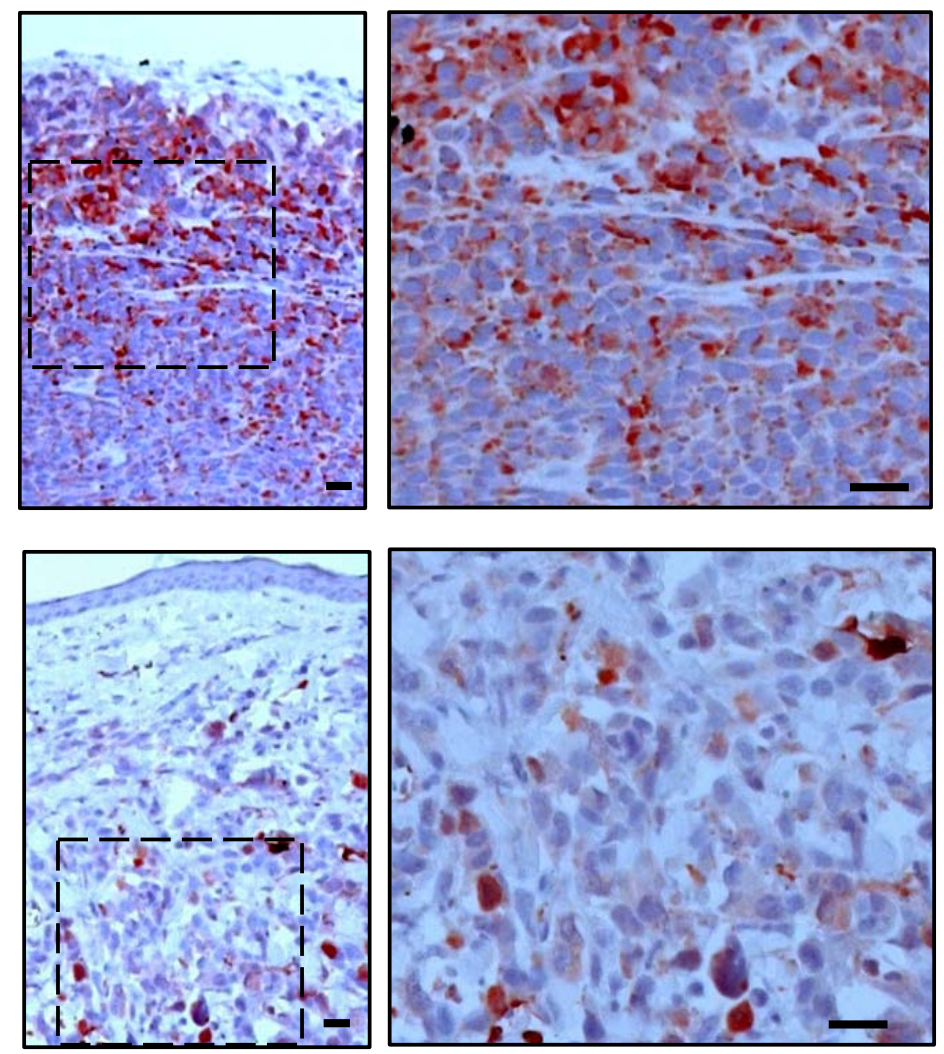

Abb. 11: ERK ist konstitutiv in vivo aktiviert Paraffinschnitte einer humanen Melanommetastase und aus unbehandelten Nacktmäusen entnommenen Tumoren wurden mit einem Antikörper gegen p-ERK gefärbt. Es zeigte sich eine zytoplasmatische Reaktivität in den Tumoren der Zelllinie A375 und LOX. In der humanen Melanommetastase wiederum wurde kein aktives ERK detektiert. Die Abbildungen zeigen repräsentative Ergebnisse für Färbungen an jeweils 2 verschiedenen Tumoren und Metastasen. Die eingezeichneten Größenstandards entsprechen $10 \mu \mathrm{m}$. 


\subsection{BAY-80-6946 inhibiert die Aktivierung von AKT in A375 und LOX}

Da es sich in dieser Arbeit um die ersten Untersuchungen von BAY-80-6946 an Melanomzellen handelt, musste zunächst überprüft werden, ob BAY-80-6946 auch in Melanomzellen sein Zielprotein PI3K inhibiert. Als Parameter der PI3K-Aktivität wurden die p-AKT-Expressionen mittels Western-Blot bestimmt. In bislang unveröffentlichten Arbeiten dieser Arbeitsgruppe wurde der neue PI3K-Inhibitor BAY-80-6946 an Myelomzellen ausgetestet. An diesen Experimenten orientierten sich die in der vorliegenden Arbeit eingesetzten in-vitro-Behandlungskonzentrationen von 100nM BAY-80-6946. Verglichen wurde mit dem bereits in der Literatur beschriebenen PI3K-Inhibitor Wortmannin in einer Konzentration von $10 \mu \mathrm{M}$. Zellen der Melanom-Zelllinien A375 und LOX wurden $1 \mathrm{~h}$ und $16 \mathrm{~h}$ mit 100 nM BAY-80-6946 und $10 \mu \mathrm{M}$ Wortmannin inkubiert. Anschließend wurden die Zellen lysiert, die Proteine elektrophoretisch aufgetrennt und im Western-Blot die aktivierte Kinase AKT nachgewiesen. Verglichen wurde mit Kontrollinkubationen mit Medium, DMSO und Vehikel in Medium. Bei Behandlungen über $1 \mathrm{~h}$ und $16 \mathrm{~h}$ konnte gezeigt werden, dass in den beiden Zelllinien A375 und LOX die Aktivierung von AKT durch BAY-80-6946 verhindert wird. (Abb. 12) Densitometrische Auswertungen ergaben eine Reduktion des p-AKT-Signals bei Behandlungen mit BAY-80-6946 über $1 \mathrm{~h}$ von $35-80 \%$ bei $\mathrm{A} 375$ und $80-90 \%$ bei LOX, verglichen mit den unbehandelten Zellen. Ebenso zeigte sich nach $16 \mathrm{~h}$ eine Reduktion um 40$100 \%$ bei $A 375$ und $70-100 \%$ bei LOX gegenüber den unbehandelten Zellen. 


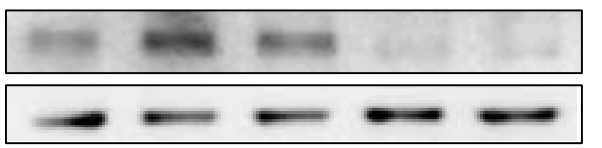

p-AKT

Aktin

A375

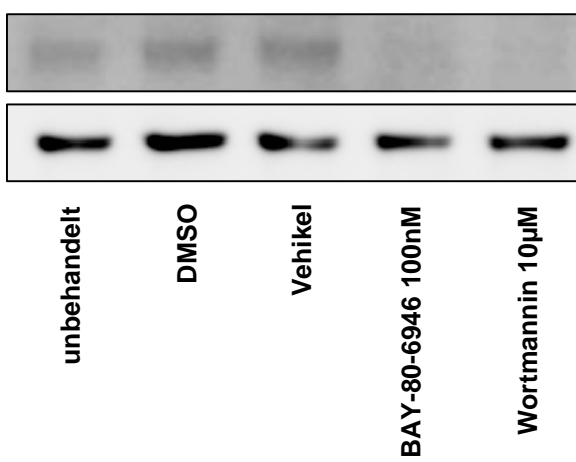

p-AKT

LOX

Aktin

Abb. 12: BAY-80-6946 inhibiert die PI3K in Melanomzellen A375 und LOX wurden $16 \mathrm{~h}$ mit Medium (Spur 1), den Lösungsmitteln DMSO und Vehikel (Spur 2 und 3) in Medium, BAY-80-6946 (100 nM in Medium; Spur 4) und Wortmannin $(10 \mu \mathrm{M}$ in Medium; Spur 5) kultiviert. Anschließend wurden die Zellen lysiert und nach elektrophoretischer Auftrennung p-AKT im Western-Blot nachgewiesen. BAY-80-6946 bewirkte wie Wortmannin eine Inhibition der Aktivierung von AKT durch PI3Ks. Die densitometrische Auswertung dieses Experiments zeigte eine Reduktion des p-AKT-Signals bei Behandlung mit BAY-80-6946 um 40\% gegenüber den unbehandelten Zellen bei A375 und um $70 \%$ bei LOX. Der in der Abbildung gezeigte Western-Blot ist repräsentativ für in weiteren 2 Wiederholungen erzielte Ergebnisse. 


\subsection{Inhibition der Signalwege AKT und ERK beeinflusst wichtige Melanomzell-Funktionen}

Nachdem in den vorangehend beschriebenen Untersuchungen die Signalwege ERK und AKT als in vielen Melanom-Zelllinien konstitutiv aktivierte Wege identifiziert wurden, galt dieser Abschnitt nun der Untersuchung des Einfluss spezifischer Inhibitoren in vitro.

Der PI3K/AKT-Weg und MAPK/ERK-Weg beeinflussen Zellwachstum und Überleben der Tumorzellen. Daher wurde in funktionellen Experimenten mit den Zelllinien A375 und LOX der Einfluss von Inhibition dieser Wege durch verschiedene Inhibitoren auf Proliferation, Zellzyklus und Apoptose geprüft. Die Durchführung der sehr aufwändigen Experimente mit sämtlichen Melanom-Zelllinien hätte den Rahmen dieser Arbeit gesprengt. Deshalb wurden die Linien A375 und LOX ausgewählt, da sie erstens in vitro unproblematisch kultiviert werden konnten, zweitens in vivo zuverlässig Tumoren in Nacktmäusen bildeten und drittens exemplarisch für Melanomzellen mit geringer beziehungsweise starker konstitutiver AKT- und ERK-Aktivierung standen.

\subsubsection{Inhibition von PI3Kinase und MEK1/2 mindert die Proliferation von Melanomzellen}

Da sowohl der PI3K/AKT-Weg als auch der MAPK/ERK-Weg die Proliferation von Zellen beeinflussen, wurde nun der Einfluss der Inhibitoren auf die Zellproliferation der Zelllinien A375 und LOX in der Zellkultur untersucht. Die Zellen wurden für $48 \mathrm{~h}$ mit den jeweiligen Inhibitoren inkubiert und anschließend eine MTTProliferationsmessung durchgeführt. Die Ergebnisse stammen aus 2 unabhängig wiederholten Experimenten, jeweils mit Tripletansätzen. Es zeigten sich zwischen den Zelllinien A375 und LOX Unterschiede hinsichtlich der Proliferationshemmung durch die Inhibitoren. Abbildung 13 zeigt die Ergebnisse der Proliferationsuntersuchungen an der Zelllinie A375. Durch Behandlung mit BAY-80-6946 fand eine Reduktion der Proliferation um 23,1 \% im Vergleich zu den unbehandelten Zellen statt $(S D \pm 12,9 ; p<0,004$ bei dem Vergleich behandelte $z u$ 
unbehandelten Zellen). Eine Behandlung mit dem Vergleichs-PI3K-Inhibitor Wortmannin reduzierte die Zellproliferation lediglich um 11,6\% (SD $\pm 4,9 ; p<0,04)$. Die MEK1/2-Inhibitoren zeigten stärkere Wirkung auf die Proliferation von A375 als die PI3K-Inhibitoren. U0126 reduzierte die Proliferation um 68,7\% (SD $\pm 3,1$; $p<0,0001)$ und PD98059 um 61,2\% (SD $\pm 6,2 ; p<0,0001)$. Kombinationsbehandlungen von BAY-80-6946 und einem MEK1/2-Inhibitor wirkten synergistisch und zeigten einen deutlich größeren Effekt auf die Zellproliferation als die jeweiligen Monobehandlungen. So war die Kombination BAY-80-6946 + U0126 mit einer Reduktion der Proliferation um 82,7\% $(S D \pm 4,5)$ die Behandlung, die die Proliferation der A375-Zellen am stärksten reduzierte. Es ergaben sich signifikante Proliferationsminderungen gegenüber den jeweiligen Monobehandlungen (zu BAY-80-6946: $p<0,0001$; zu U0126: $p<0,0001)$. Die Kombination von BAY-80-6946 und PD98059 (28,8\%; SD $\pm 4,0)$ zeigte ebenfalls Synergie (Vergleich zu BAY-80-6946: $p<0,0001$; zu PD98059 $p<0,008)$. Kombinationsbehandlungen mit dem PI3K-Inhibitor Wortmannin und den MEK-Inhibitoren U0126 und PD98059 zeigten keinen synergistischen Effekt. Die Kombination Wortmannin + U0126 reduzierte die Zellproliferation von $A 375$ um 70,7\% $(S D \pm 6,0)$ und somit nicht signifikant stärker als U0126 alleine. Eine Behandlung mit Wortmannin + PD98059 reduzierte die Proliferation von A375 um 63,8\% (SD $\pm 5,2)$ und beeinflusste die Proliferation der Zellen damit nicht stärker als eine alleinige Behandlung mit PD98059. 


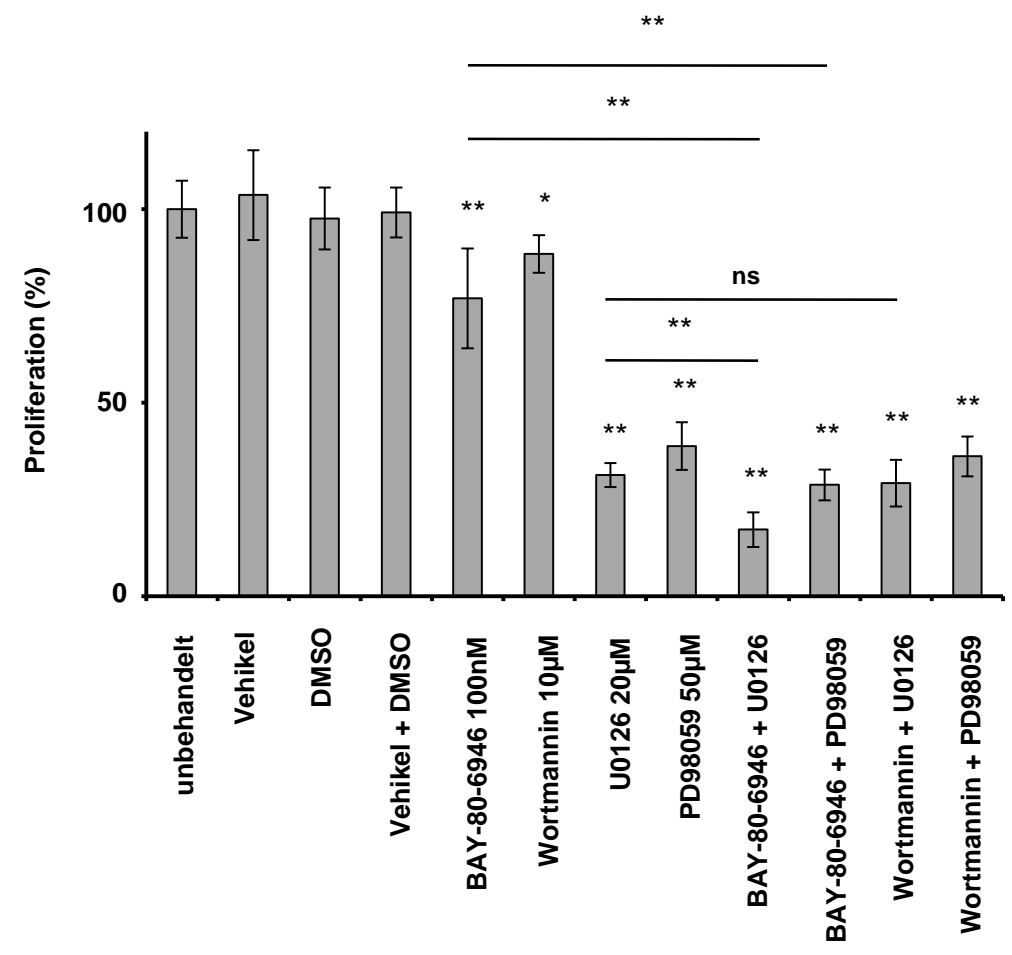

\footnotetext{
Abb. 13: PI3K-Inhibitoren und MEK1/2-Inhibitoren hemmen die Proliferation von A375 in unterschiedlichem Maß Zellen der Zelllinie A375 wurden $48 \mathrm{~h}$ mit Medium, Lösungsmittelkontrollen (Medium mit DMSO, Vehikel

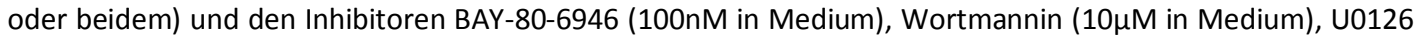
$(20 \mu \mathrm{M}$ in Medium) und PD98059 (50 $\mu \mathrm{M}$ in Medium) und deren Kombinationen inkubiert. Anschließen wurde ein MTT-Proliferationsassay durchgeführt. Die Ergebnisse stammen aus 2 unabhängig wiederholten Experimenten mit Tripletbehandlungen. In der Grafik ist die Proliferation in Prozent der unbehandelten Zellen dargestellt. Mit dem Student-t-Test wurde die Signifikanz gegenüber den unbehandelten Zellen überprüft. $\left(^{*}: p<0,05 ; * *: p<0,01\right)$. Fehlerbalken zeigen die Standardabweichung an. Es zeigte sich, dass die MEK1/2-Inhibitoren stärkeren Einfluss auf die Proliferation von A375 besitzen als die PI3K-Inhibitoren. BAY-80-6946 wirkte stärker antiproliferativ als der Vergleichsinhibitor Wortmannin. Kombinationsbehandlungen von BAY-80-6946 und einem MEK1/2-Inhibitor wirkten synergistisch und zeigten einen signifikant größeren Effekt auf die Zellproliferation als die jeweiligen Monobehandlungen.
} 
Die Zelllinie LOX (Abb. 14) zeigte in den Monobehandlungen mit den Inhibitoren ein etwas anderes Proliferationsverhalten als A375. Innerhalb der Inhibitorengruppen ergab sich ein uneinheitliches Bild. Bei den PI3K-Inhibitoren zeigte sich nach 48-h-Behandlung mit BAY-80-6946 eine signifikante Reduktion um $34,2 \%(S D \pm 5,7 ; p<0,0001)$ im Vergleich zu den unbehandelten Zellen. Die Monobehandlung mit Wortmannin ergab keinen signifikanten Effekt auf die Zellproliferation. Bei den MEK1/2-Inhibitoren zeigte U0126 eine signifikante Reduktion der Zellproliferation um 31,7\% (SD $\pm 1,9 ; p<0,0001$ ). Bei PD98059 ergab sich ein nur geringer Minderung der Proliferation um 7,2\% (SD $\pm 6,8 ; p<0,044)$ im Vergleich zur Proliferation der unbehandelten Zellen.

Auch bei den LOX-Zellen war eine stärkere Reduktion der Proliferation nach kombinierter Behandlung der Zellen durch PI3K- und MEK1/2-Inhibitoren zu beobachten. Die Kombinationsbehandlung von BAY-80-6946 und U0126 (Reduktion um 63,7\%, SD $\pm 2,2$, im Vergleich zur Proliferation der unbehandelten Zellen) zeigte synergistische Effekte der zwei Inhibitoren auf die Proliferation (zu BAY-80-6946 alleine $p<0,00001$; zu U0126 alleine $p<0,000001$ ). BAY-80-6946 in Kombination mit PD98059 reduzierte die Proliferation um 45,5\% (SD \pm 2,2; $\mathrm{p}<0,0001$, vgl. mit unbehandelt) und signifikant stärker als die Monobehandlungen mit den jeweiligen Inhibitoren (zu BAY-80-6946 alleine: $p<0,001$; zu PD98059 alleine: $p<0,00001)$. Wortmannin in Kombination mit den MEK1/2-Inhibitoren zeigte eine geringere Reduktion der Zellproliferation als die Kombinationen mit BAY-80-6946. Dennoch war auch bei den Wortmannin-Kombinationsbehandlungen zu beobachten, dass die Proliferation signifikant geringer war als bei den jeweiligen Monobehandlungen mit den Inhibitoren. Wortmannin + U0126 führten zu einer Reduktion um 39,3\% (SD $\pm 3,1 ; p<0,00001$ vgl. mit unbehandelten Zellen) und somit zu einer signifikant stärkeren Proliferationsminderung als die Monobehandlungen mit Wortmannin $(p<0,0001)$ oder U0126 $(p<0,0005)$. Die Kombination von Wortmannin und PD98059 senkte die Proliferation der LOXZellen um 24,9\% $(S D \pm 7,7 ; \quad p<0,00025)$ und signifikant stärker als die Monobehandlungen mit den jeweiligen Inhibitoren Wortmannin $(p<0,004)$ oder PD98059 ( $p<0,0017)$. 


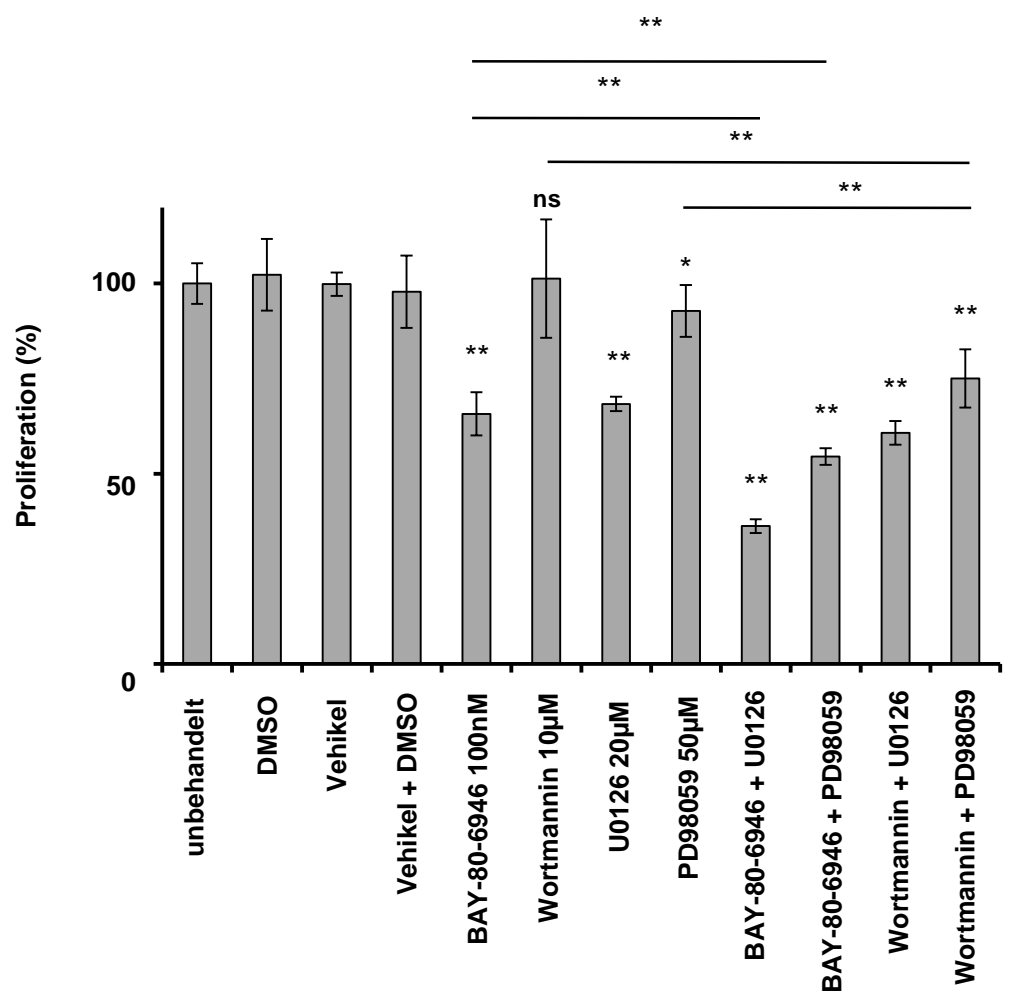

Abb. 14: PI3K-Inhibitoren und MEK1/2-Inhibitoren hemmen die Proliferation von LOX in unterschiedlichem Maß Zellen der Zelllinie LOX wurden $48 \mathrm{~h}$ mit Medium, Lösungsmittelkontrollen (Medium mit DMSO, Vehikel

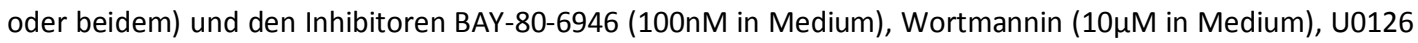
$(20 \mu \mathrm{M}$ in Medium) und PD98059 $(50 \mu \mathrm{M}$ in Medium) und deren Kombinationen inkubiert. Anschließend wurden MTT-Proliferationsmessung durchgeführt. Die Ergebnisse stammen aus 2 unabhängig wiederholten Experimenten, jeweils mit Tripletbehandlungen. In der Grafik ist die Proliferation in Prozent der unbehandelten Zellen dargestellt. Mit dem Student-t-Test wurde die Signifikanz der Behandlungen überprüft. $\left({ }^{*}: p<0,05 ;{ }^{* *}: p<0,01\right)$. Fehlerbalken zeigen die Standardabweichung an. Innerhalb der Inhibitorengruppen ergab sich ein uneinheitliches Bild. Behandlungen mit BAY-80-6946 und U0126 wirkten antiproliferativ, während Wortmannin und PD98059 keinen Effekt auf LOX-Zellen in Monobehandlung zeigten. Kombinationsbehandlungen von PI3K-Inhibitoren und MEK1/2-Inhibitor wirkten synergistisch und zeigten einen signifikant größeren Effekt auf die Zellproliferation als die jeweiligen Monobehandlungen. 


\subsubsection{Inhibition von PI3Kinase und MEK1/2 induziert Apoptose in Melanomzellen}

Sowohl der PI3K/AKT-Weg als auch der MAPK/ERK Weg sind wichtige Signalwege in der Zelle, die die Apoptosevorgänge mitsteuern. Um die Wirkung der selektiven und kombinierten Inhibitionen durch die verwendeten PI3K-Inhibitoren und die MEK1/2-Inhibitoren auf die Apoptose in den verwendeten Zelllinien zu untersuchen, wurden die Zelllinien LOX und A375 $16 \mathrm{~h}$ behandelt und anschließend ein ELISA durchgeführt. Mit diesem ELISA werden Histon-gebundene DNA-Fragmente zum Nachweis der Spät-Apoptose detektiert. Der photometrisch gemessene Wert der Substratreaktion der unbehandelten Zellen wurde als Referenzwert (=1) gesetzt. Anschließend wurden die photometrischen Messergebnisse der behandelten Zellen zu denen der unbehandelten in Relation gesetzt.

In Abbildung 15 sind die Ergebnisse der Apoptoseuntersuchungen der Zelllinie A375 dargestellt. Die hier beschriebenen Resultate stammen aus einem Versuch mit Triplets und wurden zweimal mit vergleichbaren Ergebnissen wiederholt. Bei den Monobehandlungen mit PI3K-Inhibitoren und MEK1/2-Inhibitoren zeigte sich, dass nur Wortmannin die Apoptoserate signifikant auf das 1,2-fache (SD \pm 0,07; $p<0,018)$ erhöhte. Durch die Kombination von PI3K-Inhibitoren mit MEK1/2Inhibitoren ließ sich jedoch ein deutlicher Anstieg der Apoptose erreichen. BAY-80-6946 mit U0126 kombiniert führte zu einer 3,25-fach (SD $\pm 0,09)$ erhöhten Apoptoserate verglichen mit den unbehandelten Zellen $(p<0,0001)$. Auch die Kombination mit PD98059 zeigte eine starke Erhöhung der Apoptoserate gegenüber den unbehandelten Zellen auf etwa das Doppelte $(1,86 ; \mathrm{SD} \pm 0,08$; $\mathrm{P}<0,0001)$. Wortmannin erhöhte in Kombination mit U0126 ebenfalls die Basalapoptoserate auf das etwa Doppelte $(1,73 ; S D \pm 0,29 ; p<0,0128)$ und somit auch signifikant stärker als Wortmannin alleine $(p<0,043)$. Die Kombination von Wortmannin mit PD98059 führte jedoch nicht zu einer erhöhten Apoptoserate. 


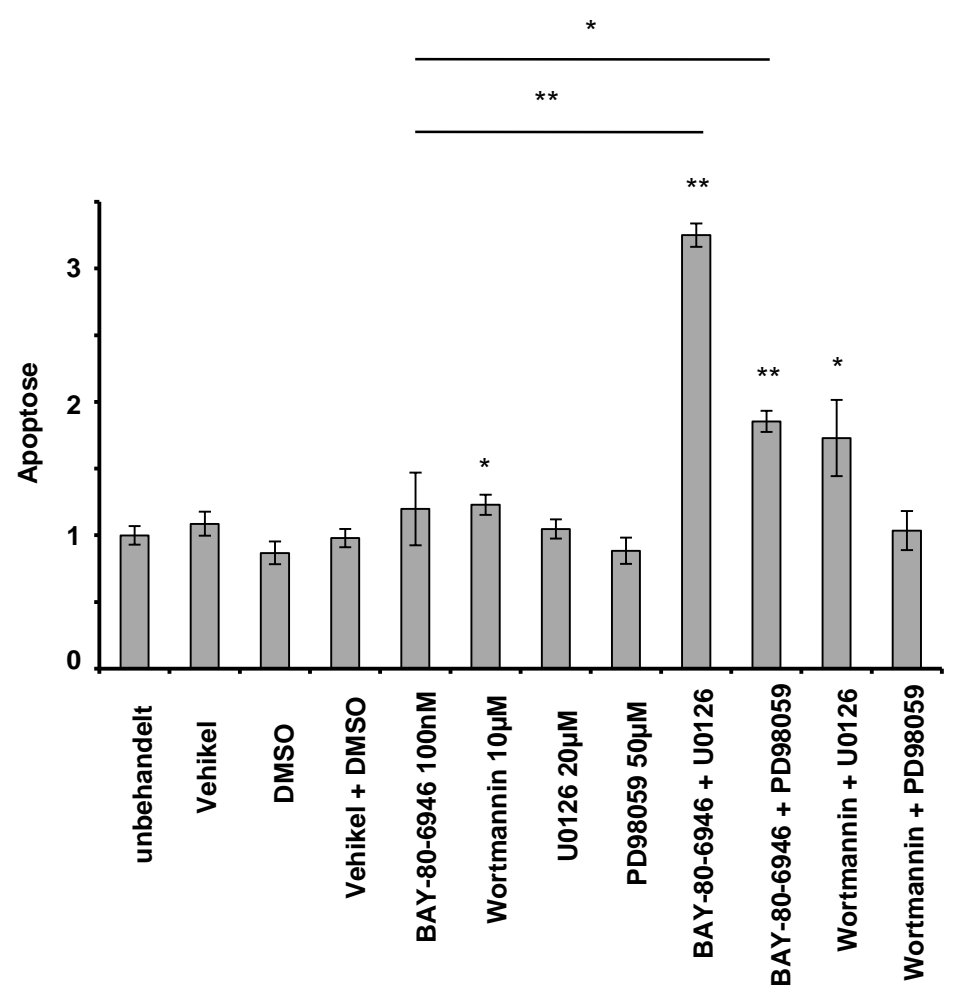

Abb. 15: PI3K-Inhibitoren und MEK1/2-Inhibitoren induzieren Apoptose in A375 Zellen der Zelllinie A375 wurden $16 \mathrm{~h}$ mit Medium, Lösungsmittelkontrollen (Medium mit DMSO, Vehikel oder beidem) und den

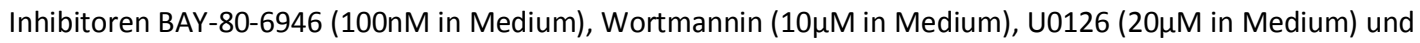
PD98059 (50 $\mu \mathrm{M}$ in Medium) und deren Kombinationen inkubiert. Anschließend wurde die Apoptoserate der Zellen durch einen Anti-Histon-ELISA bestimmt. Die hier beschriebenen Resultate stammen aus einem Versuch mit Tripletbehandlungen und wurden zweimal mit vergleichbaren Ergebnissen wiederholt. In der Grafik ist die Apoptose im Verhältnis der unbehandelten Zellen dargestellt. Mit dem Student-t-Test wurde die Signifikanz der Behandlungen überprüft. $\left({ }^{*}: p<0,05 ; * *: p<0,01\right)$. Fehlerbalken zeigen die Standardabweichung an. Es zeigte sich, dass die Monobehandlungen keine oder nur sehr wenig Apoptose in den A375-Zellen induzierten. Die Kombination von PI3K-Inhibitoren mit MEK1/2-Inhibitoren ließ jedoch die Apoptoserate deutlich ansteigen. Am stärksten Apoptose-induzierend zeigte sich dabei die Kombination von BAY-80-6946 mit U0126. 
Die Untersuchung der Apoptoseinduktion durch die verschiedenen Inhibitoren in den LOX-Zellen zeigte ein etwas anderes Ergebnis als bei der Zelllinie A375.

In Abbildung 16 sind die Ergebnisse der Apoptose-Untersuchungen an der Zelllinie LOX dargestellt. Die hier beschriebenen Resultate stammen aus einem Versuch mit Triplets und wurden zweimal mit vergleichbaren Ergebnissen wiederholt.

Bei der Zelllinie LOX wurde durch eine Behandlung mit BAY-80-6946 eine fast vierfache Erhöhung der Apoptoserate der Zellen erreicht $(3,79 S D \pm 0,90 ; p<0,006$ vgl. mit den unbehandelten Zellen). Der Vergleichs-PI3K-Inhibitor Wortmannin zeigte einen geringeren Effekt mit 1,7-facher Erhöhung (SD \pm 0,18; $p=0,0027$ vgl. mit unbehandelt). Der MEK1/2-Inhibitor U0126 führte zu einer mittleren Erhöhung der Apoptose um fast das Doppelte $(1,93 \pm 0,2 ; p<0,003)$ verglichen mit den unbehandelten Zellen, während der MEK1/2-Inhibitor PD98059 keine signifikante Erhöhung der Apoptoserate bewirkte $(1,27 \pm 0,19)$. Kombinationsbehandlungen von jeweils einem PI3K-Inhibitor und einem MEK1/2-Inhibitor zeigten einen deutlich größeren Effekt auf die Apoptoseinduktion als die jeweiligen Monobehandlungen. Die stärksten pro-apoptotischen Wirkungen zeigten dabei die Kombinationen mit BAY-80-6946. So zeigte die Kombination von BAY-80-6946 und U0126 eine 5,5-fache $(S D \pm 0,19)$ Apoptoserate im Vergleich zu den unbehandelten Zellen. Damit war die durch diese Kombinationsbehandlung erreichte Apoptoseinduktion fast 1,5-mal so stark wie die Monobehandlung mit BAY-80-6946 $(p<0,031)$ und fast dreimal so stark wie bei 00126 alleine $(p<0,00004)$. BAY-80-6946 in Kombination mit PD98059 führte zu einer 6,3-fachen Erhöhung $(S D \pm 0,11)(p=0,00001)$ der Substratreaktion im Vergleich mit den unbehandelten Zellen und einer fast 1,7-fachen im Vergleich zur Monobehandlung mit BAY-80-6946 ( $p<0,0088$ ). Die Kombinationsbehandlungen mit dem VergleichsInhibitor Wortmannin führten zu einer Erhöhung um etwa das Vierfache der Apoptoserate in den unbehandelten Zellen (Wortmannin + U0126: 4,24 $\pm 0,59$ SD; $p<0,0007$ vgl. mit unbehandelt; Wortmannin + PD98059: 3,97 $\pm 0,22 ; p<0,000023$ ). Die Kombinationsbehandlungen erhöhten somit auch signifikant die Apoptose gegenüber den jeweiligen Monobehandlungen mit Wortmannin (Wortmannin + U0126 zu Wortmannin allein: $p<0,002$; zu U0126 allein: $p<0,003$; Wortmannin + PD98059 zu Wortmannin allein: $p<0,00017$; zu PD98059 allein: $p<0,0001$ ). 


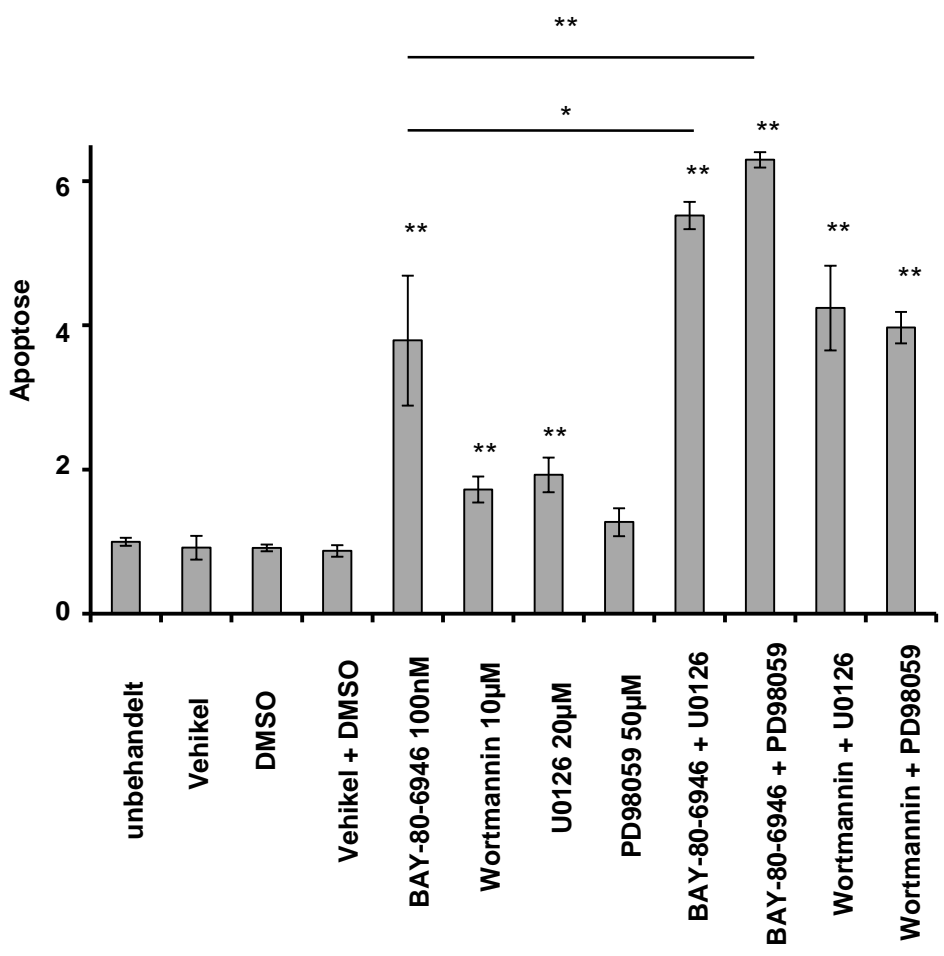

\begin{abstract}
Abbildung 16 PI3K-Inhibitoren und MEK1/2-Inhibitoren induzieren Apoptose in LOX Zellen der Zelllinie LOX wurden $16 \mathrm{~h}$ mit Medium, Lösungsmittelkontrollen (Medium mit DMSO, Vehikel oder beidem) und den

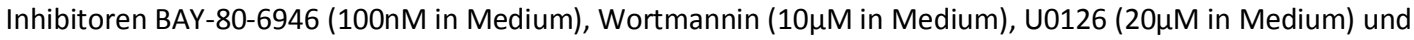
PD98059 (50 MM in Medium) und deren Kombinationen inkubiert. Anschließend wurde die Apoptoserate der Zellen durch einen Anti-Histon-ELISA bestimmt. Die hier beschriebenen Resultate stammen aus einem Versuch mit Tripletbehandlungen und wurden zweimal mit vergleichbaren Ergebnissen wiederholt. In der Grafik ist die Apoptoserate im Verhältnis der unbehandelten Zellen dargestellt. Mit dem Student-t-Test wurde die Signifikanz der Behandlungen überprüft. ( $\left.{ }^{*}: p<0,05 ;{ }^{* *}: p<0,01\right)$. Fehlerbalken zeigen die Standardabweichung an. Es zeigte sich, dass bei den Monobehandlungen BAY-80-6946 Apoptose in LOX-Zellen induzierte. Wortmannin und U0126 führten zu einer deutlich geringeren Anhebung der Apoptoserate. PD98059 in Monobehandlung induzierte keine Apoptose. Kombinationen von PI3K-Inhibitoren mit MEK1/2-Inhibitoren zeigten einen synergistischen Effekt. Am stärksten Apoptose-induzierend war dabei die Kombination von BAY-80-6946 mit einem MEK1/2-Inhibitor.
\end{abstract}




\subsubsection{BAY-80-6946 beeinflusst den Zellzyklus}

Da der PI3K/AKT-Signalweg auch in die Steuerung des Zellzyklus involviert ist, sollte mit Hilfe der Durchflusszytometrie die Verteilung der Zellen auf die einzelnen Phasen im Zellzyklus untersucht werden. Ziel war es, eventuelle Verschiebungen der Zellzyklusphasen nach Inhibition der PI3K durch BAY-80-6946 nachzuweisen.

Dazu wurden die Zelllinien A375 und LOX mit BAY-80-6946 in 3 unterschiedlichen Konzentrationen inkubiert. Die Verteilung der Zellen auf die einzelnen Phasen im Zellzyklus wurde zu mehreren Zeitpunkten nach der Behandlung gemessen. Abbildungen 17 a und b zeigen die Verteilung der Zellen auf die G0/G1-Phase und die S-Phase nach $12 \mathrm{~h}$ bei Inkubation in Medium, $10 \mathrm{nM}$ BAY-80-6946, $50 \mathrm{nM}$ BAY-80-6946 und 100 nM BAY-80-6946. Dabei zeigte sich in beiden Zelllinien, dass sich mit zunehmender Konzentration von BAY-80-6946 mehr Zellen in G0/G1Phase befanden und weniger in der S-Phase. Messungen zu späteren Zeitpunkten (nach 24 h) ließen keine derart deutlichen Effekte mehr erkennen. (Daten nicht gezeigt) 
a

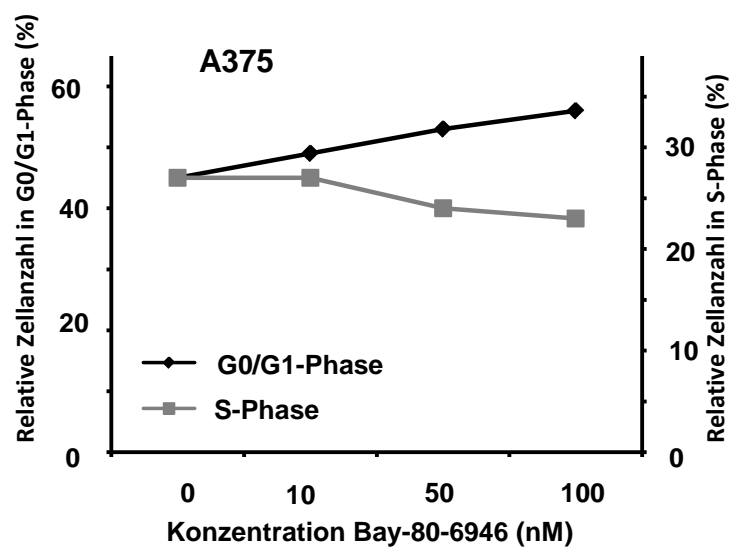

b

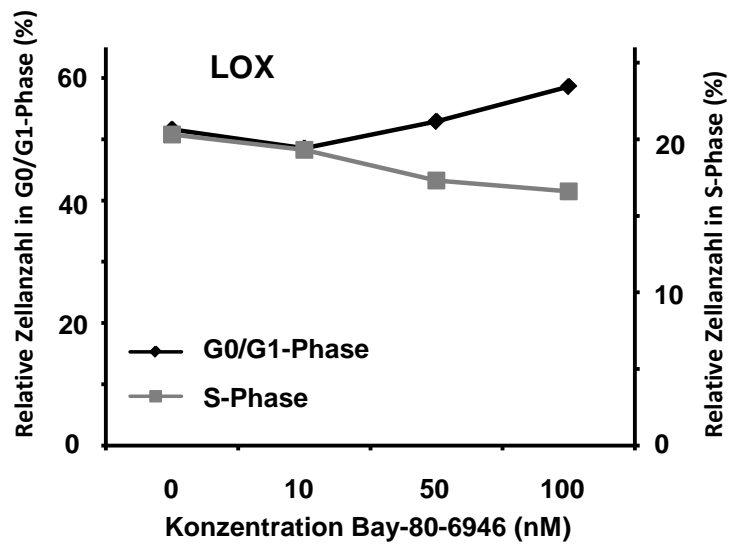

Abb. 17: BAY-80-6946 beeinflusst den Zellzyklus in A375 und LOX Die Zellinien A375 und LOX wurden $12 \mathrm{~h}$ mit $10 \mathrm{nM}, 50 \mathrm{nM}$ und $100 \mathrm{nM}$ BAY-80-6946 inkubiert. Mit Propidumiodid wurde die DNA angefärbt und im Durchflusszytometer gemessen, um die Zellpopulationen den einzelnen Phasen des Zellzyklus zuordnen zu können. Die Grafiken zeigen die prozentuale Verteilung der Zellen in G0/G1-Phase (schwarzer Graph) im Verhältnis zu S-Phase (grauer Graph). a zeigt die Ergebnisse der Zelllinie A375, b die der Zelllinie LOX. Die Ergebnisse der Experimente konnten mit ähnlichen Resultaten wiederholt werden. Es zeigte sich, dass sich bei beiden Zelllinien mit steigender Konzentration von BAY-80-6946 vermehrt Zellen in der GO/G1-Phase und weniger in der S-Phase befanden. 


\subsubsection{BAY-80-6946 reguliert Proliferations- und Apoptose-relevante Proteine}

In den vorhergehenden Experimenten wurde gezeigt, dass eine Inhibition von PI3K durch BAY-80-6946 antiproliferative und teilweise auch Apoptose-induzierende Wirkungen in den zwei Melanom-Zelllinien A375 und LOX hatte.

Um die Vorgänge in den beiden Zelllinien auf molekularer Ebene genauer zu analysieren, wurden Proteine, die in die Apoptoseregulation oder die ZellzyklusSteuerung involviert sind, im Western-Blot näher untersucht. Die Zelllinien A375 und LOX wurden dazu mit aufsteigenden Konzentrationen von BAY-80-6946 (10 nM; $50 \mathrm{nM}$ und $100 \mathrm{nM}$ in Medium) für $16 \mathrm{~h}$ inkubiert. Anschließend wurden Zelllysate gewonnen und im Western-Blot die zu analysierenden Proteine mit Antikörpern gefärbt. (Abb. 18 a und b) Dabei zeigte sich, dass in der Zelllinie LOX das pro-apoptotische Protein PUMA bei steigender Konzentration von BAY-80-6946 vermehrt zu detektieren war, während der Gehalt des Apoptoseinhibierenden Proteins XIAP sank. Die Ratio von Bcl-2, einem anti-apoptotischen Protein, und Bax, einem pro-apoptotischen Protein aus der Bcl-2-Familie, sank mit steigender BAY-80-6946-Konzentration. Dieses Bax/Bcl-2-Verhältnis wurde als Maß für die „Apoptose-Bereitschaft" von Tumorzellen beschrieben. Für A375 konnte keine konzentrationsabhängige Veränderung dieser Apoptose-beeinflussenden Proteine beobachtet werden. 
a
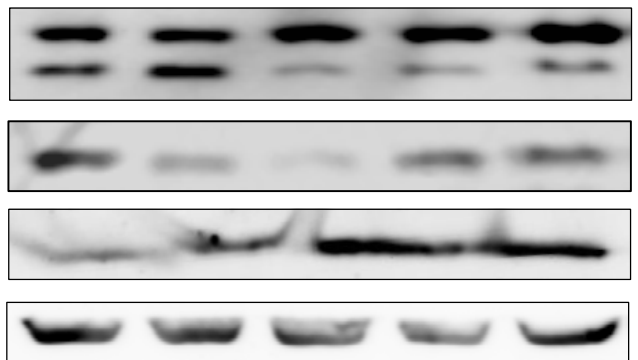

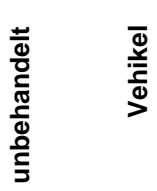

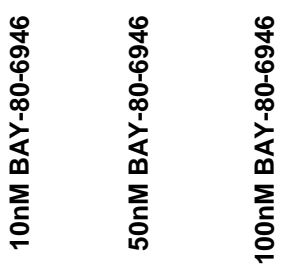

b

$\mathrm{BCl}-2$

Bax

PUMA

XIAP

Aktin
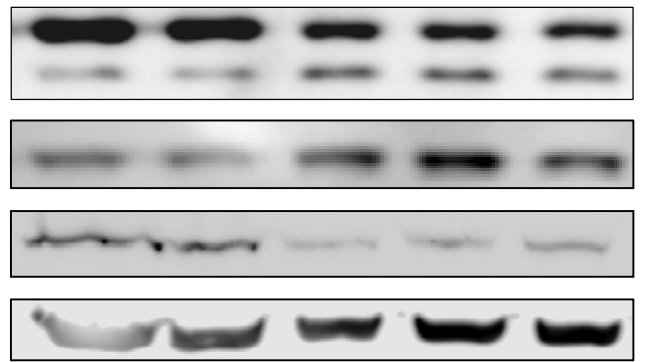

$\frac{5}{0}$
$\frac{0}{0}$
$\frac{\varpi}{0}$
$\frac{0}{5}$

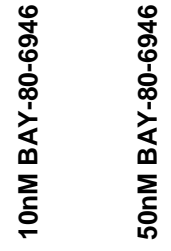

Abb. 18: BAY-80-6946 beeinflusst pro-apoptotische und anti-apoptotische Proteine Die Zelllinien A375 und LOX wurden mit aufsteigenden Konzentrationen von BAY-80-6946 (10 nM; $50 \mathrm{nM}$ und $100 \mathrm{nM}$ in Medium) und Kontrollen mit Medium und Medium mit DMSO $16 \mathrm{~h}$ inkubiert. Anschließend wurden Zelllysate gewonnen und im Western-Blot die zu analysierenden Proteine mit Antikörpern gefärbt. a BAY-80-6946 führt zu keiner Änderung von Apoptose-relevanten Proteinen in der Zelllinie A375. b BAY-80-6946 senkt die Bcl-2/Bax-Ratio und anti-apoptotisches XIAP in der Zelllinie LOX, wohingegen pro-apoptotisches PUMA steigt. 
Als nächstes wurde untersucht, ob BAY-80-6946 die Expression von CyclinD1 in Melanomzellen beeinflusst. Dazu wurden die Zelllinien A375 und LOX in aufsteigenden Konzentrationen mit BAY-80-6946 (10 nM, $50 \mathrm{nM}$ und $100 \mathrm{nM}$ in Medium) für $16 \mathrm{~h}$ inkubiert und anschließend die mRNA der Zellen aufgereinigt und mittels RT-PCR semiquantitativ analysiert. Dabei zeigte sich in den Zelllinien durch BAY-80-6946 keine Änderung der Expression von CyclinD1. (Abb. 19)
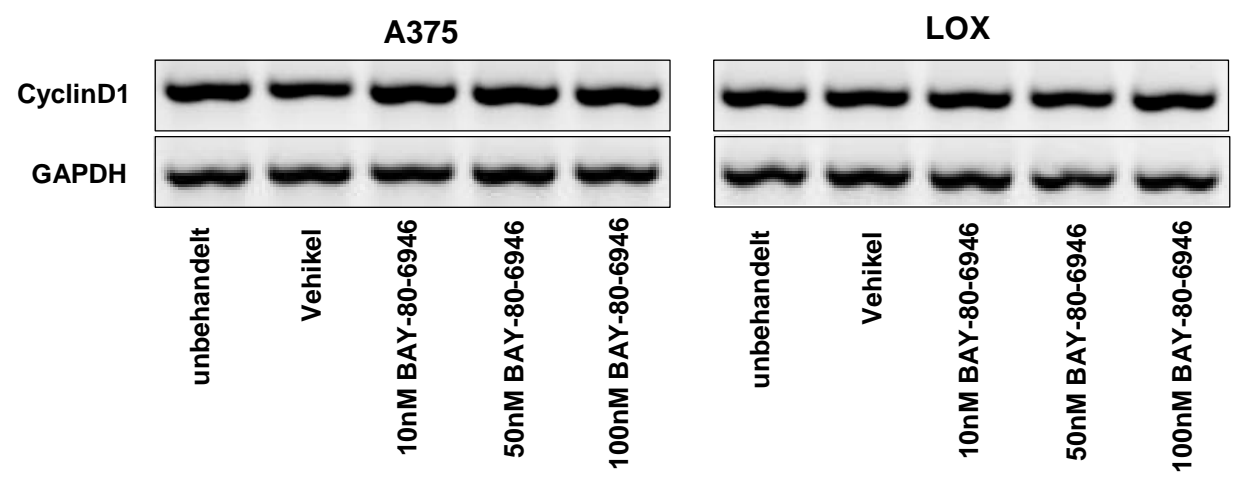

Abb. 19: BAY-80-6946 ändert nicht die Expression des Zellzyklusproteins CyclinD1 Die Zelllinien A375 und LOX wurden mit aufsteigenden Konzentrationen von BAY-80-6946 (10 nM; $50 \mathrm{nM}$ und $100 \mathrm{nM}$ in Medium) $16 \mathrm{~h}$ inkubiert. Anschließend wurde aus den Zellen mRNA isoliert und durch RT-PCR die Expression von CyclinD1 semiquanitiativ analysiert. Um gleiche mRNA-Amplifizierungsmengen nachzuweisen, diente GAPDH als Kontrollgen. Es zeigte sich keine Änderung der Expression von CyclinD1 durch BAY-80-6946. 


\subsubsection{Weitere Tumor-relevante Gene im Melanom bleiben von BAY-80-6946 unbeeinflusst}

Weiter wurde der Einfluss der PI3K-Inhibition durch BAY-80-6946 auf wichtige Tumor-relevante Gene im Melanom geprüft. Zur Untersuchung, ob BAY-80-6946 die mRNA-Expression der Gene reguliert, wurden die Zelllinien A375 und LOX in aufsteigenden Konzentrationen mit BAY-80-6946 (10 nM, $50 \mathrm{nM}$ und $100 \mathrm{nM}$ in Medium) für $16 \mathrm{~h}$ inkubiert und anschließend die mRNA der Zellen aufgereinigt und mittels RT-PCR semiquantitativ analysiert. Dabei konnte auf mRNA-Ebene keine von der Konzentration abhängige Veränderung der Expression der untersuchten Gene p21, CXCL-1, IL-8 und COX2 festgestellt werden. Zwischen den Zelllinien A375 und LOX bestanden allerdings durchaus Unterschiede in der Expression der Gene COX-2, IL-8 und CXCL1 (Abb.20).
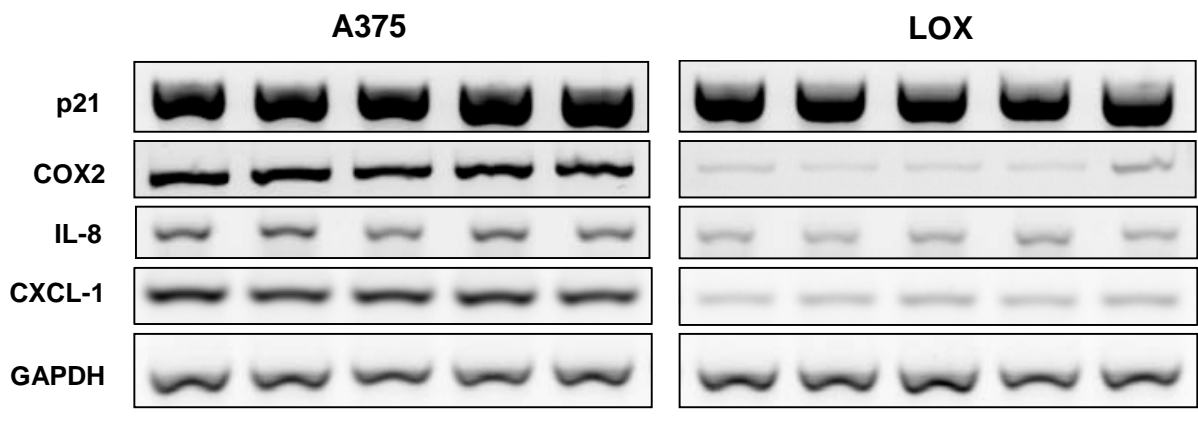

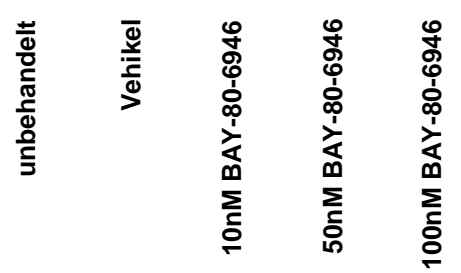

\begin{tabular}{|c|c|c|c|}
\hline 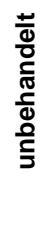 & 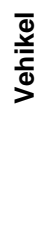 & 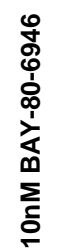 & 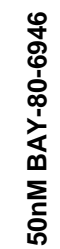 \\
\hline
\end{tabular}

Abb. 20: BAY-80-6946 zeigt keinen Einfluss auf die Expression Tumor-relevanter Gene Die Zelllinien A375 und LOX wurden mit aufsteigenden Konzentrationen von BAY-80-6946 (10 nM; 50 nM und $100 \mathrm{nM}$ in Medium) $16 \mathrm{~h}$ inkubiert. Anschließend wurde aus den Zellen mRNA isoliert und durch RT-PCR semiquanitiativ analysiert. Um gleiche mRNA-Amplifizierungsmengen nachzuweisen, diente GAPDH als Kontrollgen. BAY-80-6946 zeigte keinen Einfluss auf die Expression der Gene p21, COX2, IL-8 und CXCL-1. 


\subsection{Inhibition von PI3K und MEK1/2 in vivo beeinflusst das Wachstum von Melanomen im Mausmodell}

Da die in-vitro-Experimente mit den Melanom-Zelllinien LOX und A375 zeigten, dass durch PI3K- und MEK1/2-Inhibitoren sowohl die Proliferation eingeschränkt als auch teils vermehrt Apoptose induziert wird, sollten nun die Effekte der Inhibition in einem Mausmodell überprüft werden.

\subsubsection{Inhibition der PI3K im Nacktmausmodell verringert das Wachstum von A375-Tumoren, nicht aber von LOX}

Um den Einfluss des PI3Kinase-Inhibitors BAY-80-6946 auf das Tumorwachstum in vivo zu überprüfen, wurde athymischen Nacktmäusen nach intradermaler Injektion von $2 \times 10^{6}$ Zellen der Linie A375 oder LOX dreimal pro Woche $125 \mathrm{~nm}$ BAY-80-6946 in PBS i.p. injiziert. Die Kontrolltiere wurden in gleicher Weise mit dem verwendeten Vehikel behandelt. Die ausgewertete Tumorzahl pro Gruppe betrug $n=8$.

Bei der Zelllinie A375 konnte ein signifikanter Effekt ( $p<0,002$ im Vergleich zu Vehikel-behandelten Tieren) von BAY-80-6964 auf das Größenwachstum der Tumoren beobachtet werden. Zum Versuchsende an Tag 16 betrug die mittlere Tumorgröße der behandelten Tiere $140 \mathrm{~mm}^{3}$ (SD $\pm 108 \mathrm{~mm}^{3}$ ) im Vergleich zu den Kontrolltumoren mit $380 \mathrm{~mm}^{3}$ (SD $\pm 122 \mathrm{~mm}^{3}$ ). Dies entspricht einer um mehr als die Hälfte geringeren mittleren Tumorgröße. Bei der Zelllinie LOX zeigte sich hingegen keine Wachstumsinhibition durch BAY-80-6946. Die Tumoren der Vehikelgruppe waren im Durchschnitt $602 \mathrm{~mm}^{3}$ (SD $\pm 333 \mathrm{~mm}^{3}$ ) groß. Im Vergleich dazu zeigten die mit BAY-80-6946 behandelten Tumoren mit einem mittleren Volumen von $461 \mathrm{~mm}^{3}$ (SD $\pm 163 \mathrm{~mm}^{3}$ ) keine signifikante Wachstumsminderung. (Abb. 21) 
a

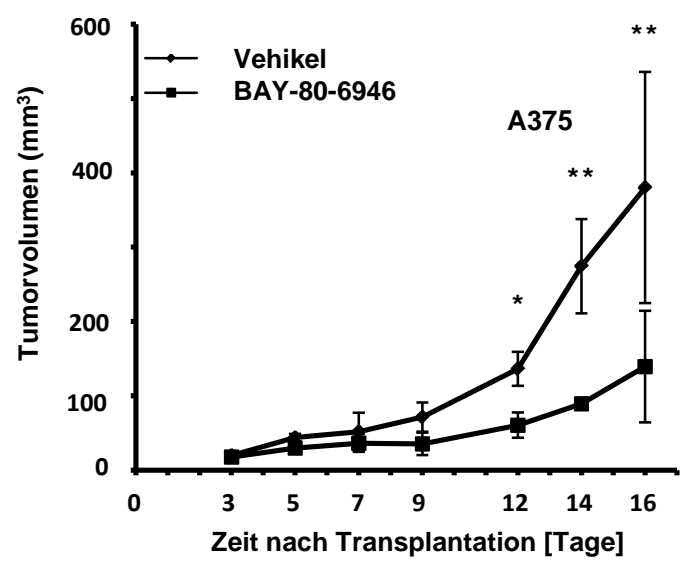

b

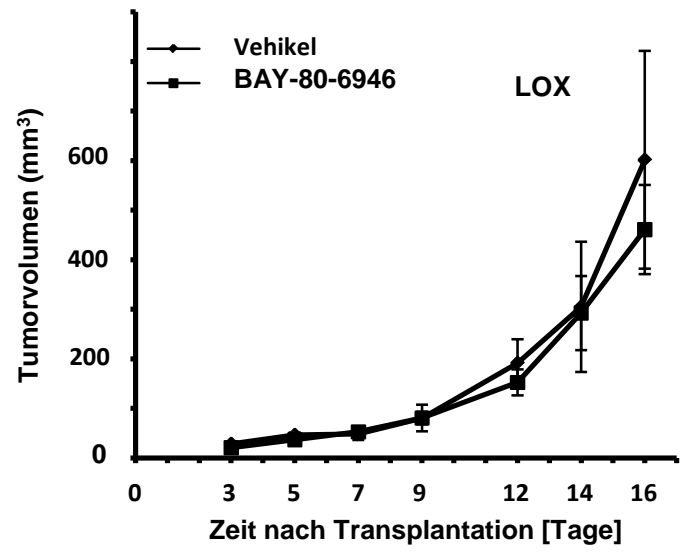

Abbildung 21 BAY-80-6946 verringert das Wachstum von A375-Tumoren in Nacktmäusen Athymischen Nacktmäusen wurden $2 \times 10^{6}$ Zellen intradermal injiziert. Die Tiere wurden dreimal pro Woche mit $125 \mathrm{~nm}$ BAY-80-6946 in PBS i.p. behandelt (Graph „BAY-80-6946“). Kontrolltiere wurden nach dem gleichen Schema mit dem Lösungsmittel „Vehikel“ in PBS behandelt (Graph „Vehikel“). Über die Formel „Höhe $\times$ Breite $\times$ Länge“ wurden die Volumina der Tumoren im Versuchsverlauf in $\mathrm{mm}^{3}$ näherungsweise berechnet. Die Werte stammen aus der Vermessung der Tumoren mit der Schieblehre. Die eingetragenen Fehlerbalken zeigen die Standardabweichung, die ausgewertete Tumorzahl beträgt $n=8$ pro Gruppe. Mit dem Student-t-Test wurde die Signifikanz gegenüber der Vehikel-Gruppe überprüft. $(*: p<0,05 ; * *: p<0,01)$. a BAY-80-6946 bewirkte eine signifikante Wachstumsminderung bei den A375-Tumoren ( $p<0,002$ bei Versuchsende). $\mathbf{b}$ Das Wachstum der LOX-Tumoren wurde nicht signifikant durch BAY-80-6946 gemindert. 


\subsubsection{Inhibition von MEK1/2 im Nacktmausmodell verringert das Wachstum von A375-Tumoren}

In athymischen Nacktmäusen wurden durch intradermale Injektionen der Tumorzellen LOX und A375 Tumoren transplantiert. Die Tiere wurden anschließend jeden zweiten Tag mit dem MEK1/-Inhibitor U0126 behandelt. Dazu wurde den Nacktmäusen an das Gewicht adaptiert 600-900 nm U0126 in PBS i.p. injiziert. Kontrolltiere wurden parallel mit dem entsprechenden Vehikel behandelt. Die ausgewertete Tumorzahl pro Gruppe betrug $n=8$. Es zeigte sich, dass U0126 eine signifikante Inhibition des Wachstums von A375-Tumoren bewirkte. Bei Versuchsende an Tag 21 betrug die mittlere Tumorgröße der Tiere, die mit U0126 behandelt wurden, $432 \mathrm{~mm}^{3}$ (SD $\pm 782 \mathrm{~mm}^{3}$ ) im Vergleich zu den Kontrolltumoren, die $1659 \mathrm{~mm}^{3}\left(S D \pm 1298 \mathrm{~mm}^{3}\right)$ groß waren $(p=0,038)$. Dies entspricht einer Verringerung der mittleren Tumorgröße auf beinahe ein Viertel (Abb. 22a). Auch bei LOX konnte eine Verringerung der mittleren Tumorgröße um etwa die Hälfte festgestellt werden, jedoch war dieser Unterschied bei der hier untersuchten Gruppengröße nicht signifikant ( $p=0,20 ;$ U0126 im Vergleich mit Kontrolltieren) (Abb. 22b). 


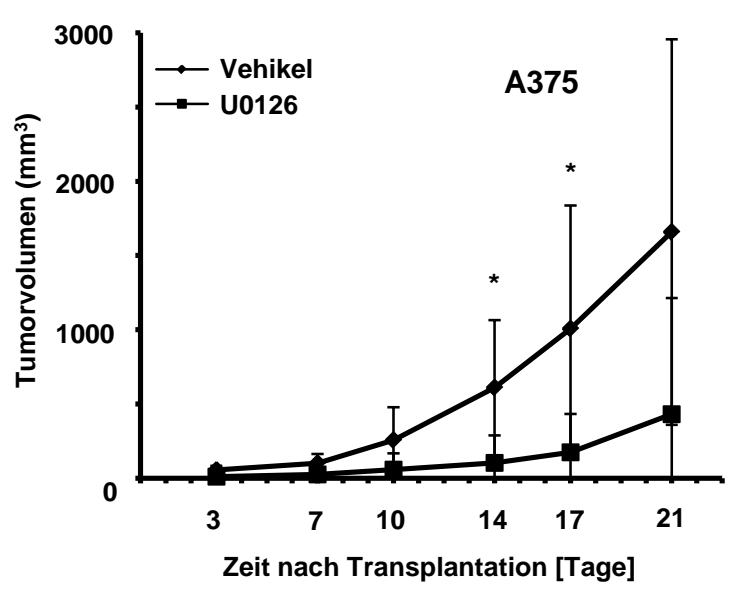

b

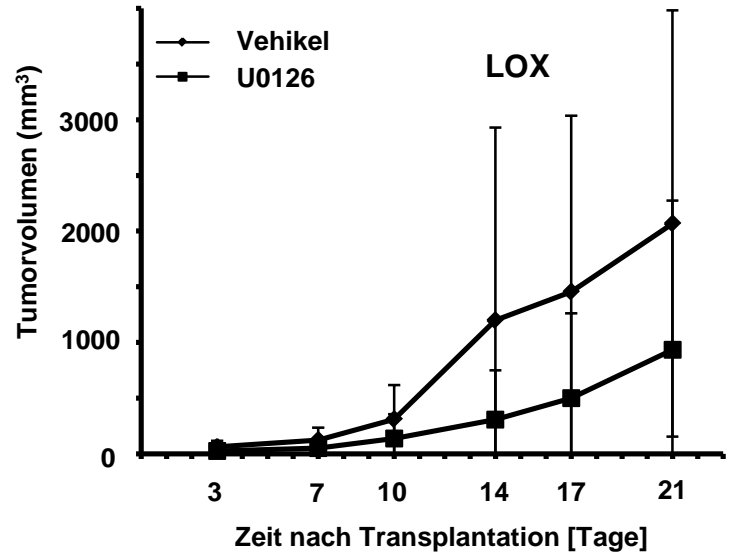

Abbildung 22 U0126 verringert das Wachstum von A375-Tumoren in Nacktmäusen Athymischen Nacktmäusen wurden $2 \times 10^{6}$ Zellen der Zelllinien A375 und LOX intradermal injiziert. Die Tiere wurden jeden zweiten Tag an das Gewicht adaptiert mit 100-180 $\mu$ l einer $5 \mathrm{mM}$ U0126-Lösung in PBS i.p. behandelt (Graph „U0126“). Kontrolltiere wurden parallel mit dem Lösungsmittel „Vehikel“ in PBS behandelt (Graph „Vehikel“). Über die Formel „Höhe $\times$ Breite $\times$ Länge“ wurden die Volumina der Tumoren im Versuchsverlauf in $\mathrm{mm}^{3}$ näherungsweise berechnet. Die Werte stammen aus der Vermessung der Tumoren mit der Schieblehre. Die eingetragenen Fehlerbalken zeigen die Standardabweichung, die ausgewertete Tumorzahl pro Versuchsgruppe beträgt $n=8$. Mit dem Student-t-Test wurde die Signifikanz gegenüber der Vehikel-Gruppe überprüft. $\left({ }^{*}: p<0,05 ;{ }^{* *}: p<0,01\right)$. a U0126 bewirkte eine signifikante Wachstumsminderung bei den A375Tumoren $(p<0,038)$. b Das Wachstum der LOX-Tumoren wurde nicht signifikant durch $\mathrm{U} 0126$ gemindert. 


\section{Diskussion}

\subsection{Melanomzellen unterscheiden sich in der Aktivierung der Signaltransduktionswege und dem Zellwachstum im Mausmodell}

Bei der Pathogenese des Melanoms wirken mehrere molekulare Vorgänge in komplexer Weise zusammen; am Ende steht auf zellulärer Ebene die Dysregulation von Zellproliferation, Zellzyklus und Apoptose. In den letzten Jahren sind mehrere Wege identifiziert worden, die an der Melanomentstehung und dem Krankheitsprogress beteiligt sind (Cohen et al. 2002, Dai et al. 2005, Davies H. et al. 2002, Davies M. A. et al. 2008, Lin et al. 2008, Lopez-Bergami et al. 2008, Smalley und Herlyn 2005, Ueda und Richmond 2006). In dieser Arbeit konnte gezeigt werden, dass sowohl in vitro als auch in vivo der MAPK/ERK-Weg und PI3K/AKTSignalweg in vielen Melanomen konstitutiv aktiviert sind. Beide Signalwege stellen Schlüsselwege bei Entstehung und Progression vieler Melanome dar (Davies H. et al. 2002, Jorgensen et al. 2006, Lopez-Bergami et al. 2007, Niu et al. 2002, Satyamoorthy et al. 2003). Die Melanom-Zelllinien unterschieden sich zudem darin, welche Signalwege aktiviert waren. P-AKT als Surrogatparameter der PI3K/AKT-Weg-Aktivität war in vier von sechs Zelllinien (67\%) konstitutiv stark exprimiert. Dies entspricht den Ergebnissen anderer Arbeiten (Dai et al. 2005, Dhawan et al. 2002). Der MAPK/ERK-Weg war bei drei von sechs Zelllinien (50\%) konstitutiv aktiviert. Auch dieses deckt sich mit früheren Untersuchungen (Davies H. et al. 2002). Somit ist davon auszugehen, dass für das maligne Verhalten der Melanomzellen verschiedene Wege verantwortlich sein können.

Sechs Melanom-Zelllinien wurden zudem in einem in-vivo-Modell hinsichtlich ihrer Fähigkeit, Tumoren zu bilden, miteinander verglichen. Dazu wurde ein Xenotransplantations-Tiermodell genutzt, bei dem athymische immundefiziente Nacktmäuse mit humanen Melanomzellen inokuliert wurden. Es handelt sich um ein etabliertes und bereits häufig eingesetztes Tiermodell (Fodstad et al. 1988, Giovanella et al. 1983, Rofstad 1994, Rofstad und Lyng 1996). Auf Grund der 
Immundefizienz der Tiere ist es möglich, das Wachstumsverhalten humaner Melanomzellen in einem kompletten Organismus zu verfolgen, ohne dass die Zellen vom Immunsystem des Wirts abgestoßen werden. Die Melanom-Zelllinien A375 und LOX erwiesen sich hierbei als stark tumorigen im Mausmodell. Daher wurden diese beiden Zelllinien für die weiterführenden Experimente mit MAPKund PI3K-Inhibitoren ausgewählt. Desweiteren konnte mit diesen Zelllinien untersucht werden, ob die Stärke der konstitutiven Aktivität der Signalwege die Effektivität der Inhibitoren beeinflusst, da im Western-Blot und in der Durchflusszytometrie die LOX-Melanom-Zelllinie eine höhere konstitutive Aktivierung des PI3K/AKT- und MAPK/ERK- Signalweges zeigte als die A375Zelllinie. 


\subsection{Kombinierte PI3K-Inhibition und MEK1/2-Inhibition in vitro zeigen größeren therapeutischen Effekt als die Einzelinhibition}

Um zu untersuchen, ob PI3K-Inhibition und MEK1/2-Inhibition in vitro therapeutische Effekte gegen Melanomzellen zeigen und ob diese in kombinierter Behandlung noch verstärkt werden können, wurden verschiedene PI3K- und MEK1/2-Inhibitoren untersucht. BAY-80-6946, ein neuer spezifischer Klasse-I-PI3KInhibitor (Patnaik et al. 2011), und Wortmannin, ein bereits etablierter PI3KInhibitor, wurden im Hinblick auf wichtige Tumorfunktionen wie Zellproliferation, Zellzyklus und Apoptose miteinander verglichen. Desweiteren wurden die MEK1/2Inhibitoren U0126 und PD98059 in Melanomzellen untersucht und die Auswirkungen der Blockade des MAPK/ERK- Signalweges auf Zellproliferation und Apoptose analysiert.

Der Klasse-I-PI3K-Inhibitor BAY-80-6946 wurde in dieser Arbeit erstmals an Melanomzellen untersucht. In Western-Blot-Analysen konnte gezeigt werden, dass BAY-80-6946 auch in Melanomzellen sein Zielprotein, die PI3K, inhibierte und dadurch weniger aktiviertes AKT in den Zellen vorlag.

Aus vorherigen Studien ist bekannt, dass die Inhibition der Proliferation durch die Blockade der PI3K zwischen den einzelnen Melanom-Zelllinien variiert (Marone et al. 2009, Meier et al. 2007, Smalley et al. 2006, Spofford et al. 2006). Dieses Phänomen zeigte sich auch in den vorliegenden Untersuchungen. In der Zelllinie A375 führte die Behandlung mit BAY-80-6946 und Wortmannin zu einer geringen Inhibition der Proliferation, wohingegen BAY-80-6946 die Proliferation der LOXZellen deutlich blockierte, der Vergleichsinhibitor Wortmannin wiederum zeigte hier keinen Effekt. Analog zu den Wirkungen der PI3K-Inhibition durch BAY-80-6946 auf die zelluläre Proliferation zeigte sich, dass beide Zelllinien mit steigender Konzentration von BAY-80-6946 prozentual mehr Zellen in der G0/G1Phase aufwiesen und dafür weniger in der S-Phase. Dies bedeutet, dass durch die PI3K-Inhibition der Eintritt in die replikative Phase des Zellzyklus verzögert wird und sich somit die Zellteilungsrate verlangsamt. Auch dieses Phänomen der PI3K- 
Blockade wird durch andere Arbeiten gestützt (Gille und Downward 1999, Spofford et al. 2006). Es erschien möglich, dass dieser Zellzyklus-Arrest über eine veränderte Regulation von CyclinD1 hervorgerufen wurde. CyclinD1 spielt eine wichtige Rolle für den G1-zu-S-Phase-Übergang. Durch die Aktivität von AKT wird die transkriptionelle, posttranskriptionelle und posttranslationale Regulation von CyclinD1 beeinflusst (Dufourny et al. 2000, Muise-Helmericks et al. 1998). Dies führt zu einer Akkumulation von CyclinD1 in der Zelle (Diehl et al. 1998). Außerdem kann die aktivierte Kinase AKT zusammen mit dem aktivierten MAPK/ERK-Signalweg die Expression von CyclinD1 induzieren (Aktas et al. 1997, Gille und Downward 1999, Klippel et al. 1998). Die Analyse der CyclinD1-Expression in BAY-80-6946 behandelten Melanomzellen zeigte jedoch keine Reduktion von CyclinD1 (Abb. 18). Auch bei dem untersuchten cdK-Inhibitor p21 stellte sich keine konzentrationsabhängige Expressionsänderung durch BAY-80-6946 dar (Abb. 20). Folglich ist davon auszugehen, dass der Zellzyklus-Arrest in Melanomzellen durch andere AKT-abhängige Mechanismen vermittelt wird. Spofford et al. zeigten, dass auch CyclinD3-Expression in Melanomzellen über den PI3K/AKT-Signalweg reguliert wird und dass eine erhöhte CyclinD3-Expression neben CyclinD1 für den G1-zu-S-Phase-Progress benötigt wird (Spofford et al. 2006). Eine mögliche Erklärung für die Zellzyklus-Verlangsamung durch BAY-80-6946 könnte also eine verringerte CyclinD3-Expression sein. Diese Hypothese muss in weiteren Experimenten überprüft werden.

Melanomzellen zeigen im Vergleich zu anderen Tumorentitäten eine geringe Spontanapoptose in vivo und sind im Allgemeinen sehr resistent gegenüber Medikamenten-induzierter Apoptose in vitro (Gray-Schopfer et al. 2007, Soengas und Lowe 2003). Dabei kann die konstitutive Aktivierung von AKT durch die Aktivität der PI3K zu einer Apoptoseresistenz in Melanomzellen führen (Vivanco und Sawyers 2002). Daher war es interessant, den Einfluss von PI3K-Inhibition auf die Apoptose in Melanomzellen zu untersuchen. In früheren Studien wurde gezeigt, dass Apoptoseinduktion durch PIK3-Inhibitoren zwischen den MelanomZellinien schwankt (Meier et al. 2007, Smalley et al. 2006). Die zwei in dieser Arbeit ausgewählten PI3K-Inhibitoren induzierten ebenfalls unterschiedlich stark Apoptose in den Melanom-Zelllinien. Bei A375 induzierte Wortmannin einen 
leichten Anstieg der Apoptoserate, BAY-80-6946 nicht. In der Zelllinie LOX hingegen lösten beide Inhibitoren einen Anstieg der Apoptoserate aus, BAY-80-6946 zeigte dabei einen deutlich stärkeren Effekt als Wortmannin. In früheren Studien konnten Meier et al. bei der Behandlung mehrerer MelanomZelllinien mit Wortmannin keine Steigerung der Apoptose beobachten (Meier et al. 2007). Sie untersuchten jedoch andere Melanom-Zelllinien als in dieser Arbeit, was wiederum die Hypothese einer Apotoseinduktion in Abhängigkeit von der Zelllinie bestätigt.

Um die Apoptosevorgänge unter BAY-80-6946-Behandlung in den beiden Zelllinien genauer zu analysieren, wurden Apoptose-relevante Proteine im Western-Blot näher untersucht. Das Bcl-2-Signalnetzwerk ist einer der wichtigsten Regulatoren der zellulären Apoptose (Russo et al. 2009). Zu dieser Proteinfamilie gehören unter anderem pro-apoptotische Proteine wie Bax und PUMA und anti-apoptotische wie Bcl-2 und XIAP (Borner et al. 1999, Heere-Ress et al. 2002, Helmbach et al. 2001, Jansen et al. 2000). In der Melanom-Zelllinie LOX wurde durch die Behandlung mit dem PI3K-Inhibitor BAY-80-6946 die Expression der pro-apoptotische Proteine wie PUMA und Bax in Abhängigkeit von der Konzentration gesteigert. Parallel dazu wurde die Expression der anti-apoptotischen Proteine wie XIAP und Bcl-2 verringert. In den A375-Melanomzellen ergab sich keine Expressionsänderung der Apoptose-relevanten Proteine durch die Behandlung mit BAY-80-6946. Diese Expressionsanalysen bestätigen die Ergebnisse aus den Apoptose-Untersuchungen; der PI3K-Inhibitor BAY-80-6946 induziert in der Melanom-Zellline LOX, aber nicht in A375 Apoptose, indem die Expression von pro-apoptotischen Proteinen gesteigert und von anti-apoptotischen verringert wird. Eine besondere Rolle nimmt hierbei das Verhältnis von anti-apoptotischem Bcl-2 zu pro-apoptotischem Bax ein; es ist entscheidend für die Freisetzung von Cytochrom $C$ im Zuge der Apoptose und wird als Maß für die Apoptose-Bereitschaft von Zellen angesehen (Raisova et al. 2001, Schön et al. 2003). Diese Ratio von Bcl-2 und Bax sank mit steigender BAY-80-6946-Konzentration, was einer vermehrten Bereitschaft der Tumorzellen entspricht, Apoptose einzuleiten. 
Da der PI3K-Weg neben den schon beschriebenen Einflüssen auf Zellüberleben und Wachstum noch weitere auf Migration, Tumorinvasion und Immunantwort des Körpers auf die Tumorzellen hat, wurde ergänzend untersucht, ob BAY-80-6946 einen Effekt auf die Expression von Genen hat, die in diesen Tumorrelevanten Zellfunktionen eine wichtige Rolle spielen. Die Chemokine IL-8, COX-2 und CXCL1 sind in Tumorwachstum, -metastasierung und Angiogenese involviert. IL-8 ist zudem noch an der Tumorinvasion, der autokrinen Wachstumsstimulation und als Mediator an der Immunantwort beteiligt (Altinoz und Korkmaz 2004, Bertagnolli 2007, Dhawan und Richmond 2002, Homey et al. 2002, Liao et al. 2007, Payne und Cornelius 2002). In dieser Arbeit wurde gezeigt, dass die Behandlung mit dem PI3K-Inhibitor BAY-80-6946 zu keiner eindeutigen Änderung der Expression in den untersuchten Zelllinien führte. Dies lässt vermuten, dass diese Gene durch einen anderen AKT-unabhängigen Mechanismus aktiviert sind oder dass ihre Rolle in den redundanten Regulationssystemen der Tumorzelle nicht essentiell ist.

Ein weiteres Phänomen fiel bei den Untersuchungen der PI3K-Inhibitoren auf: Die hier verwendeten PI3K-Inhibitoren BAY-80-6946 und Wortmannin hemmen beide, in den beschriebenen Konzentrationen in Melanomzellen, spezifisch ihr Zielprotein und inhibieren die Aktivierung der Kinase AKT. Trotzdem zeigte BAY-80-6946 eine stärkere antiproliferative und Apoptose-induzierende Wirkung in den Zellen als Wortmannin. Eine mögliche Erklärung dafür könnte die geringe Stabilität von Wortmannin im Medium sein (Holleran et al. 2003). Zudem unterscheiden sich BAY-80-6946 und Wortmannin in der genauen Wirkungsweise der PI3K-Inhibition: BAY-80-6946 hemmt spezifisch die Klasse-I-PI3K, Wortmannin hingegen ist als PanPI3K-Inhibitor weniger spezifisch in der PI3K-Inhibiton (Berndorff et al. 2011, Patnaik et al. 2011, Vanhaesebroeck et al. 2001). Dies könnte in den redundanten Signalwegen des Melanoms zu weiteren Signalwegaktivierungen führen.

Interessant ist, dass die Effekte durch PI3K-Inhibition, wie auch in dieser Arbeit beobachtet, stark in Abhängigkeit von der untersuchten Melanom-Zelllinie variieren. Vor allem die Apoptoseinduktion unterscheidet sich stark. Da in den beiden Zelllinien Unterschiede in dem AKT-Aktivierungsstatus nachgewiesen 
wurden, kann man darin einen möglichen Grund für die unterschiedliche Apoptose-Induzierbarkeit durch PI3K-Inhibition vermuten. A375 besitzt wenig konstitutive AKT-Aktivität und durch Inhibition der PI3K wird wenig Apoptose induziert. In LOX wiederum ist viel AKT konstitutiv aktiviert und Inhibition der PI3K durch BAY-80-6946 induziert hier mehr Apoptose und eine verringerte Proliferation. Hohe konstitutive PI3K-Aktivität, die gehemmt wird, scheint also mit einem vermehrten therapeutischen Nutzen verbunden. Eine kürzlich publizierte Arbeit spricht jedoch eher gegen diese Hypothese: Für einen anderen PI3KInhibitor, Ly294002, konnte gezeigt werden, dass die p-AKT-Expression nicht mit dem therapeutischen Effekt korrelierte (Aziz et al. 2009). Es bleibt also abschließend zu klären, was maßgebend für die Beeinflussbarkeit durch PI3KInhibitoren ist. Obwohl der PI3K/AKT-Weg einen hohen Stellenwert in Melanomentstehung und der Tumorprogression besitzt, hat sich gezeigt, dass Monobehandlungen mit Inhibitoren, die auf diesen Weg abzielen, nicht den erhofften Erfolg bei der Melanomtherapie erreichen. Tatsächlich gilt diese Feststellung auch für zahlreiche weitere Chemotherapeutika (Vaubel und Schadendorf 2011).

Ein weiter Signalweg, der ein zentrales Element in Entstehung und Progress des Melanoms darstellt, ist der MAPK/ERK-Signalweg. Dieser nimmt eine wichtige Rolle in der Regulation von Zellwachstum im Melanom vor allem über die Beeinflussung des G1-Zellzyklus-Kontrollpunkt ein (Smalley 2010). In der vorliegenden Arbeit wurde gezeigt, dass MEK-Inhibition durch U0126 und PD98059 das Wachstum von A375- und LOX-Melanomzellen in vitro inhibiert. Diese Ergebnisse stehen mit denen anderer Arbeitsgruppen in Einklang, die zeigen konnten, dass MEK-Inhibition die Proliferation von Melanomzellen vermindern kann (Karasarides et al. 2004, Kortylewski et al. 2001, Meier et al. 2007, Meier et al. 2005, Smalley et al. 2006). Die erreichte Wachstums-Inhibition unterschied sich jedoch stark zwischen den zwei untersuchten Zelllinien. A375 zeigte eine deutlich stärkere Proliferationsminderung durch beide MEK1/2-Inhibitoren als LOX. Auch dieser Zellreihen-spezifische Effekt wurde von weiteren Arbeiten bereits beschrieben (Meier et al. 2007, Smalley et al. 2006). Der aktivierte MAPK/ERK-Weg unterdrückt die Apoptose und gilt als mitverantwortlich für die bestehende 
weitreichende Apoptoseresistenz des Melanoms (Cartlidge et al. 2008, Eisenmann et al. 2003, Zhang et al. 2003). Durch MAPK/ERK-Weg-Inhibition wird jedoch bei Melanomzellen wiederum nur unregelmäßig Apoptose induziert (Flaherty und McArthur 2010, Meier et al. 2007, Smalley et al. 2006, Verhaegen et al. 2006). In der vorgelegten Arbeit zeigte die MEK-Inhibition durch U0126 und PD98059 in Monobehandlung in den Zelllinien A375 und LOX ebenfalls nur geringen oder gar keinen Einfluss auf die Apoptoserate. Es wird diskutiert, dass ein Zusammenhang zwischen BRAF-Mutationsstatus und Sensitivität gegenüber MEK-Inhibitoren besteht (Solit et al. 2006). Tumor-Zelllinien, die BRAF-mutiert waren, reagierten stärker auf MEK-Inhibition, als Zelllinien, die das Wild-Typ-Allel dieses Gens aufwiesen (Solit et al. 2006). Beide in dieser Arbeit verwendeten Zelllinien sind jedoch BRAF-mutiert (Park et al. 2005, Tsao et al. 2004, Yang et al.), sodass sich hierin nicht der Unterschied in der Sensitivität der Zelllinien erklären lässt. In der vorgelegten Arbeit wurde gezeigt, dass LOX mehr konstitutives ERK als A375 besitzt und weniger auf Inhibition von MEK1/2 in vitro anspricht. Es muss also weitere Faktoren geben, die die Unterschiede in der Sensitivität gegenüber MEK1/2-Inhibition bedingen. Ein weiterer interessanter Ansatzpunkt besteht darin, dass Tumor-Zelllinien, in denen neben dem MEK/ERK-Signalweg auch der PI3KSignalweg aktiviert war, schlechter auf MEK1/2-Inhibition ansprachen, als Zellen, in denen der PI3K-Weg nicht aktiviert war (Wee et al. 2009). Sie sahen PI3K-Aktivität als eigenständigen prognostischen Faktor für die MEK-Inhibitor-Suszeptibilität. Dieses Phänomen lässt sich auch in der vorliegenden Arbeit erkennen. So ist in der Zelllinie LOX neben dem MAPK/ERK-Weg der PI3K-Weg aktiviert und MEK1/2Inhibition zeigt hier weniger Effekte als bei A375. Dafür spräche zudem, dass in Kombitherapie mit PI3K-Inhibition ein wesentlich größerer Effekt auf Proliferation und Apoptose in dieser Zelllinie erreicht wurde. Allerdings war dieser synergistische Effekt auch in der Zelllinie A375 zu beobachten. In Betracht zu ziehen ist auch, dass durch Hemmung von ERK überhaupt erst weitere Signalwege in den Zellen aktiviert werden können. Dafür sprechen die Arbeiten von Krasilnikov et al. (Krasilnikov et al. 2003). Sie zeigten, dass STAT3-Aktivität nach Inhibition von entweder MEK1/2 oder PI3K in Melanomzellen deutlich anstieg (Krasilnikov et al. 2003). Im Hinblick auf eine therapeutische Anwendung wäre es gut, einen Marker 
für das Ansprechen auf MEK-Inhibition zu finden, um gezielter therapieren zu können.

Die Wirksamkeit der Inhibition von entweder BRAF/MEK/ERK-Signalweg oder $\mathrm{PI3K} / \mathrm{AKT} / \mathrm{mTOR}$ in Melanomzellen ist limitiert. Die erzielten Effekte sind vor allem zytostatisch und variieren stark zwischen den einzelnen verwendeten Zelllinien (Karasarides et al. 2004, Krasilnikov et al. 2003, Lasithiotakis et al. 2008, Meier et al. 2007, Smalley et al. 2006, Tran et al. 2008, Verhaegen et al. 2006). Der MAPK/ERK-Weg und der PI3K/AKT-Weg haben überschneidende Funktionen hinsichtlich des Melanomprogresses. Beide modulieren die Funktionen von zahlreichen Substraten, die in die Regulation von Zellwachstum, Proliferation, Überleben und Invasion involviert sind, und es scheint komplexe Verknüpfungen dieser Wege zu geben, die eine Chemoresistenz des Melanoms verstärken (Smalley 2010, Wee et al 2009). Im Melanom sind Mutationsprofile häufig, die gleichzeitig den MAPK/ERK-Weg und den PI3K/AKT-Weg aktivieren (Davies M. A. et al. 2008, Lin et al. 2008, Tsao et al. 2004, Tsao et al. 2000). Dieses stützt die Vermutung, dass eine simultane Aktivierung beider Wege für die Entstehung und den Progress des Melanoms notwendig ist. Die ersten Erkenntnisse für diese Hypothese lieferten die Arbeiten mit einem BRAF-V600E-Mutations-Mausmodell (Dankort et al. 2009). In diesem Modell führte die Expression von V600Emutiertem-BRAF alleine bei Mäusen nur zu einer benignen melanozytären Hyperplasie. Kombiniert man aber diese Mutation zusätzlich mit einer Aktivierung des PI3K/AKT-Weges über die Inhibition von PTEN, entstanden in 100\% Melanome, die mit kurzer Latenz auftraten und auch Metastasen zeigten (Dankort et al. 2009). Es erschien daher sinnvoll, beide Wege in den Melanomzellen simultan zu hemmen. Und in der Tat konnten in der vorliegenden Arbeit eindeutige synergistische Effekte durch duale Inhibition der PI3K und MEK1/2 beobachtet werden. Die Zelllinien A375 und LOX wurden in vitro mit jeweils einer Kombination von PI3K-Inhibitor (BAY-80-6946 oder Wortmannin) und MEK1/2-Inhibitor (U0126 oder PD98059) behandelt. Dabei zeigte sich, dass in beiden Zelllinien die kombinierte Inhibition von PI3K und MEK1/2 synergistisch die Proliferation der Melanomzellen verlangsamt und dabei deutlich stärker als die jeweiligen Monobehandlungen wirkt. Während Inhibierung von entweder PI3K oder MEK1/2 
keine bis nur geringe Apoptose in Abhängigkeit von den verwendeten Zellen einleitete, war bei kombinierter Inhibition eine sehr starke Apoptoseinduktion in beiden Zelllinien zu beobachten. Auch weitere Studien konnten darlegen, dass die Kombinationsbehandlungen mit Inhibitoren, die auf BRAF/MEK/ERK-Signalweg und PI3K/AKT/mTOR-Weg abzielen, stärkere Wirkung besitzen als die jeweiligen Monobehandlungen. In 3D-Zellkulturen und Xenotransplantaten zeigten Monobehandlungen mit MEK- oder PI3K-Inhibitoren geringe Effektivität das Wachstum zu verringern, während die Kombination von beiden hoch effektiv war (Bedogni et al. 2004, Smalley et al. 2006). Ebenso war die liposomale Anwendung von RNAi gegen BRAF alleine relativ schwach wirksam und unterdrückte das Wachstum von Melanom-Xenotransplantaten kaum, kombiniert mit si-RNA gegen AKT wurde der Effekt jedoch wesentlich stärker (Tran et al. 2008). Es gibt zudem Hinweise auf eine synergistische pro-apoptotische Aktivität von Sorafenib/MEKInhibitoren und Rapamycin (ein mTOR-Inhibitor) in präklinischen Untersuchungen (Lasithiotakis et al. 2008, Meier et al. 2007, Molhoek et al. 2005). Erste Analysen zur Effektivität von dualer Inhibition von PI3K/AKT/mTOR-Signalweg und RAS/MEK/ERK-Signalweg in Phase-I-Studien an Patienten mit fortgeschrittenen Tumorerkrankungen zeigten Hinweise auf eine Überlegenheit der dualen Inhibition gegenüber den Monobehandlungen (Shimizu et al. 2012). Dabei präsentierte sich dieser Effekt besonders bei Tumoren, die eine duale Aktivierung des $\mathrm{PI3K} / \mathrm{AKT} / \mathrm{mTOR}$-Signalweges und des RAS/MEK/ERK-Signalweges aufwiesen (Shimizu et al. 2012). Eine Hypothese, die die durchschlagenden synergistischen Wirkungen erklären könnte, ist, dass der neue Inhibitor vielleicht Tumorzellen, die in ihrem Wachstum von unregulierter PI3K-Aktivität abhängen, gegenüber den Wirkungen anderer Zytostatika sensibilisiert. Derartige Wirkungen wurden beispielsweise bereits durch gezielte Inhibition des NF-kB-Signalweges beobachtet (Schön et al. 2008). Kombinationsbehandlungen bieten also einen vielversprechenden Ansatzpunkt für die Melanomtherapie, da die Apoptoseinhibierenden Mechanismen unterbunden werden und die Zellen so wieder in die durch die Chemotherapie ausgelöste Apoptose eintreten können. 


\subsection{Inhibitoren im Mausmodell}

Nach den umfangreichen Untersuchungen der Effekte von PI3K- und MEK1/2Inhibition in Melanom-Zelllinien sollte nun der Einfluss der Inhibitoren auf das Tumorwachstum in vivo überprüft werden. Auch für andere PI3K-Inhibitoren konnte schon in-vivo-Wirksamkeit gegen Melanome gezeigt werden (Bedogni et al. 2004, Stahl et al. 2004, Tran et al. 2008, Yaguchi et al. 2006). Da BAY-80-6946 stärkere Effekte in vitro auf die Melanomzellen zeigte als Wortmannin und U0126 eine größere Wirksamkeit in vitro besaß als PD98059, wurden diese beiden für die Mausexperimente ausgewählt. Es handelte sich hierbei um die ersten Untersuchungen von BAY-80-6946 in einem in-vivo-Melanom-Mausmodell.

Bei der Untersuchung im in-vivo-Nacktmaus-Modell zeigte sich, dass die Tumoren der Zelllinie A375 in ihrem Wachstum durch beide Inhibitoren signifikant eingeschränkt wurden. Obwohl LOX in vitro ein stärkeres Ansprechen auf BAY-806946 als A375 zeigte, war in vivo kein signifikanter Tumor-inhibierender Effekt nachweisbar. Auch die MEK1/2-Inhibition durch U0126 führte zu keiner signifikanten Wachstumsinhibition. Es wurde deutlich, dass die Tumoren im in-vivo-Modell anders auf die Inhibitoren reagierten als in vitro. Dafür könnte das unterschiedliche Zytokinmilieu in Maus und in vitro verantwortlich sein. Es wird diskutiert, dass das Umgebungsmilieu in Anhängigkeit von Zytokinen, Zell-ZellInteraktionen und Zellumgebung die Suszeptibilität der Melanomzellen für die Auswirkung der Inhibition einzelner Wege mitbestimmend ist (Smalley et al. 2006). Diese unterscheiden sich zwischen in-vitro- und in-vivo-Modell. Auch die verschiedenen Signalweg-Profile der beiden ausgewählten Zelllinien könnten für das unterschiedliche Verhalten der beiden Zelllinien im Mausexperiment verantwortlich sein. LOX zeigte in vitro eine konstitutive Aktivierung von AKT- und ERK- Signalweg und ein deutlich aggressiveres Wachstumsverhalten in vivo, das durch PI3K- und MEK1/2-Inhibition nicht signifikant gemindert wurde. Es ist eine vermehrte Resistenz von Tumoren gegenüber Inhibitoren, die auf den MEK/ERKSignalweg zielen, beobachtet worden, wenn diese zusätzlich einen aktivierten PI3K/AKT-Signalweg aufwiesen (Wee et al. 2009). Dies scheint also auch im Melanom-Mausmodell der Fall zu sein, trotz des anderen Zytokinmilieus. Zieht 
man die Ergebnisse der in-vitro-Versuche hinzu, die zeigten, dass durch kombinierte Inhibition der beiden Signalwege effektiver die Proliferation der Melanomzellen gehemmt und Apoptose induziert werden kann, so wäre es interessant, auch in vivo im Mausmodell eine Kombinationstherapie mit beiden Inhibitoren zu untersuchen. Therapieansätze mit kombinierter Signalweginhibition könnten der Schlüssel zu einer erfolgreichen Therapie des Melanoms sein. 


\section{Zusammenfassung}

Konstitutiv aktivierte Signalwege sind für das maligne Verhalten von Melanomzellen verantwortlich. Besonders in den Fokus der Forschung sind hierbei der MAPK/ERK-Weg und der PI3Kinase-AKT-Weg gerückt. In dieser Arbeit wurde untersucht, ob Inhibitionen von PI3K oder MEK1/2 Tumor-relevante Zellfunktionen in Melanomzellen beeinflussen und zur Therapie des Melanoms genutzt werden können. Ein besonderer Schwerpunkt dieser Arbeit lag dabei auf der Analyse der Wirkung des neuen Klasse-I-PI3K-Inhibitors BAY-80-6946, dessen Wirkung im Rahmen dieser Arbeit erstmals an Melanom-Zelllinien untersucht wurde.

Sechs humane Melanom-Zelllinien wurden in vitro hinsichtlich ihrer konstitutiv aktivierten Signaltransduktionswege überprüft. Es zeigte sich, dass in den Zelllinien unterschiedliche Signalwege aktiviert waren. In in-vivo-Xenotransplantationsexperimenten wurden die Zelllinien weiter hinsichtlich ihrer Tumorigenität charakterisiert. Auf der Basis dieser Experimente wurden die Zelllinien A375 und LOX für weitere Experimente ausgewählt, da sie in vivo zuverlässig Tumoren bildeten und das schnellste Wachstum zeigten. Zudem unterschieden sie sich in der Aktivierung der Signalwege, sodass sie exemplarisch für Melanomzellen mit geringer beziehungsweise starker konstitutiver AKT- und ERK-Aktivierung standen.

Die humanen Melanom-Zelllinien A375 und LOX wurden in vitro mit den PI3KInhibitoren BAY-80-6946 und Wortmannin sowie den MEK1/2-Inhibitoren U0126 und PD98059 behandelt und Tumor-relevante Funktionen wie Proliferation und Apoptose überprüft. Dabei zeigte sich, dass Therapie-relevante Eigenschaften wie Proliferation und Apoptose Zelllinien-spezifisch beeinflusst wurden. ZellzyklusAnalysen ergaben, dass BAY-80-6946 den Übergang von G1- zur S-Phase in A375 und LOX verlangsamt. In weiteren Experimenten wurde die Beeinflussung Tumorrelevanter Gene und Proteine durch den neuen PI3K-Inhibitor untersucht. Da es Hinweise auf Redundanzen im PI3K/AKT- und im MEK/ERK-Signalweg gibt, wurde in vitro untersucht, ob die kombinierte Inhibition beider Wege zu verstärkter antitumoraler Wirkung führt. In der Tat zeigte sich, dass im Vergleich zu den jeweiligen Monobehandlungen die simultanen Behandlungen der Melanom-Zelllinien mit 
jeweils einem PI3K- und einem MEK1/2-Inhibitor sowohl die Proliferation deutlich minderten, als auch Apoptose deutlich stärker induziert wurde.

Der Frage, ob PI3K-Inhibition durch BAY-80-6946 und MEK1/2-Inhibition auch in vivo Effekte auf das Wachstum von Melanomen zeigt, wurde in einem Xenotransplantations-Modell nachgegangen. Dabei ergab sich, dass beide Inhibitoren in der Zelllinie A375 zu einer signifikanten Einschränkung des Tumorwachstums führten, die Zelllinie LOX jedoch nicht in ihrem Wachstum gemindert wurde.

Zusammenfassend zeigte sich in dieser Arbeit, dass PI3K-Inhibition und MEK1/2Inhibition alleine nur unzureichende Effekte auf Melanomzellen besitzen, die in Abhängigkeit von der Zelllinie variieren. Vielversprechendere Ansätze bieten jedoch Kombinationsbehandlungen. 


\section{Literatur}

Afshari CA und Barrett JC (1993): Cell cycle controls: potential targets for chemical carcinogens? Environ Health Perspect 101 Suppl 5: 9-14.

Aktas H, Cai H, Cooper GM (1997): Ras links growth factor signaling to the cell cycle machinery via regulation of cyclin D1 and the Cdk inhibitor p27KIP1. Mol Cell Biol 17: 3850-3857.

Altinoz MA und Korkmaz R (2004): NF-kappaB, macrophage migration inhibitory factor and cyclooxygenase-inhibitions as likely mechanisms behind the acetaminophen- and NSAID-prevention of the ovarian cancer. Neoplasma 51: 239-247.

Atkins MB, Lotze MT, Dutcher JP, Fisher RI, Weiss G, Margolin K, Abrams J, Sznol M, Parkinson D, Hawkins $M$, et al. (1999): High-dose recombinant interleukin 2 therapy for patients with metastatic melanoma: analysis of 270 patients treated between 1985 and 1993. J Clin Oncol 17: 2105-2116.

Aziz SA, Davies M, Pick E, Zito C, Jilaveanu L, Camp RL, Rimm DL, Kluger Y, Kluger HM (2009): Phosphatidylinositol-3-kinase as a therapeutic target in melanoma. Clin Cancer Res 15: 3029-3036.

Bauer J, Buttner P, Wiecker TS, Luther H, Garbe C (2005): Risk factors of incident melanocytic nevi: a longitudinal study in a cohort of 1,232 young German children. Int J Cancer 115: 121-126.

Bedogni B, O'Neill MS, Welford SM, Bouley DM, Giaccia AJ, Denko NC, Powell MB (2004): Topical treatment with inhibitors of the phosphatidylinositol 3'kinase/Akt and Raf/mitogen-activated protein kinase kinase/extracellular signal-regulated kinase pathways reduces melanoma development in severe combined immunodeficient mice. Cancer Res 64: 2552-2560.

Berndorff D, Mueller A, Haegebarth A, Berndt M, Scholz A, Puehler F, Liu N (2011): $8 \mathrm{~F}-\mathrm{FLT}$, a potential biomarker for predicting the synergistic combination of PI3K inhibitor BAY 80-6946* and MEK inhibitor BAY 86-9766. (Abstract). Mol Cancer Ther 10: Issue 11, Supplement 1 (ohne Seitenzahlen)

Bertagnolli MM (2007): Chemoprevention of colorectal cancer with cyclooxygenase-2 inhibitors: two steps forward, one step back. Lancet Oncol 8: 439-443. 
Bhatt KV, Spofford LS, Aram G, McMullen M, Pumiglia K, Aplin AE (2005): Adhesion control of cyclin D1 and p27Kip1 levels is deregulated in melanoma cells through BRAF-MEK-ERK signaling. Oncogene 24: 3459-3471.

Birck A, Ahrenkiel V, Zeuthen J, Hou-Jensen K, Guldberg P (2000): Mutation and allelic loss of the PTEN/MMAC1 gene in primary and metastatic melanoma biopsies. J Invest Dermatol 114: 277-280.

Borner C, Schlagbauer-Wadl H, Fellay I, Selzer E, Polterauer P, Jansen B (1999): Mutated N-ras upregulates $\mathrm{Bcl}-2$ in human melanoma in vitro and in SCID mice. Melanoma Res 9: 347-350.

Brose MS, Volpe P, Feldman M, Kumar M, Rishi I, Gerrero R, Einhorn E, Herlyn M, Minna J, Nicholson A, et al. (2002): BRAF and RAS mutations in human lung cancer and melanoma. Cancer Res 62: 6997-7000.

Brunet A, Bonni A, Zigmond MJ, Lin MZ, Juo P, Hu LS, Anderson MJ, Arden KC, Blenis J, Greenberg ME (1999): Akt promotes cell survival by phosphorylating and inhibiting a Forkhead transcription factor. Cell $\underline{96}$ : 857-868.

Burgering BM und Coffer PJ (1995): Protein kinase B (c-Akt) in phosphatidylinositol-3-OH kinase signal transduction. Nature 376: 599-602.

Cardone MH, Roy N, Stennicke HR, Salvesen GS, Franke TF, Stanbridge E, Frisch S, Reed JC (1998): Regulation of cell death protease caspase-9 by phosphorylation. Science 282: 1318-1321.

Cartlidge RA, Thomas GR, Cagnol S, Jong KA, Molton SA, Finch AJ, McMahon M (2008): Oncogenic BRAF(V600E) inhibits BIM expression to promote melanoma cell survival. Pigment Cell Melanoma Res 21: 534-544.

Chapman PB, Hauschild A, Robert C, Haanen JB, Ascierto P, Larkin J, Dummer R, Garbe C, Testori A, Maio M, et al. (2011): Improved survival with vemurafenib in melanoma with BRAF V600E mutation. $N$ Engl J Med 364: 2507-2516.

Cohen C, Zavala-Pompa A, Sequeira JH, Shoji M, Sexton DG, Cotsonis G, Cerimele F, Govindarajan B, Macaron N, Arbiser JL (2002): Mitogen-actived protein kinase activation is an early event in melanoma progression. Clin Cancer Res 8: 3728-3733. 
Crews CM, Alessandrini A, Erikson RL (1992): The primary structure of MEK, a protein kinase that phosphorylates the ERK gene product. Science 258: 478480.

Cross DA, Alessi DR, Cohen P, Andjelkovich M, Hemmings BA (1995): Inhibition of glycogen synthase kinase- 3 by insulin mediated by protein kinase B. Nature 378: 785-789.

Dai DL, Martinka M, Li G (2005): Prognostic significance of activated Akt expression in melanoma: a clinicopathologic study of 292 cases. J Clin Oncol 23: 14731482.

Dankort D, Curley DP, Cartlidge RA, Nelson B, Karnezis AN, Damsky WE, Jr., You MJ, DePinho RA, McMahon M, Bosenberg M (2009): Braf(V600E) cooperates with Pten loss to induce metastatic melanoma. Nat Genet 41: 544-552.

Datta SR, Dudek H, Tao X, Masters S, Fu H, Gotoh Y, Greenberg ME (1997): Akt phosphorylation of BAD couples survival signals to the cell-intrinsic death machinery. Cell 91: 231-241.

Davies H, Bignell GR, Cox C, Stephens P, Edkins S, Clegg S, Teague J, Woffendin H, Garnett MJ, Bottomley W, et al. (2002): Mutations of the BRAF gene in human cancer. Nature 417: 949-954.

Davies MA, Stemke-Hale K, Tellez C, Calderone TL, Deng W, Prieto VG, Lazar AJ, Gershenwald JE, Mills GB (2008): A novel AKT3 mutation in melanoma tumours and cell lines. Br J Cancer 99: 1265-1268.

Demunter A, Stas M, Degreef H, De Wolf-Peeters C, van den Oord JJ (2001): Analysis of $\mathrm{N}$ - and $\mathrm{K}$-ras mutations in the distinctive tumor progression phases of melanoma. J Invest Dermatol 117: 1483-1489.

Dhawan P und Richmond A (2002): Role of CXCL1 in tumorigenesis of melanoma. J Leukoc Biol 72: 9-18.

Dhawan P, Singh AB, Ellis DL, Richmond A (2002): Constitutive activation of Akt/protein kinase $B$ in melanoma leads to up-regulation of nuclear factorkappaB and tumor progression. Cancer Res 62: 7335-7342.

Diehl JA, Cheng M, Roussel MF, Sherr CJ (1998): Glycogen synthase kinase-3beta regulates cyclin D1 proteolysis and subcellular localization. Genes Dev $\underline{12}$ : 3499-3511. 
Dufourny B, van Teeffelen HA, Hamelers IH, Sussenbach JS, Steenbergh PH (2000): Stabilization of cyclin D1 mRNA via the phosphatidylinositol 3-kinase pathway in MCF-7 human breast cancer cells. J Endocrinol 166: 329-338.

Eggermont AM und Kirkwood JM (2004): Re-evaluating the role of dacarbazine in metastatic melanoma: what have we learned in 30 years? Eur J Cancer $\underline{40}$ : 1825-1836.

Eisenmann KM, VanBrocklin MW, Staffend NA, Kitchen SM, Koo HM (2003): Mitogen-activated protein kinase pathway-dependent tumor-specific survival signaling in melanoma cells through inactivation of the proapoptotic protein bad. Cancer Res 63: 8330-8337.

Engelman JA, Luo J, Cantley LC (2006): The evolution of phosphatidylinositol 3kinases as regulators of growth and metabolism. Nat Rev Genet 7: 606-619.

Flaherty KT und McArthur G (2010): BRAF, a target in melanoma: implications for solid tumor drug development. Cancer 116: 4902-4913.

Fodstad O, Aamdal S, McMenamin M, Nesland JM, Pihl A (1988): A new experimental metastasis model in athymic nude mice, the human malignant melanoma LOX. Int J Cancer 41: 442-449.

Franke TF, Yang SI, Chan TO, Datta K, Kazlauskas A, Morrison DK, Kaplan DR, Tsichlis PN (1995): The protein kinase encoded by the Akt proto-oncogene is a target of the PDGF-activated phosphatidylinositol 3-kinase. Cell $\underline{81}$ : 727-736.

Franke TF, Kaplan DR, Cantley LC (1997): PI3K: downstream AKTion blocks apoptosis. Cell 88: 435-437.

Garbe C und Eigentler TK (2007): Diagnosis and treatment of cutaneous melanoma: state of the art 2006. Melanoma Res 17: 117-127.

Garbe C, Eigentler TK, Keilholz U, Hauschild A, Kirkwood JM (2011): Systematic review of medical treatment in melanoma: current status and future prospects. Oncologist 16: 5-24.

Garnett MJ und Marais R (2004): Guilty as charged: B-RAF is a human oncogene. Cancer Cell $\underline{6}$ : 313-319.

Gille H und Downward J (1999): Multiple ras effector pathways contribute to G(1) cell cycle progression. J Biol Chem 274: 22033-22040. 
Giovanella BC, Stehlin JS, Jr., Shepard RC, Williams LJ, Jr. (1983): Correlation between response to chemotherapy of human tumors in patients and in nude mice. Cancer 52: 1146-1152.

Gorden A, Osman I, Gai W, He D, Huang W, Davidson A, Houghton AN, Busam K, Polsky D (2003): Analysis of BRAF and N-RAS mutations in metastatic melanoma tissues. Cancer Res 63: 3955-3957.

Gottlieb TM, Leal JF, Seger R, Taya Y, Oren M (2002): Cross-talk between Akt, p53 and $\mathrm{Mdm} 2$ : possible implications for the regulation of apoptosis. Oncogene 21: 1299-1303.

Gray-Schopfer V, Wellbrock C, Marais R (2007): Melanoma biology and new targeted therapy. Nature $\underline{445}$ : 851-857.

Guldberg P, thor Straten P, Birck A, Ahrenkiel V, Kirkin AF, Zeuthen J (1997): Disruption of the MMAC1/PTEN gene by deletion or mutation is a frequent event in malignant melanoma. Cancer Res $\underline{57}$ : 3660-3663.

Haass NK, Sproesser K, Nguyen TK, Contractor R, Medina CA, Nathanson KL, Herlyn $M$, Smalley KS (2008): The mitogen-activated protein/extracellular signalregulated kinase kinase inhibitor AZD6244 (ARRY-142886) induces growth arrest in melanoma cells and tumor regression when combined with docetaxel. Clin Cancer Res 14: 230-239.

Hanahan D und Weinberg RA (2011): Hallmarks of cancer: the next generation. Cell 144: 646-674.

Harada H, Quearry B, Ruiz-Vela A, Korsmeyer SJ (2004): Survival factor-induced extracellular signal-regulated kinase phosphorylates BIM, inhibiting its association with BAX and proapoptotic activity. Proc Natl Acad Sci U S A 101: 15313-15317.

Heere-Ress E, Thallinger C, Lucas T, Schlagbauer-Wadl H, Wacheck V, Monia BP, Wolff $\mathrm{K}$, Pehamberger $\mathrm{H}$, Jansen $\mathrm{B}$ (2002): $\mathrm{BCl}-\mathrm{X}(\mathrm{L})$ is a chemoresistance factor in human melanoma cells that can be inhibited by antisense therapy. Int J Cancer 99: 29-34.

Helmbach H, Rossmann E, Kern MA, Schadendorf D (2001): Drug-resistance in human melanoma. Int J Cancer 93: 617-622.

Hennessy BT, Smith DL, Ram PT, Lu Y, Mills GB (2005): Exploiting the PI3K/AKT pathway for cancer drug discovery. Nat Rev Drug Discov 4: 988-1004. 
Holleran JL, Egorin MJ, Zuhowski EG, Parise RA, Musser SM, Pan SS (2003): Use of high-performance liquid chromatography to characterize the rapid decomposition of wortmannin in tissue culture media. Anal Biochem 323: 19-25.

Holly EA, Kelly JW, Shpall SN, Chiu SH (1987): Number of melanocytic nevi as a major risk factor for malignant melanoma. J Am Acad Dermatol 17: 459468.

Homey B, Müller A, Zlotnik A (2002): Chemokines: agents for the immunotherapy of cancer? Nat Rev Immunol 2: 175-184.

Jansen B, Wacheck V, Heere-Ress E, Schlagbauer-Wadl H, Hoeller C, Lucas T, Hoermann M, Hollenstein U, Wolff K, Pehamberger $H$ (2000): Chemosensitisation of malignant melanoma by BCL2 antisense therapy. Lancet 356: 1728-1733.

Jiang BH und Liu LZ (2009): PI3K/PTEN signaling in angiogenesis and tumorigenesis. Adv Cancer Res 102: 19-65.

Jorgensen K, Davidson B, Florenes VA (2006): Activation of c-jun N-terminal kinase is associated with cell proliferation and shorter relapse-free period in superficial spreading malignant melanoma. Mod Pathol 19: 1446-1455.

Kaatsch P, Spix C, Katalinic A, Hentschel S, Baras N, Barnes B, Bertz J, Dahm S, Haberland J, Kraywinkel K, et al.: Krebs in Deutschland 2007/2008, 8. Ausgabe; Robert Koch-Institut und die Gesellschaft der epidemiologischen Krebsregister in Deutschland e.V., Berlin 2012

Kane LP, Shapiro VS, Stokoe D, Weiss A (1999): Induction of NF-kappaB by the Akt/PKB kinase. Curr Biol 9: 601-604.

Karasarides M, Chiloeches A, Hayward R, Niculescu-Duvaz D, Scanlon I, Friedlos F, Ogilvie L, Hedley D, Martin J, Marshall CJ, et al. (2004): B-RAF is a therapeutic target in melanoma. Oncogene 23: 6292-6298.

Karbowniczek M, Spittle CS, Morrison T, Wu H, Henske EP (2008): mTOR is activated in the majority of malignant melanomas. J Invest Dermatol $\underline{128}$ : 980-987.

Katso R, Okkenhaug K, Ahmadi K, White S, Timms J, Waterfield MD (2001): Cellular function of phosphoinositide 3-kinases: implications for development, homeostasis, and cancer. Annu Rev Cell Dev Biol 17: 615-675. 
King AJ, Patrick DR, Batorsky RS, Ho ML, Do HT, Zhang SY, Kumar R, Rusnak DW, Takle AK, Wilson DM, et al. (2006): Demonstration of a genetic therapeutic index for tumors expressing oncogenic BRAF by the kinase inhibitor SB590885. Cancer Res 66: 11100-11105.

Klippel A, Escobedo MA, Wachowicz MS, Apell G, Brown TW, Giedlin MA, Kavanaugh WM, Williams LT (1998): Activation of phosphatidylinositol 3kinase is sufficient for cell cycle entry and promotes cellular changes characteristic of oncogenic transformation. Mol Cell Biol 18: 5699-5711.

Kohn AD, Kovacina KS, Roth RA (1995): Insulin stimulates the kinase activity of RAC-PK, a pleckstrin homology domain containing ser/thr kinase. EMBO J 14: 4288-4295.

Kortylewski M, Heinrich PC, Kauffmann ME, Bohm M, MacKiewicz A, Behrmann I (2001): Mitogen-activated protein kinases control p27/Kip1 expression and growth of human melanoma cells. Biochem J 357: 297-303.

Kraemer KH, Lee MM, Andrews AD, Lambert WC (1994): The role of sunlight and DNA repair in melanoma and nonmelanoma skin cancer. The xeroderma pigmentosum paradigm. Arch Dermatol 130: 1018-1021.

Krasilnikov M, Ivanov VN, Dong J, Ronai Z (2003): ERK and PI3K negatively regulate STAT-transcriptional activities in human melanoma cells: implications towards sensitization to apoptosis. Oncogene 22: 4092-4101.

Kumar R, Angelini S, Czene K, Sauroja I, Hahka-Kemppinen M, Pyrhonen S, Hemminki K (2003): BRAF mutations in metastatic melanoma: a possible association with clinical outcome. Clin Cancer Res 9: 3362-3368.

Kyriakis JM, App H, Zhang XF, Banerjee P, Brautigan DL, Rapp UR, Avruch J (1992): Raf-1 activates MAP kinase-kinase. Nature 358: 417-421.

Lasithiotakis KG, Sinnberg TW, Schittek B, Flaherty KT, Kulms D, Maczey E, Garbe C, Meier FE (2008): Combined inhibition of MAPK and mTOR signaling inhibits growth, induces cell death, and abrogates invasive growth of melanoma cells. J Invest Dermatol 128: 2013-2023.

Lens M, Testori A, Ferucci PF (2012): Ipilimumab Targeting CD28-Ctla-4 Axis: New Hope in the Treatment of Melanoma. Curr Top Med Chem 12: 61-66. 
Li J, Yen C, Liaw D, Podsypanina K, Bose S, Wang SI, Puc J, Miliaresis C, Rodgers L, McCombie R, et al. (1997): PTEN, a putative protein tyrosine phosphatase gene mutated in human brain, breast, and prostate cancer. Science 275: 1943-1947.

Liao Z, Mason KA, Milas L (2007): Cyclo-oxygenase-2 and its inhibition in cancer: is there a role? Drugs 67: 821-845.

Lin WM, Baker AC, Beroukhim R, Winckler W, Feng W, Marmion JM, Laine E, Greulich H, Tseng H, Gates C, et al. (2008): Modeling genomic diversity and tumor dependency in malignant melanoma. Cancer Res 68: 664-673.

Lopez-Bergami P, Huang C, Goydos JS, Yip D, Bar-Eli M, Herlyn M, Smalley KS, Mahale A, Eroshkin A, Aaronson S, et al. (2007): Rewired ERK-JNK signaling pathways in melanoma. Cancer Cell 11: 447-460.

Lopez-Bergami P, Fitchman B, Ronai Z (2008): Understanding signaling cascades in melanoma. Photochem Photobiol 84: 289-306.

Maehama T und Dixon JE (1998): The tumor suppressor, PTEN/MMAC1, dephosphorylates the lipid second messenger, phosphatidylinositol 3,4,5trisphosphate. J Biol Chem 273: 13375-13378.

Markovic SN, Erickson LA, Rao RD, Weenig RH, Pockaj BA, Bardia A, Vachon CM, Schild SE, McWilliams RR, Hand JL, et al. (2007 a): Malignant melanoma in the 21st century, part 1: staging, prognosis, and treatment. Mayo Clin Proc 82: 490-513.

Markovic SN, Erickson LA, Rao RD, Weenig RH, Pockaj BA, Bardia A, Vachon CM, Schild SE, McWilliams RR, Hand JL, et al. (2007 b): Malignant melanoma in the 21st century, part 2: epidemiology, risk factors, screening, prevention, and diagnosis. Mayo Clin Proc 82: 364-380.

Marone R, Erhart D, Mertz AC, Bohnacker T, Schnell C, Cmiljanovic V, Stauffer F, Garcia-Echeverria C, Giese B, Maira SM, et al. (2009): Targeting melanoma with dual phosphoinositide 3-kinase/mammalian target of rapamycin inhibitors. Mol Cancer Res $\underline{7}$ : 601-613.

Mayo LD und Donner DB (2001): A phosphatidylinositol 3-kinase/Akt pathway promotes translocation of $\mathrm{Mdm} 2$ from the cytoplasm to the nucleus. Proc Natl Acad Sci U S A 98: 11598-11603. 
Meier F, Schittek B, Busch S, Garbe C, Smalley K, Satyamoorthy K, Li G, Herlyn M (2005): The RAS/RAF/MEK/ERK and PI3K/AKT signaling pathways present molecular targets for the effective treatment of advanced melanoma. Front Biosci 10: 2986-3001.

Meier F, Busch S, Lasithiotakis K, Kulms D, Garbe C, Maczey E, Herlyn M, Schittek B (2007): Combined targeting of MAPK and AKT signalling pathways is a promising strategy for melanoma treatment. Br J Dermatol 156: 1204-1213.

Molhoek KR, Brautigan DL, Slingluff CL, Jr. (2005): Synergistic inhibition of human melanoma proliferation by combination treatment with B-Raf inhibitor BAY43-9006 and mTOR inhibitor Rapamycin. J Transl Med $\underline{3}$ : 39.

Muise-Helmericks RC, Grimes HL, Bellacosa A, Malstrom SE, Tsichlis PN, Rosen N (1998): Cyclin D expression is controlled post-transcriptionally via a phosphatidylinositol 3-kinase/Akt-dependent pathway. J Biol Chem 273: 29864-29872.

Niu G, Bowman T, Huang M, Shivers S, Reintgen D, Daud A, Chang A, Kraker A, Jove R, Yu H (2002): Roles of activated Src and Stat3 signaling in melanoma tumor cell growth. Oncogene 21: 7001-7010.

Omholt K, Platz A, Kanter L, Ringborg U, Hansson J (2003): NRAS and BRAF mutations arise early during melanoma pathogenesis and are preserved throughout tumor progression. Clin Cancer Res $\underline{9}$ : 6483-6488.

Oren M, Damalas A, Gottlieb T, Michael D, Taplick J, Leal JF, Maya R, Moas M, Seger R, Taya Y, et al. (2002): Regulation of p53: intricate loops and delicate balances. Biochem Pharmacol 64: 865-871.

Padua RA, Barrass N, Currie GA (1984): A novel transforming gene in a human malignant melanoma cell line. Nature 311: 671-673.

Padua RA, Barrass NC, Currie GA (1985): Activation of N-ras in a human melanoma cell line. Mol Cell Biol $\underline{5}$ : 582-585.

Park S, Yeung ML, Beach S, Shields JM, Yeung KC (2005): RKIP downregulates B-Raf kinase activity in melanoma cancer cells. Oncogene 24: 3535-3540.

Patnaik A, Appleman LJ, Mountz JM, Ramanathan RK, Beeram M, Tolcher AW, Papadopoulos KP, Lotze MT, Petro DP, Laymon C (2011): A first-in-human phase I study of intravenous PI3K inhibitor BAY 80-6946 in patients with advanced solid tumors: Results of dose-escalation phase.(Abstract). J Clin Oncol 29. (ohne Seitenzahlen) 
Payne AS und Cornelius LA (2002): The role of chemokines in melanoma tumor growth and metastasis. J Invest Dermatol 118: 915-922.

Pfahlberg A, Kolmel KF, Gefeller O, Febim Study G (2001): Timing of excessive ultraviolet radiation and melanoma: epidemiology does not support the existence of a critical period of high susceptibility to solar ultraviolet radiation- induced melanoma. Br J Dermatol 144: 471-475.

Raisova M, Hossini AM, Eberle J, Riebeling C, Wieder T, Sturm I, Daniel PT, Orfanos $\mathrm{CE}$, Geilen CC (2001): The Bax/Bcl-2 ratio determines the susceptibility of human melanoma cells to CD95/Fas-mediated apoptosis. J Invest Dermatol 117: 333-340.

Robinson MJ und Cobb MH (1997): Mitogen-activated protein kinase pathways. Curr Opin Cell Biol 9: 180-186.

Rodriguez-Viciana P, Marte BM, Warne PH, Downward J (1996): Phosphatidylinositol 3' kinase: one of the effectors of Ras. Philos Trans $R$ Soc Lond B Biol Sci 351: 225-231; discussion 231-222.

Rofstad EK (1994): Orthotopic human melanoma xenograft model systems for studies of tumour angiogenesis, pathophysiology, treatment sensitivity and metastatic pattern. Br J Cancer 70: 804-812.

Rofstad EK und Lyng H (1996): Xenograft model systems for human melanoma. Mol Med Today 2: 394-403.

Romashkova JA und Makarov SS (1999): NF-kappaB is a target of AKT in antiapoptotic PDGF signalling. Nature 401: 86-90.

Russo AE, Torrisi E, Bevelacqua Y, Perrotta R, Libra M, McCubrey JA, Spandidos DA, Stivala F, Malaponte G (2009): Melanoma: molecular pathogenesis and emerging target therapies (Review). Int J Oncol 34: 1481-1489.

Salmena L, Carracedo A, Pandolfi PP (2008): Tenets of PTEN tumor suppression. Cell 133: 403-414.

Satyamoorthy K, Li G, Gerrero MR, Brose MS, Volpe P, Weber BL, Van Belle P, Elder DE, Herlyn M (2003): Constitutive mitogen-activated protein kinase activation in melanoma is mediated by both BRAF mutations and autocrine growth factor stimulation. Cancer Res 63: 756-759. 
Schmitt E, Paquet C, Beauchemin M, Bertrand R (2007): DNA-damage response network at the crossroads of cell-cycle checkpoints, cellular senescence and apoptosis. J Zhejiang Univ Sci B 8 : 377-397.

Schön $M$, Bong $A B$, Drewniok C, Herz J, Geilen CC, Reifenberger J, Benninghoff $B$, Slade HB, Gollnick H, Schön MP (2003): Tumor-selective induction of apoptosis and the small-molecule immune response modifier imiquimod. $J$ Natl Cancer Inst 95: 1138-1149.

Schön M, Wienrich BG, Kneitz S, Sennefelder H, Amschler K, Vöhringer V, Weber O, Stiewe T, Ziegelbauer K, Schön MP (2008): KINK-1, a novel small-molecule inhibitor of IKKbeta, and the susceptibility of melanoma cells to antitumoral treatment. J Natl Cancer Inst 100: 862-875.

Serunian LA, Auger KR, Roberts TM, Cantley LC (1990): Production of novel polyphosphoinositides in vivo is linked to cell transformation by polyomavirus middle T antigen. J Virol 64: 4718-4725.

Shimizu T, Tolcher AW, Papadopoulos KP, Beeram M, Rasco D, Smith LS, Gunn S, Smetzer L, Mays TA, Kaiser B, et al. (2012): The clinical effect of the dualtargeting strategy involving PI3K/AKT/mTOR and RAS/MEK/ERK pathways in patients with advanced cancer. Clin Cancer Res [Epub ahead of print].

Smalley KS (2010): Understanding melanoma signaling networks as the basis for molecular targeted therapy. J Invest Dermatol 130: 28-37.

Smalley KS und Herlyn M (2005): Targeting intracellular signaling pathways as a novel strategy in melanoma therapeutics. Ann N Y Acad Sci 1059: 16-25.

Smalley KS, Haass NK, Brafford PA, Lioni M, Flaherty KT, Herlyn M (2006): Multiple signaling pathways must be targeted to overcome drug resistance in cell lines derived from melanoma metastases. Mol Cancer Ther $\underline{5}$ : 1136-1144.

Smalley KS, Contractor R, Haass NK, Lee JT, Nathanson KL, Medina CA, Flaherty KT, Herlyn M (2007): Ki67 expression levels are a better marker of reduced melanoma growth following MEK inhibitor treatment than phospho-ERK levels. Br J Cancer 96: 445-449.

Soengas MS und Lowe SW (2003): Apoptosis and melanoma chemoresistance. Oncogene 22: 3138-3151.

Solit DB, Garraway LA, Pratilas CA, Sawai A, Getz G, Basso A, Ye Q, Lobo JM, She Y, Osman I, et al. (2006): BRAF mutation predicts sensitivity to MEK inhibition. Nature 439: 358-362. 
Spofford LS, Abel EV, Boisvert-Adamo K, Aplin AE (2006): Cyclin D3 expression in melanoma cells is regulated by adhesion-dependent phosphatidylinositol 3kinase signaling and contributes to G1-S progression. J Biol Chem 281: 25644-25651.

Stahl JM, Sharma A, Cheung M, Zimmerman M, Cheng JQ, Bosenberg MW, Kester M, Sandirasegarane L, Robertson GP (2004): Deregulated Akt3 activity promotes development of malignant melanoma. Cancer Res 64: 7002-7010.

Steck PA, Pershouse MA, Jasser SA, Yung WK, Lin H, Ligon AH, Langford LA, Baumgard ML, Hattier T, Davis T, et al. (1997): Identification of a candidate tumour suppressor gene, MMAC1, at chromosome 10q23.3 that is mutated in multiple advanced cancers. Nat Genet 15: 356-362.

Sugimoto Y, Whitman M, Cantley LC, Erikson RL (1984): Evidence that the Rous sarcoma virus transforming gene product phosphorylates phosphatidylinositol and diacylglycerol. Proc Natl Acad Sci U S A 81: 21172121.

Teng DH, Hu R, Lin H, Davis T, lliev D, Frye C, Swedlund B, Hansen KL, Vinson VL, Gumpper KL, et al. (1997): MMAC1/PTEN mutations in primary tumor specimens and tumor cell lines. Cancer Res 57: 5221-5225.

Tran MA, Gowda R, Sharma A, Park EJ, Adair J, Kester M, Smith NB, Robertson GP (2008): Targeting V600EB-Raf and Akt3 using nanoliposomal-small interfering RNA inhibits cutaneous melanocytic lesion development. Cancer Res 68: 7638-7649.

Tsai J, Lee JT, Wang W, Zhang J, Cho H, Mamo S, Bremer R, Gillette S, Kong J, Haass NK, et al. (2008): Discovery of a selective inhibitor of oncogenic B-Raf kinase with potent antimelanoma activity. Proc Natl Acad Sci U S A 105: 3041-3046.

Tsao H, Zhang X, Fowlkes K, Haluska FG (2000): Relative reciprocity of NRAS and PTEN/MMAC1 alterations in cutaneous melanoma cell lines. Cancer Res $\underline{60}$ : 1800-1804.

Tsao H, Goel V, Wu H, Yang G, Haluska FG (2004): Genetic interaction between NRAS and BRAF mutations and PTEN/MMAC1 inactivation in melanoma. $J$ Invest Dermatol 122: 337-341.

Ueda Y und Richmond A (2006): NF-kappaB activation in melanoma. Pigment Cell Res 19: 112-124. 
van Elsas A, Zerp S, van der Flier S, Kruse-Wolters M, Vacca A, Ruiter DJ, Schrier P (1995): Analysis of $\mathrm{N}$-ras mutations in human cutaneous melanoma: tumor heterogeneity detected by polymerase chain reaction/single-stranded conformation polymorphism analysis. Recent Results Cancer Res 139: 5767.

Vanhaesebroeck B, Leevers SJ, Ahmadi K, Timms J, Katso R, Driscoll PC, Woscholski R, Parker PJ, Waterfield MD (2001): Synthesis and function of 3phosphorylated inositol lipids. Annu Rev Biochem 70: 535-602.

Vaubel J und Schadendorf D (2011): [State-of-the-art pharmacotherapy of malignant melanoma]. Internist (Berl) 52: 756-764.

Verhaegen M, Bauer JA, Martin de la Vega C, Wang G, Wolter KG, Brenner JC, Nikolovska-Coleska Z, Bengtson A, Nair R, Elder JT, et al. (2006): A novel BH3 mimetic reveals a mitogen-activated protein kinase-dependent mechanism of melanoma cell death controlled by $\mathrm{p} 53$ and reactive oxygen species. Cancer Res 66: 11348-11359.

Vivanco I und Sawyers CL (2002): The phosphatidylinositol 3-Kinase AKT pathway in human cancer. Nat Rev Cancer 2: 489-501.

Walter SD, King WD, Marrett LD (1999): Association of cutaneous malignant melanoma with intermittent exposure to ultraviolet radiation: results of a case-control study in Ontario, Canada. Int J Epidemiol 28: 418-427.

Wee S, Jagani Z, Xiang KX, Loo A, Dorsch M, Yao YM, Sellers WR, Lengauer C, Stegmeier $F$ (2009): PI3K pathway activation mediates resistance to MEK inhibitors in KRAS mutant cancers. Cancer Res 69: 4286-4293.

Whitman M, Kaplan DR, Schaffhausen B, Cantley L, Roberts TM (1985): Association of phosphatidylinositol kinase activity with polyoma middle-T competent for transformation. Nature 315: 239-242.

Yaguchi S, Fukui Y, Koshimizu I, Yoshimi H, Matsuno T, Gouda H, Hirono S, Yamazaki K, Yamori T (2006): Antitumor activity of ZSTK474, a new phosphatidylinositol 3-kinase inhibitor. J Natl Cancer Inst 98: 545-556.

Yang H, Higgins B, Kolinsky K, Packman K, Go Z, lyer R, Kolis S, Zhao S, Lee R, Grippo JF, et al. RG7204 (PLX4032), a selective BRAFV600E inhibitor, displays potent antitumor activity in preclinical melanoma models. Cancer Res $\underline{70}$ : 5518-5527. 
Zhang XD, Borrow JM, Zhang XY, Nguyen T, Hersey P (2003): Activation of ERK1/2 protects melanoma cells from TRAIL-induced apoptosis by inhibiting Smac/DIABLO release from mitochondria. Oncogene 22: 2869-2881. 


\section{Danksagung}

Ich möchte mich herzlich bei Herrn Prof. Dr. M.P. Schön bedanken für die Vergabe des Themas und die überaus freundliche Unterstützung bei der Durchführung und Bearbeitung dieser Dissertation. Sein stetiges Interesse und seine freundliche Motivation während der gesamten Projektzeit haben wesentlich zu dem Gelingen beigetragen und mich für die wissenschaftliche Arbeit begeistern können. Mein besonderer Dank gilt zudem Frau Prof. Dr. M. Schön, die meine Arbeit betreut, sich viel Zeit für die Lösung jeglicher während der gesamten Dissertationszeit auftretender Probleme genommen hat und stets ein offenes Ohr und freundliche Worte für mich besaß. Beiden möchte ich besonders danken für die hilfreichen Diskussionen neuer Ergebnisse und die Mithilfe bei dem Verfassen dieser Arbeit.

Zudem danke ich der gesamten Arbeitsgruppe Schön, die mich von Anfang an herzlich empfangen hat und mit der mich nach mehreren Jahren gemeinsamer Arbeit eine tiefe Freundschaft verbindet. Ich danke alle Mitgliedern für die wundervolle Zusammenarbeit. Besonders danken möchte ich dabei Nadin Pletz, die mich in die Wunder der Labortechniken einführte, und Verena Lorenz, die beide für viele konstruktive Anregungen zur Bewältigung der Arbeit und auch an dunklen Tagen für Sonne und Helligkeit sorgten. Großen Dank schulde ich außerdem Bianca Messerschmidt, Daniela Glahn, Karolin Zachmann und Anette Bennemann für ihre liebevolle praktische Unterstützung und die vielen wertvollen Ratschläge für meine Experimente. Dr. Katrin Wallbrecht möchte ich danken für die Zeit, die sie mit mir vor allem bei der Etablierung und Durchführung der Ultraschall-gestützten Mausexperimente verbracht hat. Ich danke weiterhin Herrn Prof. Dr. Bertsch für die Bereitstellung der humanen MelanommetastasenPräparate. 


\section{Veröffentlichte Arbeiten:}

Lumma PP, Schneider P, Strauss A, Plothe KD, Thelen P, Ringert RH, Loertzer H (2011): Impact of ureteral stenting prior to ureterorenoscopy on stone-free rates and complications. World J Urol [Epub ahead of print]

Loertzer H*, Schneider P*, Thelen P, Ringert RH, Strauß A (2012): [Laser now also to be used in organ-preserving kidney surgery?]. Urologe A 51: 837-42.

*geteilte Erstautorenschaft

Loertzer H, Schneider P, Thelen P, Ringert RH, Strauß A (2012):[Prolapse surgery : With abdominal or vaginal meshes?]. Urologe $A$ [Epub ahead of print] 